ORNLTM-12742

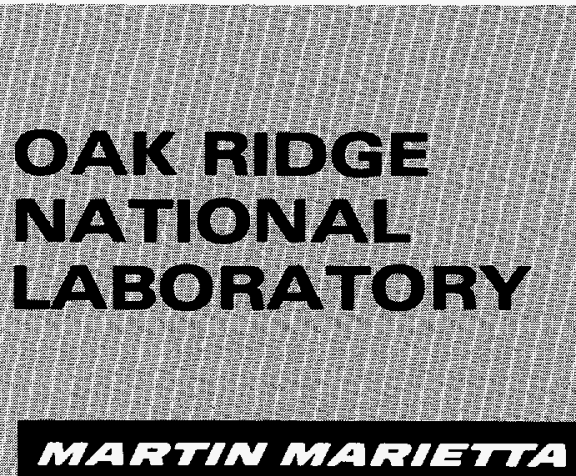

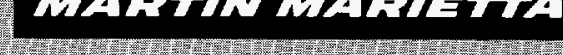
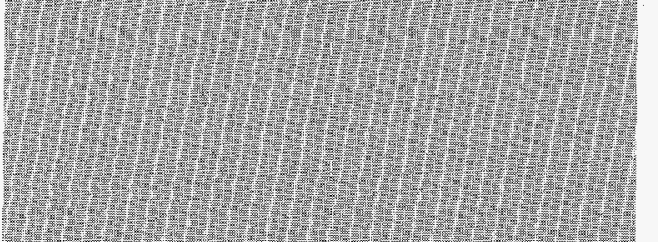

Investigation of Nuclide Importance to Functional Requirements Related to Transport and Long-Term Storage of LWR Spent Fuel

\author{
B. L. Broadhead \\ M. D. DeHart \\ J. C. Ryman \\ J. S. Tang \\ C. V. Parks
}

RECEIVED

JUN 291995

OSTI
MANAGED BY

MARTIN MARIETTA ENERGY SYSTEMS, INC.

FOR THE UNITED STATES

DEPARTMENT OF ENERGY 
This report has been reproduced directly from the best available copy.

Available to DOE and DOE contractors from the Office of Scientific and Technical Information, P.O. Box 62, Oak Ridge, TN 37831; prices available from (615) 576-8401, FTS 626-8401.

Available to the public from the National Technical Information Service, U.S. Department of Commerce, 5285 Port Royal Rd., Springfield, VA 22161.

This report was prepared as an account of work sponsored by an agency of the United States Government. Neither the United States Government nor any agency thereof, nor any of their employees, makes any warranty, express or implied, or assumes any legal liability or responsibility for the accuracy, completeness, or usefulness of any information, apparatus, product, or process disclosed, or represents that its use would not infringe privately owned rights. Reference herein to any specific commercial product, process, or service by trade name, trademark, manufacturer, or otherwise, does not necessarily constitute or imply its endorsement, recommendation, or favoring by the United States Government or any agency thereof. The views and opinions of authors expressed herein do not necessarily state or reflect those of the United States Government or any agency thereof. 


\section{DISCLAIMER}

Portions of this document may be illegible in electronic image products. Images are produced from the best available original document. 
Computational Physics and Engineering Division

\title{
INVESTIGATION OF NUCLIDE IMPORTANCE TO FUNCTIONAL REQUIREMENTS RELATED TO TRANSPORT AND LONG-TERM STORAGE OF LWR SPENT FUEL
}

\author{
B. L. Broadhead \\ M. D. DeHart \\ J. C. Ryman \\ J. S. Tang \\ C. V. Parks
}

Date Completed: October 1994

Date Published: June 1995

Prepared for

TRW Environmental Safety Systems

under Contract AT7708RT3X

with Oak Ridge National Laboratory

Prepared by the

OAK RIDGE NATIONAL LABORATORY

managed by

LOCKHEED MARTIN ENERGY SYSTEMS

for the

U.S. DEPARTMENT OF ENERGY

under contract DE-AC05-84OR21400 

LIST OF FIGURES $\ldots \ldots \ldots \ldots \ldots \ldots \ldots \ldots \ldots \ldots \ldots \ldots \ldots \ldots \ldots \ldots \ldots \ldots$ iv

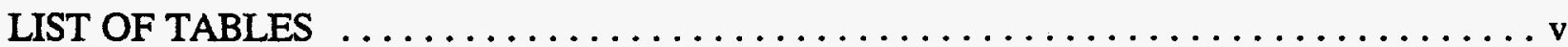

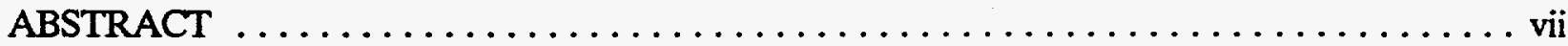

1. INTRODUCTION $\ldots \ldots \ldots \ldots \ldots \ldots \ldots \ldots \ldots \ldots \ldots \ldots \ldots \ldots \ldots \ldots \ldots \ldots \ldots \ldots \ldots \ldots$

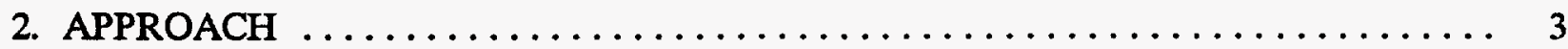

2.1 AREAS OF INTEREST $\ldots \ldots \ldots \ldots \ldots \ldots \ldots \ldots \ldots \ldots \ldots \ldots \ldots \ldots \ldots \ldots \ldots, 3$

2.2 ANALYSIS METHOD $\ldots \ldots \ldots \ldots \ldots \ldots \ldots \ldots \ldots \ldots \ldots \ldots \ldots, 3$

3. RESULTS AND DISCUSSION $\ldots \ldots \ldots \ldots \ldots \ldots \ldots \ldots \ldots \ldots \ldots \ldots \ldots \ldots \ldots \ldots$

3.1 CRITICALITY SAFETY RANKINGS $\ldots \ldots \ldots \ldots \ldots \ldots \ldots \ldots \ldots, 5$

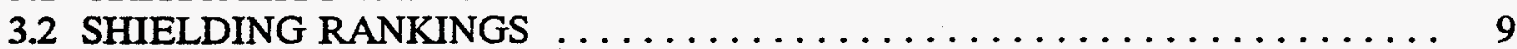

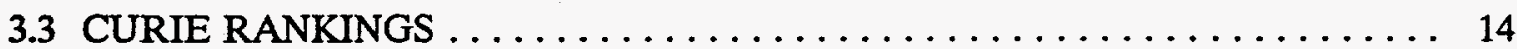

3.4 DECAY HEAT RANKINGS $\ldots \ldots \ldots \ldots \ldots \ldots \ldots \ldots \ldots \ldots \ldots \ldots \ldots \ldots$

3.5 RADIOLOGICAL TOXICITY RANKINGS $\ldots \ldots \ldots \ldots \ldots \ldots \ldots \ldots \ldots \ldots \ldots$

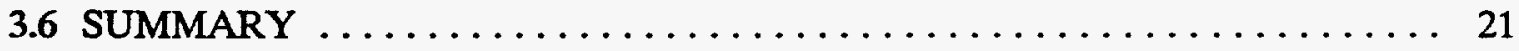

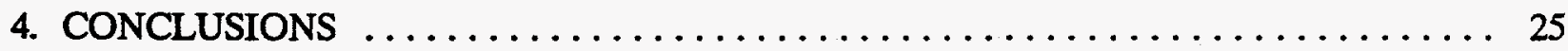

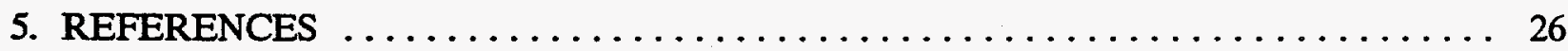

APPENDIX A. CRITICALITY SAFETY PLOTS $\ldots \ldots \ldots \ldots \ldots \ldots \ldots \ldots \ldots \ldots \ldots$

APPENDIX B. DOSE RATE FRACTION PLOTS $\ldots \ldots \ldots \ldots \ldots \ldots \ldots \ldots \ldots \ldots \ldots .49$

APPENDIX C. CURIE LEVEL FRACTION PLOTS $\ldots \ldots \ldots \ldots \ldots \ldots \ldots \ldots \ldots .81$

APPENDIX D. DECAY HEAT FRACTION PLOTS $\ldots \ldots \ldots \ldots \ldots \ldots \ldots \ldots \ldots \ldots .89$

APPENDIX E. RADIOLOGICAL TOXICITY FRACTION PLOTS $\ldots \ldots \ldots \ldots \ldots .97$ 


\section{LIST OF FIGURES}

Figure $\quad$ Page

$1 \quad$ Effect of long-term cooling on $k_{\infty} \ldots \ldots \ldots \ldots \ldots \ldots \ldots \ldots$ 


\section{LIST OF TABLES}

Table

1 Burnup and enrichment combinations used in ranking studies and their relationships to industry average burnups $\ldots \ldots \ldots \ldots \ldots \ldots \ldots \ldots \ldots \ldots \ldots$

2 Rankings of actinides with greater than $1 \%$ of total absorptions

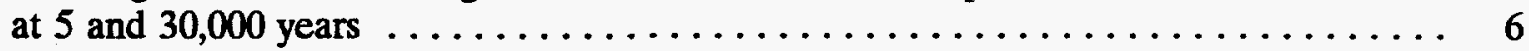

3 Rankings of fission products with greater than $0.1 \%$ of total absorptions at

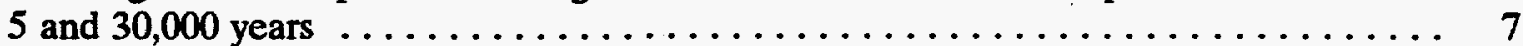

4 Actinide sensitivities and comparison of $k_{\text {eff }}$-vs-absorption rankings $\ldots \ldots \ldots \ldots \ldots$

5 Fission-product sensitivities and comparison of $k_{\text {eff }}$ and absorption rankings $\ldots \ldots \ldots 11$

6 Shielding rankings of actinides with greater than $1 \%$ of total dose at

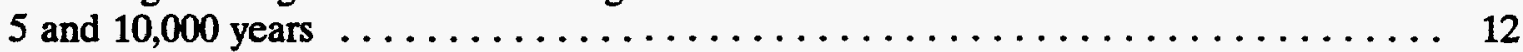

7 Shielding rankings of fission products and light elements with greater than $1 \%$

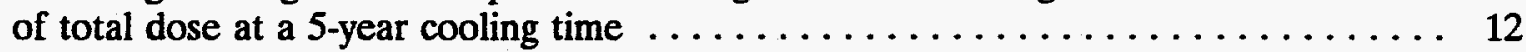

8 Curie rankings of actinides, fission products, and light elements with greater than $0.1 \%$ of total curies at 5 and 10,000 years $\ldots \ldots \ldots \ldots \ldots \ldots$

9 Decay heat rankings of actinides, fission products, and light elements with greater than $1 \%$ of total decay heat at 5 and 10,000 years $\ldots \ldots \ldots \ldots \ldots$

10 Ingestion toxicity rankings of light elements, actinides, and fission products with greater than $0.1 \%$ of total potential committed effective

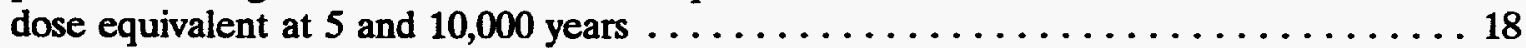

11 Inhalation toxicity rankings of light elements, actinides, and fission products with greater than $0.1 \%$ of total potential committed effective dose equivalent

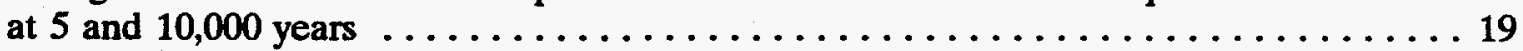

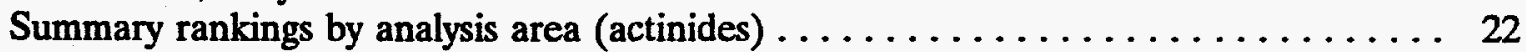
Summary rankings by analysis areas (fission products and light elements) $\ldots \ldots \ldots 23$ 



\begin{abstract}
The radionuclide characteristics of light-water-reactor (LWR) spent fuel play key roles in the design and licensing activities for radioactive waste transportation systems, interim storage facilities, and the final repository site. Several areas of analysis require detailed information concerning the time-dependent behavior of radioactive nuclides including (1) neutron/gamma-ray sources for shielding studies, (2) fissile/absorber concentrations for criticality safety determinations, (3) residual decay heat predictions for thermal considerations, and (4) curie and/or radiological toxicity levels for materials assumed to be released into the ground/environment after long periods of time. The crucial nature of the radionuclide predictions over both short and long periods of time has resulted in an increased emphasis on thorough validation for radionuclide generation/depletion codes.

Current radionuclide generation/depletion codes have the capability to follow the evolution of some 1600 isotopes during both irradiation and decay time periods. Of these, typically only 10 to 20 nuclides dominate contributions to each analysis area. Thus a quantitative ranking of nuclides over various time periods is desired for each of the analysis areas of shielding, criticality, heat transfer, and environmental dose (radiological toxicity). These rankings should allow for validation and data improvement efforts to be focused only on the most important nuclides.

This study investigates the relative importances of the various actinide, fission-product, and light-element isotopes associated with LWR spent fuel with respect to five analysis areas: criticality safety (absorption fractions), shielding (dose rate fractions), curies (fractional curies levels), decay heat (fraction of total watts), and radiological toxicity (fraction of potential committed effective dose equivalent). These rankings are presented for up to six different burnup/enrichment scenarios and at decay times from 2 to 100,000 years. Ranking plots for each of these analysis areas are given in an Appendix for completeness, as well as summary tables in the main body of the report. Summary rankings are presented in terms of high (greater than $10 \%$ contribution to the total), medium (between $1 \%$ and $10 \%$ contribution), and low (less than $1 \%$ contribution) for both short- and longterm cooling. When compared with the expected measurement accuracies, these rankings show that most of the important isotopes can be characterized sufficiently for the purpose of radionuclide generation/depletion code validation in each of the analysis areas. Because the main focus of this work is on the relative importances of isotopes associated with LWR spent fuel, some conclusions may not be applicable to similar areas such as high-level waste (HLW) and nonfuel-bearing components (NFBC).
\end{abstract}




\section{INTRODUCTION}

The Department of Energy's (DOE) Office of Civilian Radioactive Waste Management Program (OCRWM) was established, in accordance with the Nuclear Waste Policy Act of 1982, to serve as the lead office for (1) siting, constructing, and operating nuclear waste repositories, (2) transporting commercial spent nuclear fuel and high-level wastes, (3) developing a proposal to construct a monitored retrievable storage facility, and (4) aiding utilities in solving spent fuel storage problems. Information about the radionuclide characteristics of various spent fuel and high-level wastes during different time frames is necessary for each of these work areas.

To meet this need, the DOE-OCRWM has developed the Characteristic Data Base (CDB) to provide program participants with a consistent and qualified source of information about the quantities, dimensions, and compositions of spent fuel, high-level waste, and radioactive commercial nuclear reactor components. The CDB (currently revision 1) is comprised of a four-volume hard copy $^{1}$ report and six data bases that can be accessed via personal computer (PC). The CDB has undergone an extensive technical peer review, and has been "certified" by OCRWM for use in "quality affecting" work within the OCRWM program. One of the six data bases is the Radiological Data Base (RADDB) and provides users with compositions, curies, decay heat, photon source, and neutron source, based on the type of reactor [pressurized-water reactor (PWR) or boiling-water reactor (BWR)], initial enrichment, burnup, and cooling time of the fuel. The RADDB was created from multiple applications of the ORIGEN2 computer code ${ }^{2}$ using recently developed cross-section libraries. ${ }^{3}$ One important outcome of the peer review was the recognition that future revisions of the $\mathrm{CDB}$ would require that the analysis methods used to generate the data comply with OCRWM quality assurance $(\mathrm{QA})$ requirements for software.

OCRWM formed the CDB Users Group in April 1993 as a discussion forum for CDB Users nationwide and to provide technical input to help guide future $\mathrm{CDB}$ development. Many of the charter members of the CDB Users Group were assigned to subcommittees aligned technically with each of the six PC data bases. The radiological subcommittee was assigned to help guide further development of the RADDB and the verification and validation efforts related to the analysis methodology. The crucial nature of the radionuclide predictions over both short and long periods of time has resulted in a heightened interest in the accuracy of the radionuclide generation/depletion codes used in the design and safety evaluation of transportation system, interim storage, and highlevel-waste repository facilities. However, the validation of analysis methods used to predict spent fuel isotopics is hampered by the paucity of measured data that are available relative to the more than 1600 nuclides typically tracked in a standard point-depletion calculation using an ORIGEN-type code. In addition, the available measured data cover only a limited range of possible spent fuel characteristics (burnup, initial enrichment, cooling time, and assembly type). Thus to help direct future validation efforts and assist OCRWM in identifying the nuclides of importance to the functional requirements, the radiological subcommittee of the CDB Users Group recommended that work be done to provide a quantitative measure of the nuclide ranking for important analysis areas.

The radionuclide characteristics play key roles in the transportation system, interim storage facility, and repository design and licensing processes for several analysis areas including (1) neutron/gamma-ray sources for shielding studies, (2) fissile/absorber concentrations for criticality safety determinations, (3) residual decay heat predictions for thermal considerations, and (4) curie and/or radiological toxicity levels for materials assumed to be released into the ground/environment after long periods of time. The transportation of radioactive waste from reactor sites to the interim retrievable storage facility and ultimately to the final repository typically involves 5 to 50 years out-ofreactor time frames. Once the waste is placed in a final repository, time frames of interest include 
10 to 1,000 years after repository closure for heating considerations and 1,000 to 10,000 years after closure for curie levels and cumulative release limits to the environment. For criticality concerns, the time frames of interest are somewhat open since the principal fissile isotopes have half-lives on the order of $10^{8}$ years.

Each radioactive isotope has a different half-life, which can shift the relative importance of each isotope over the long time periods of concern to the repository design. Thus a nuclide ranking study needs to consider the effect that radioactive decay has on the ranking for each analysis area-shielding, criticality, heat transfer, and environmental dose (radiological toxicity). These rankings should allow for detailed validation and data improvement efforts to be concentrated on the limited number of nuclides that may have a significant impact on the functional requirements of the OCRWM objectives.

The development of this nuclide importance ranking report is the culmination of the efforts by ORNL to provide OCRWM and the CDB Users Group radiological subcommittee with a quantitative means to assess (validate) the ORIGEN model (embodied in ORIGEN2 and ORIGEN-S, ${ }^{4}$ the SCALE system version of ORIGEN), as well as to judge the relative importance of obtaining additional isotopic data. 


\section{APPROACH}

\subsection{AREAS OF INTEREST}

The rankings generated in this work cover the basic analysis areas of shielding, criticality safety, decay heat, curie levels, and radiological toxicity. In shielding analyses, the photon and neutron energy spectra from the spent fuel composition, coupled with the dimensions, compositions, and cross sections of the shielding material, contribute to the relative importance of each nuclide. Because of the importance of spent fuel transport and storage casks in the OCRWM program, dose rates at the cask surface for three cask types and two fuel burnup/enrichments were chosen as the basis for ranking nuclides on their importance to the shielding analysis area. For criticality safety, absorption fractions were generated for the major actinide and fission-product absorbers for six burnup/enrichment combinations. Even though the absorption fractions represent only an indirect measure of importance for criticality, absorption reactions contribute directly to $k_{\text {effi }}$, an absorption capture decreases $k_{\text {eff }}$, but an absorption fission increases $k_{\text {eff }}$. The fractional contributions to the total decay heat were obtained for two burnup/enrichment states. Similarly, fractional contributions to the total curie levels and radiological toxicity values as a function of decay time were obtained for the same two burnup/enrichment scenarios. These fractional contributions allow the ranking of radionuclide importances over time with respect to criticality safety, shielding, decay heat generation, curie levels, and toxicity for the LWR spent fuel burnup/enrichment cases considered. Not explicitly treated in this work are other types of HLW (i.e., ${ }^{233} \mathrm{U}$-fueled systems) and the associated irradiated components in a reactor (NFBC, pressure vessel, biological shield, etc.).

\subsection{ANALYSIS METHOD}

The basis for the ranking studies in each analysis area is a common set of radioisotope concentrations corresponding to Westinghouse $17 \times 17$ pressurized-water-reactor (PWR) fuel elements with enrichment and burnup characteristics, as given in Table 1. The spent fuel inventories were generated via the SAS2H/ORIGEN-S computer code ${ }^{5}$ assuming a reactor specific power of $40 \mathrm{MW} / \mathrm{t}$ and a power history with $80 \%$ uptime, $20 \%$ downtime in each cycle. Typical $(0.46 \mathrm{wt} \%)$ loadings of Co impurity were assumed in the Inconel grid spacer material. The base cross-section library used in these burnup/depletion calculations was the recently developed SCALE 44-group library, ${ }^{6}$ based primarily on ENDF/B-V data, with ${ }^{16} \mathrm{O},{ }^{154} \mathrm{Eu}$, and ${ }^{155} \mathrm{Eu}$ data obtained from ENDF/B-VI. Major changes were made in the ENDF/B-VI data for ${ }^{154} \mathrm{Eu}$ and ${ }^{155} \mathrm{Eu}$; hence, updated cross sections were used in this study. The end-of-irradiation concentrations were computed at decay times of $2,5,10,20,100,200,1,000,3,000,10,000,30,000$, and 100,000 years. Some analysis areas did not utilize all enrichment/burnup and cooling-time combinations. The shielding, decay heat, and curie rankings were desired at a low and a high burnup and used the $20-\mathrm{GWd} / \mathrm{t}$ and $50-\mathrm{GWd} / \mathrm{t}$ burnups with cooling time up to 10000 years. The absorption ranking studies investigated all six burnup/enrichment combinations and each of the eleven cooling times. Criticality rankings were desired at each burnup/enrichment combination to show the changes in importance for underburned vs overburned fuel. Overburned and underburned fuel correspond to the irradiation of a fuel assembly substantially longer or shorter than the industry average for a given enrichment (see Table 1). The toxicity rankings analyzed the $20-\mathrm{GWd} / \mathrm{t}$ and $50-\mathrm{GWd} / \mathrm{t}$ burnups and cooling times up to the full 100,000 years. 
Table 1. Burnup and enrichment combinations used in ranking studies and their relationships to industry average burnups

\begin{tabular}{cccl}
\hline $\begin{array}{c}\text { Enrichment, } \\
\text { wt \% }{ }^{235} \mathrm{U}\end{array}$ & $\begin{array}{c}\text { Burnup } \\
(\mathrm{GWd} / \mathrm{t})\end{array}$ & $\begin{array}{c}\text { Estimated } \\
\text { industry-average } \\
\text { burnup }(\mathrm{GWd} / \mathrm{T})\end{array}$ & \multicolumn{1}{c}{ Comments } \\
\hline 3.0 & 20 & 27 & Underburned \\
3.0 & 35 & 27 & Overburned \\
4.0 & 30 & 43 & Underburned \\
4.0 & 40 & 43 & Average \\
4.0 & 45 & 43 & Overburned \\
4.5 & 50 & 53 & Average \\
\hline
\end{tabular}

Computed absorption fractions, curie levels, and decay heat values in watts were obtained directly from the ORIGEN-S outputs. The absorption fractions were plotted directly; the curie and decay heat results were converted separately to fractional values and plotted. The rankings were tabulated separately for actinide and fission product materials to show their relative importances.

For the shielding rankings, the neutron and gamma-ray sources were taken from the ORIGEN-S outputs and input into the one-dimensional (1-D) discrete-ordinates module SAS1/XSDRNPM-S ${ }^{7}$ to obtain the radial dose rate at the cask surface. Three cask models were analyzed to determine the variation of rankings with cask type. The first model consisted of a $27-\mathrm{cm}$ carbon steel $/ 13-\mathrm{cm}$ resin shield, the second configuration contained a $12.7-\mathrm{cm}$ lead/13-cm resin shield, and the final cask consisted of a $50-\mathrm{cm}$ concrete shield. Calculations were performed using the SCALE coupled 27-neutron/18-gamma-group library with all radionuclides present to obtain total dose rate information, followed by repetitive calculations with individual isotopes to obtain partial dose rate information. Contributions to the neutron dose rates and primary/secondary gamma dose rates were separately tabulated to show their relative importances.

The radiological toxicity rankings were derived from the ORIGEN-S outputs by multiplying the activity of each nuclide by the committed effective dose equivalent per unit intake, taken from Federal Guidance Report No. $11 .^{8}$ This report gives the potential committed effective dose equivalent (i.e., the effective dose equivalent that would be received over a 50 -year period following intake, assuming all the nuclide present is ingested or inhaled). Thus the radiological toxicity rankings do not account for the mitigating effects of release fraction and dispersion (for airborne releases) or solubility, retardation, and exposure pathways (for underground waste package releases). The fraction of the total committed effective dose equivalent from each nuclide was derived both for ingestion and inhalation, and analyzed separately for the actinides, fission products, and light elements.

The rankings for each of the respective analysis areas are generated and presented as the fractional contribution to the total response. Thus for the criticality rankings, the fractional absorption for each nuclide is generated based on the total absorptions in the system. Similarly for decay heat, curies, and toxicity, the fractional contributions are based on the total watts, curies, and committed dose, respectively. For the shielding analyses, the fractional contributions are also based on the total dose rates. However, since actinides contribute to both neutron and gamma-ray doses, the fractional contributions from neutrons and gamma rays are listed separately for each actinide. 


\section{RESULTS AND DISCUSSION}

\subsection{CRITICALITY SAFETY RANKINGS}

The nuclide importance rankings for criticality safety at decay times of 5 and 30,000 years are given in Tables 2 and 3 in this section. A complete set of fractional absorption plots for all decay times is provided in Appendix A. These rankings are based on the fractional absorption for each nuclide at each of the various decay times. The rankings are tabulated at 5 years to correspond to the minimum cooling time at which OCRWM will accept spent fuel. The 30,000-year ranking period was chosen because (1) the $\mathrm{k}_{\infty}$ value of spent fuel has a local peak in that general time frame, as seen in Fig. 1 and (2) it represents significant decay time in terms of repository design issues.

The key features in these rankings are dominance of primary actinides ${ }^{235} \mathrm{U}$, ${ }^{238} \mathrm{U}$, and ${ }^{239} \mathrm{Pu}$, along with the large number of fission products which should be included for accurate results. Specific features seen are:

1. For low burnup and short cooling times, actinides are responsible for about $90 \%$ of all absorptions; after 100,000 years actinides still represent $87 \%$ of all absorptions. For high burnup, actinides absorb $85 \%$ of ill neutrons after 5 years, but less than $79 \%$ of absorptions occur in actinides after 100,000 years.

2. $\quad{ }^{235} \mathrm{U}$ is the most important actinide absorber for underburned fuel only. It falls well below ${ }^{238} \mathrm{U}$ and ${ }^{239} \mathrm{Pu}$ for more highly burned fuel at 5-year decay times. The 5-year decay trends should follow closely the trends seen during irradiation where the concentration of ${ }^{235} \mathrm{U}$ is constantly decreasing due to burnup, while the amount of ${ }^{239} \mathrm{Pu}$ is generally increasing due to capture in ${ }^{238} \mathrm{U}$. At 30,000 -year decay times, ${ }^{235} \mathrm{U}$ is again the most important actinide absorber because ${ }^{239} \mathrm{Pu}$ decays to ${ }^{235} \mathrm{U}$ with a 24,000 -year half-life.

3. ${ }^{239} \mathrm{Pu}$ is the most important absorber for moderately burned fuel, but its fractional absorption decreases as fuel is overburned because the ${ }^{239} \mathrm{Pu}$ present begins to serve as fuel when its concentrations become significant. However, the decrease is small and it remains the largest absorber until fuel is highly overburned.

4. ${ }^{238} \mathrm{U}$ is always one of the top two absorbers, and its fractional contribution is insensitive to burnup because large initial inventories and relatively small cross sections allow a nearconstant abundance during irradiation.

5. ${ }^{149} \mathrm{Sm}$ is the highest ranking fission-product absorber for low burnup; however, it is insensitive to burnup and becomes less important as burnup increases because its cross section is so large that depletion becomes significant for high burnups.

6. ${ }^{143} \mathrm{Nd}$ increases in importance with increasing exposure and becomes more important than

${ }^{149} \mathrm{Sm}$ for overburned fuel, since its much lower cross sections relative to ${ }^{149} \mathrm{Sm}$ allow it to continue to build up even with high burnups.

7. ${ }^{155} \mathrm{Gd}$ is sensitive to both burnup and cooling time. For underburned fuel it ranks ninth after 5 years of cooling and fifth after 30,000 years. For moderate- and high-burnup cases it increases in relative importance as an absorber. For the highly burned $4.5 \mathrm{wt} \%, 50-\mathrm{GWd} / \mathrm{t}$ case, ${ }^{155} \mathrm{Gd}$ ranks sixth after 5 years, but it is the second most important absorber after 30,000 
Table 2. Rankings of actinides with greater than $1 \%$ of total absorptions at 5 and 30,000 years

\begin{tabular}{lcccccc}
\hline \multicolumn{7}{c}{ Burnup/Enrichment } \\
\cline { 2 - 7 } Nuclide & $20 \mathrm{GWd} / \mathrm{t}$ & $35 \mathrm{GWd} / \mathrm{t}$ & $30 \mathrm{GWd} / \mathrm{t}$ & $40 \mathrm{GWd} / \mathrm{t}$ & $45 \mathrm{GWd} / \mathrm{t}$ & $50 \mathrm{GWd} / \mathrm{t}$ \\
\hline 5-year rankings & $3.0 \mathrm{wt} \%$ & $3.0 \mathrm{wt} \%$ & $4.0 \mathrm{wt} \%$ & $4.0 \mathrm{wt} \%$ & $4.0 \mathrm{wt} \%$ & $4.5 \mathrm{wt} \%$ \\
\hline U-235 & $1(29)^{a}$ & $3(15)$ & $1(28)$ & $3(20)$ & $3(16)$ & $3(17)$ \\
U-238 & $2(26)$ & $2(26)$ & $2(24)$ & $2(25)$ & $2(25)$ & $2(24)$ \\
Pu-239 & $3(23)$ & $1(27)$ & $3(24)$ & $1(25)$ & $1(26)$ & $1(26)$ \\
Pu-240 & $4(5)$ & $4(7)$ & $4(6)$ & $4(7)$ & $4(7)$ & $4(7)$ \\
Pu-241 & $5(3)$ & $5(6)$ & $5(4)$ & $5(6)$ & $5(6)$ & $5(6)$ \\
Am-241 & $6(1)$ & $6(1)$ & $6(1)$ & $6(1)$ & $6(1)$ & $6(1)$ \\
$30,000-$ year rankings & & & & & \\
U-235 & $1(44)$ & $1(30)$ & $1(43)$ & $1(35)$ & $1(31)$ & $1(32)$ \\
U-238 & $2(29)$ & $2(30)$ & $2(27)$ & $2(27)$ & $2(28)$ & $2(27)$ \\
Pu-239 & $3(12)$ & $3(16)$ & $3(13)$ & $3(15)$ & $3(16)$ & $3(15)$ \\
Np-237 & $4(2)$ & $4(3)$ & $4(2)$ & $4(3)$ & $4(3)$ & $4(3)$ \\
U-236 & $5(1)$ & $5(1)$ & $5(1)$ & $5(1)$ & $5(1)$ & $5(1)$ \\
\hline
\end{tabular}

"Isotopes percentage contribution to the total number of absorptions. 
Table 3. Rankings of fission products with greater than $0.1 \%$ of total absorptions at 5 and 30,000 years

\begin{tabular}{|c|c|c|c|c|c|c|}
\hline \multirow[b]{2}{*}{ Nuclide } & \multicolumn{6}{|c|}{ Burnup/Enrichment } \\
\hline & $\begin{array}{l}20 \mathrm{GWd} / \mathrm{t} \\
3.0 \mathrm{wt} \%\end{array}$ & $\begin{array}{l}35 \mathrm{GWd} / \mathrm{t} \\
3.0 \mathrm{wt} \%\end{array}$ & $\begin{array}{l}30 \mathrm{GWd} / \mathrm{t} \\
4.0 \mathrm{wt} \%\end{array}$ & $\begin{array}{l}40 \mathrm{GWd} / \mathrm{t} \\
4.0 \mathrm{wt} \%\end{array}$ & $\begin{array}{l}45 \mathrm{GWd} / \mathrm{t} \\
4.0 \mathrm{wt} \%\end{array}$ & $\begin{array}{l}50 \mathrm{GWd} / \mathrm{t} \\
4.5 \mathrm{wt} \%\end{array}$ \\
\hline \multicolumn{7}{|c|}{ 5-year rankings 30,000 years } \\
\hline Sm-149 & $1 / 1^{a}(1 / 2)^{b}$ & $1 / 1(2 / 2)$ & $1 / 1(1 / 2)$ & $1 / 1(1 / 2)$ & $2 / 2(2 / 2)$ & $2 / 3(1 / 2)$ \\
\hline Nd-143 & $2 / 2(1 / 1)$ & $2 / 2(1 / 2)$ & $2 / 2(1 / 2)$ & $2 / 2(1 / 2)$ & $1 / 1(2 / 2)$ & $1 / 1(2 / 2)$ \\
\hline Rh-103 & $3 / 3(0.8 / 1)$ & $3 / 4(1 / 2)$ & $3 / 3(1 / 1)$ & $3 / 4(1 / 2)$ & $3 / 4(1 / 2)$ & $3 / 4(1 / 2)$ \\
\hline Sm-151 & $4 /-(0.7 /-)$ & $4 /-(0.9 /-)$ & $4 /-(0.8 /-)$ & $4 /-(0.9 /-)$ & $4 /-(1 /-)$ & $4 /-(1 /-)$ \\
\hline Xe-131 & $5 / 6(0.5 / 0.5)$ & $5 / 6(0.7 / 0.8)$ & $5 / 6(0.6 / 0.6)$ & $5 / 6(0.7 / 0.8)$ & $6 / 6(0.7 / 0.8)$ & $7 \pi(0.8 / 0.9)$ \\
\hline Cs-133 & $6 \pi(0.4 / 0.4)$ & $7 /(0.6 / 0.7)$ & $6 / 7(0.5 / 0.6)$ & $6 /(0.7 / 0.7)$ & $7 /(0.7 / 0.8)$ & $5 / 6(0.8 / 0.9)$ \\
\hline Tc-99 & $7 / 9(0.3 / 0.3)$ & $8 / 9(0.5 / 0.5)$ & $7 / 8(0.4 / 0.4)$ & $8 / 8(0.5 / 0.5)$ & $8 / 8(0.6 / 0.6)$ & $8 / 8(0.6 / 0.6)$ \\
\hline $\mathrm{Sm}-152$ & $8 / 8(0.3 / 0.3)$ & $9 / 8(0.5 / 0.5)$ & $8 / 9(0.4 / 0.4)$ & $9 / 9(0.5 / 0.5)$ & $9 / 9(0.5 / 0.6)$ & $9 / 9(0.5 / 0.6)$ \\
\hline Gd-155 & $9 / 5(0.3 / 0.6)$ & $6 / 3(0.7 / 2)$ & $9 / 4(0.4 / 0.9)$ & $7 / 3(0.6 / 2)$ & $5 / 3(0.7 / 2)$ & $6 / 2(0.8 / 2)$ \\
\hline Nd-145 & $10 / 11(0.2 / 0.2)$ & $11 / 11(0.3 / 0.4)$ & $10 / 11(0.3 / 0.3)$ & $11 / 11(0.3 / 0.4)$ & $11 / 11(0.4 / 0.4)$ & $11 / 11(0.4 / 0.5)$ \\
\hline Sm-147 & $11 / 10(0.2 / 0.2)$ & $13 / 12(0.2 / 0.3))$ & $12 / 10(0.2 / 0.3)$ & $12 / 12(0.3 / 0.4)$ & $13 / 12(0.3 / 0.4)$ & $13 / 12(0.3 / 0.4)$ \\
\hline Eu-153 & $12 / 12(0.2 / 0.2)$ & $10 / 10(0.4 / 0.4)$ & $11 / 12(0.2 / 0.3)$ & $10 / 10(0.4 / 0.4)$ & $10 / 10(0.4 / 0.5)$ & $10 / 10(0.5 / 0.5)$ \\
\hline Mo-95 & $13 / 14(0.1 / 0.2)$ & $15 / 15(0.2 / 0.3)$ & $13 / 14(0.2 / 0.2)$ & $14 / 14(0.2 / 0.3)$ & $14 / 14(0.3 / 0.3)$ & $14 / 14(0.3 / 0.3)$ \\
\hline $\mathrm{Sm}-150$ & $14 / 13(0.1 / 0.2)$ & $12 / 13(0.3 / 0.3)$ & $14 / 13(0.2 / 0.2)$ & $13 / 13(0.3 / 0.3)$ & $12 / 13(0.3 / 0.4)$ & $12 / 13(0.3 / 0.4)$ \\
\hline Ag-109 & $15 / 15(0.1 / 0.1)$ & $14 / 14(0.2 / 0.3)$ & $15 / 15(0.2 / 0.2)$ & $15 / 15(0.2 / 0.2)$ & $15 / 15(0.3 / 0.3)$ & $15 / 15(0.3 / 0.3)$ \\
\hline Ru-101 & - & $16 / 16(0.2 / 0.2)$ & $16 / 16(0.1 / 0.1)$ & $16 / 16(0.2 / 0.2)$ & $16 / 16(0.2 / 0.2)$ & $16 / 16(0.2 / 0.2)$ \\
\hline Pd-105 & - & $17 / 19(0.1 / 0.1)$ & - & $17 / 19(0.1 / 0.1)$ & $17 / 19(0.1 / 0.1)$ & $17 / 18(0.1 / 0.2)$ \\
\hline Pr-141 & - & $-/ 18(-10.1)$ & - & $-/ 18(-/ 0.1)$ & $18 / 18(0.1 / 0.1)$ & $18 / 19(0.1 / 0.2)$ \\
\hline Gd-157 & - & $-/ 17(-10.1)$ & - & $-/ 17(-/ 0.1)$ & $19 / 17(0.1 / 0.2)$ & $19 / 17(0.1 / 0.2)$ \\
\hline Eu-151 & $-14(-10.7)$ & $-15(-11)$ & $-15(-10.8)$ & $-15(-11)$ & $-15(-11)$ & $-15(-/ 1)$ \\
\hline
\end{tabular}

Rankings correspond to $5 / 30,000$ years.

Percentage contributions corresponding to $5 / 30,000$ years. 
$K$-infinity vs Decay Time

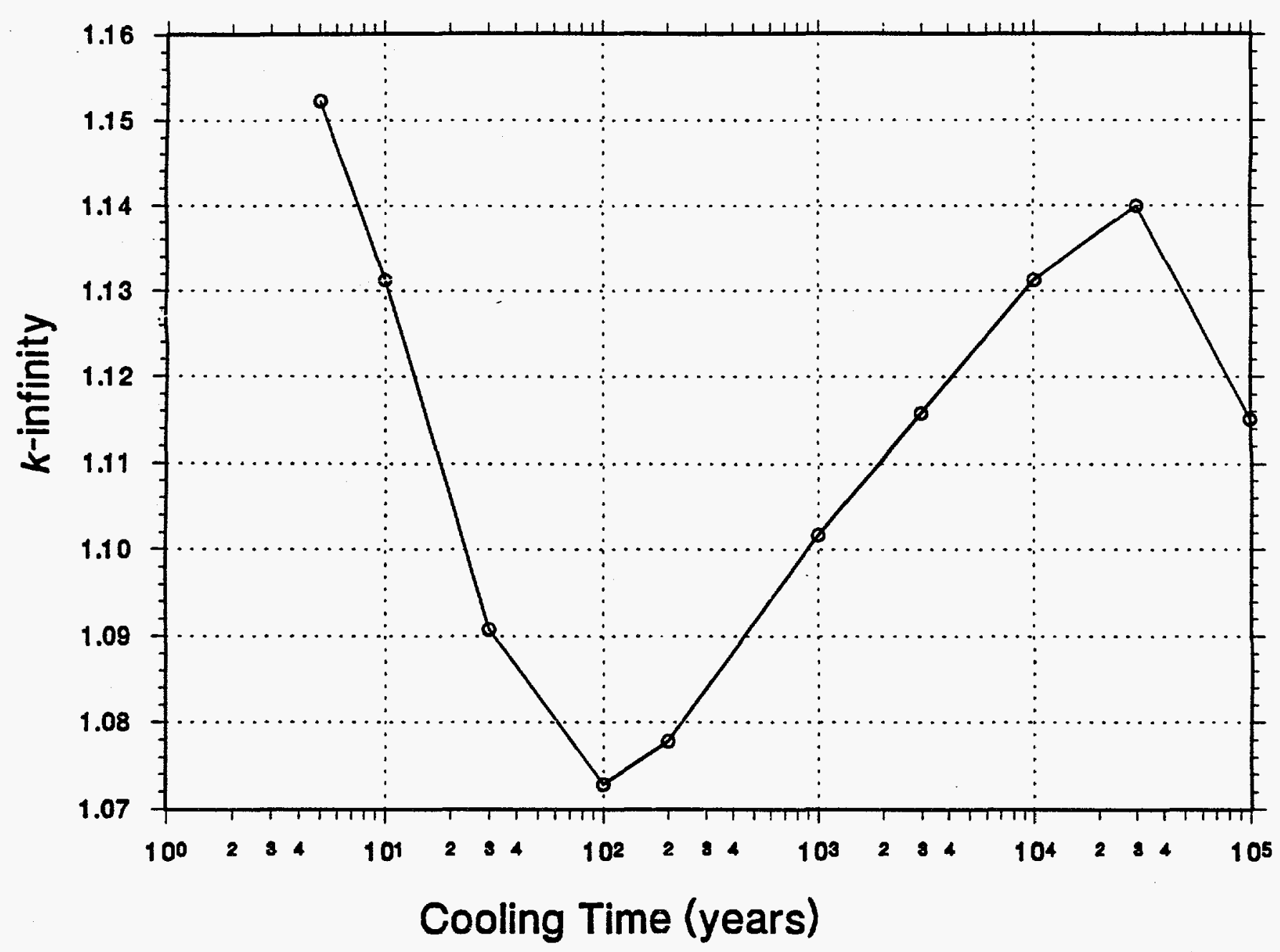

Fig. 1. Effect of long-term cooling on $k_{\infty}$. 
years. Note that the use of ENDF/B-V or earlier data for ${ }^{155} \mathrm{Eu}$ causes the importances for ${ }^{155} \mathrm{Gd}$ to be roughly double the values reported here. Major cross-section changes were made in the ENDF/B-VI ${ }^{155}$ Eu data. ${ }^{9}$

8. $\quad{ }^{151} \mathrm{Sm}$ is important for early decay periods but decays (90-year half-life) to ${ }^{151} \mathrm{Eu}$, which then becomes important at later decay periods.

9. The rankings for extended decay times show interesting characteristics for various decay chains, such as ${ }^{241} \mathrm{Pu} \rightarrow{ }^{241} \mathrm{Am} \rightarrow{ }^{237} \mathrm{~Np}$, where each nuclide is important over different periods of decay.

All criticality safety rankings presented thus far are based on the assumption that the relative rankings for fractional absorptions are the same as the relative rankings for the effective neutron multiplication factor, $\mathrm{k}_{\text {eff }}$. To confirm this assumption, $\mathrm{k}_{\text {eff }}$ calculations were performed for an infinite array of fuel pins with the nuclide concentrations corresponding to the $3.0 \mathrm{wt} \%, 30-\mathrm{GWd} / \mathrm{t}$ case shown above at a cooling time of 5 years. The base case $k_{\text {eff }}$ was computed with 11 actinides and 19 fission products included. Sensitivity calculations were then performed by changing concentrations for each nuclide individually and recomputing $k_{\text {eff }}$. The results shown in Tables 4 and 5 give the base $k_{e f f}$ as well as the percentage change in $k_{e f f}$ for actinide and fission-product perturbations, respectively. The actual rankings for the multiplication factor are then compared with those predicted from the absorption fractions. Identical rankings are seen, except for a few cases where two nuclides with very similar sensitivities have reversed importances.

\subsection{SHIELDING RANKINGS}

The rankings for the shielding portion of this work are given in Tables 6 and 7 for two burnups $(20 \mathrm{GWd} / \mathrm{t}$ and $50 \mathrm{GWd} / \mathrm{t})$ and their corresponding enrichments $(3.0 \mathrm{wt} \%$ and $4.5 \mathrm{wt} \%)$ for three different cask types. These rankings are presented for decay times of 5 and 10,000 years after irradiation. Complete plots and rankings for the fractional contribution to the total dose rates for the various actinides, fission products, and light elements are shown in Appendix B for ten decay times ranging from 2 to 10,000 years.

Nuclide ranking studies for determining the important contributors to a shielding analysis are highly sensitive to the shield thickness and shield material. For thin shields, the gamma-ray energy is much less important than for thick shields, where typically particles with energies at or above 1 $\mathrm{MeV}$ dominate the dose contribution. The composition of the shielding material(s) affects the relative contributions of neutrons, primary gamma rays, and secondary gamma rays since hydrogenous materials are much more effective for attenuating neutrons, while high- $\mathrm{Z}$ materials are much more effective shields for gamma rays. The casks considered in this work represent three examples of thick shields: iron/resin, lead/resin, and concrete materials. The curie rankings for fission products and light elements given in a later section would be more appropriate dose rankings for a thin shield.

The key features seen in the rankings given in Tables 6 and 7 are the dominance for a 5-year decay time of the actinide ${ }^{244} \mathrm{Cm}$ and the high-activity fission products and light elements with highenergy gamma rays. For a 10,000-year decay time, the fission products and light elements are unimportant, while the actinides ${ }^{240} \mathrm{Pu},{ }^{242} \mathrm{Pu},{ }^{239} \mathrm{Pu}$, and ${ }^{214} \mathrm{Bi}$ dominate the dose rate contributions. The specific features seen from an analysis of the plots shown in the Appendix include: 
Table 4. Actinide sensitivities ${ }^{a}$ and comparison of $\mathrm{k}_{\mathrm{eff}}$ and absorption rankings

\begin{tabular}{lccccc}
\hline Case & $\begin{array}{c}\text { Nuclide } \\
\text { composition, } \\
\text { \% change }\end{array}$ & $\mathrm{k}_{\text {eff }}$ & $\begin{array}{c}\text { Sensitivity } \\
\text { coefficient }\end{array}$ & $\begin{array}{c}\Delta \mathrm{k} \\
\text { rank }\end{array}$ & $\begin{array}{c}\text { Absorption } \\
\text { fraction rank }\end{array}$ \\
\hline Base case & & 0.982666 & & & \\
Pu-239 & 1 & 0.984308 & 0.1642 & 1 & 1 \\
U-238 & 1 & 0.981040 & -0.1626 & 2 & 2 \\
U-235 & 1 & 0.983751 & 0.1085 & 3 & 3 \\
Pu-240 & 2 & 0.981465 & $-6.005 E-2$ & 4 & 4 \\
Pu-241 & 2 & 0.983686 & $5.100 \mathrm{E}-2$ & 5 & 5 \\
Am-241 & 10 & 0.981345 & $-1.321 \mathrm{E}-2$ & 6 & 6 \\
Np-237 & 25 & 0.981191 & $-5.900 \mathrm{E}-3$ & 7 & 8 \\
U-236 & 25 & 0.981362 & $-5.216 \mathrm{E}-3$ & 8 & 7 \\
Pu-242 & 25 & 0.981525 & $-4.564 \mathrm{E}-3$ & 9 & 9 \\
Am-243 & 100 & 0.980841 & $-1.825 \mathrm{E}-3$ & 10 & 10 \\
U-234 & 100 & 0.981619 & $-1.047 \mathrm{E}-3$ & 11 & 11 \\
\hline
\end{tabular}

${ }^{a}$ Corresponds to $17 \times 17$ PWR, 3\% enrichment, 35-GWd/MTU with 5-year cooling time.

${ }^{b}$ Sensitivity coefficient, $S_{N}=\frac{\Delta k / k}{\Delta N / N}$, where $k$ is the multiplication factor and $N$ is the nuclide concentration. 
Table 5. Fission-product sensitivities ${ }^{a}$ and comparison of $k_{\text {eff }}$ and absorption rankings

\begin{tabular}{lccccc}
\hline Case & $\begin{array}{c}\text { Nuclide } \\
\text { composition, } \\
\text { \% change }\end{array}$ & $\mathrm{k}_{\text {eff }}$ & $\begin{array}{c}\text { Sensitivity } \\
\text { coefficient }^{b}\end{array}$ & $\begin{array}{c}\Delta \mathrm{k} \\
\text { rank }\end{array}$ & $\begin{array}{c}\text { Absorption } \\
\text { fraction rank }\end{array}$ \\
\hline Base case & & 0.982666 & & & \\
Sm-149 & 10 & 0.980837 & $-1.829 \mathrm{E}-2$ & 1 & 1 \\
Nd-143 & 10 & 0.980970 & $-1.696 \mathrm{E}-2$ & 2 & 2 \\
Rh-103 & 10 & 0.981284 & $-1.382 \mathrm{E}-2$ & 3 & 3 \\
Sm-151 & 10 & 0.981621 & $-1.045 \mathrm{E}-2$ & 4 & 4 \\
Gd-155 & 25 & 0.980729 & $-7.748 \mathrm{E}-3$ & 5 & 6 \\
Xe-131 & 25 & 0.980950 & $-6.864 \mathrm{E}-3$ & 6 & 5 \\
Cs-133 & 25 & 0.981056 & $-6.440 \mathrm{E}-3$ & 7 & 7 \\
Tc-99 & 25 & 0.981391 & $-5.100 \mathrm{E}-3$ & 8 & 8 \\
Sm-152 & 25 & 0.981517 & $-4.596 \mathrm{E}-3$ & 9 & 9 \\
Eu-153 & 25 & 0.981617 & $-4.196 \mathrm{E}-3$ & 10 & 10 \\
Nd-145 & 25 & 0.981758 & $-3.632 \mathrm{E}-3$ & 11 & 11 \\
Sm-150 & 25 & 0.981941 & $-2.900 \mathrm{E}-3$ & 12 & 12 \\
Sm-147 & 25 & 0.982008 & $-2.632 \mathrm{E}-3$ & 13 & 13 \\
Ag-109 & 25 & 0.982035 & $-2.524 \mathrm{E}-3$ & 14 & 14 \\
Mo-95 & 25 & 0.982081 & $-2.340 \mathrm{E}-3$ & 15 & 15 \\
Ru-101 & 100 & 0.981042 & $-1.624 \mathrm{E}-3$ & 16 & 16 \\
Gd-157 & 100 & 0.981107 & $-1.559 \mathrm{E}-3$ & 17 & 18 \\
Pd-105 & 100 & 0.981506 & $-1.160 \mathrm{E}-3$ & 18 & 17 \\
Pr-141 & 100 & 0.981560 & $-1.106 \mathrm{E}-3$ & 19 & 19 \\
\hline
\end{tabular}

${ }^{a}$ Corresponds to $17 \times 17$ PWR, $3 \%$ enrichment, $35 \mathrm{GWd} / \mathrm{MTU}$ with 5-year cooling time.

${ }^{b}$ Sensitivity coefficient, $S_{N}=\frac{\Delta k / k}{\Delta N / N}$, where $k$ is the multiplication factor and $N$ is the nuclide concentration. 
Table 6. Shielding rankings of actinides with greater than $1 \%$ of total dose at 5 and 10,000 years

\begin{tabular}{|c|c|c|c|c|c|c|}
\hline \multirow[b]{2}{*}{ Nuclide } & \multicolumn{2}{|c|}{ Iron cask ${ }^{a}$} & \multicolumn{2}{|c|}{ Lead cask $^{a}$} & \multicolumn{2}{|c|}{ Concrete cask ${ }^{\circ}$} \\
\hline & $\begin{array}{l}20 \mathrm{GWd} / \mathrm{t} \\
3.0 \mathrm{wt} \%\end{array}$ & $\begin{array}{c}50 \mathrm{GWd} / \mathrm{t} \\
4.5 \mathrm{wt} \%\end{array}$ & $\begin{array}{l}20 \mathrm{GWd} / \mathrm{t} \\
3.0 \mathrm{wt} \%\end{array}$ & $\begin{array}{l}50 \mathrm{GWd} / \mathrm{t} \\
4.5 \mathrm{wt} \%\end{array}$ & $\begin{array}{l}20 \mathrm{GWd} / \mathrm{t} \\
3.0 \mathrm{wt} \%\end{array}$ & $\begin{array}{l}50 \mathrm{GWd} / \mathrm{t} \\
4.5 \mathrm{wt} \%\end{array}$ \\
\hline \multicolumn{7}{|c|}{ 5-year rankings } \\
\hline $\mathrm{Cm}-244$ & $1 / H^{b}(1 /-)^{c}$ & $1 / 1 /-(12 / 7 /-)$ & $1 /-/-(2 /-/-)$ & $1 / 1 /-(19 / 1 /-)$ & $-1-1-(-1-1-)$ & $1 / 1 /-(2 / 2 /-)$ \\
\hline \multicolumn{7}{|c|}{ 10,000-year rankings } \\
\hline $\begin{array}{l}\text { Pu-240 } \\
\text { Pu-242 } \\
\text { Pu-239 } \\
\text { Bi-214 }\end{array}$ & $\begin{array}{c}1 / 1 / 1(34 / 3 / 17) \\
2 / 2 / 2(16 / 1 / 8) \\
3 /-/ 3(10 /-15) \\
-/-14(-/-14)\end{array}$ & $\begin{array}{c}2 / 2 / 2(25 / 1 / 14) \\
1 / 1 / 1(30 / 1 / 16) \\
3 /-14(5 /-12) \\
-/-13(-/-/ 4)\end{array}$ & $\begin{array}{c}1 / 2 / 2(50 / 1 / 2) \\
2 /-/ 3(24 /-/ 1) \\
3 /-/-(16 /-/-) \\
-/ 1 / 1(-/ 2 / 3)\end{array}$ & $\begin{array}{c}2 /-/ 3(38 /-12) \\
1 /-/ 2(44 /-/ 2) \\
3 /-/-(8 /-/-) \\
-/ 1 / 1(-/ 1 / 3)\end{array}$ & $\begin{array}{c}1 / 1 / 1(23 / 6 / 15) \\
2 / 3 / 3(11 / 3 / 7) \\
3 / 4 / 4(7 / 2 / 4) \\
-12 / 2(-/ 5 / 11) \\
\end{array}$ & $\begin{array}{c}2 / 2 / 2(18 / 3 / 13) \\
1 / 1 / 1(21 / 4 / 16) \\
3 /-/ 4(3 /-/ 2) \\
-/-/ 3(-/-/ 11) \\
\end{array}$ \\
\hline
\end{tabular}

${ }^{a}$ Gamma shields consist of $27-\mathrm{cm}$ steel, $12.7-\mathrm{cm}$ lead, and $50-\mathrm{cm}$ concrete for the iron, lead, and concrete casks, respectively.

${ }^{b}$ Rankings with respect to neutron/primary gamma/secondary gamma dose rates. The $/ /$ symbol indicates all contributions less than $1 \%$.

Percentage contribution from each isotope to the total dose, listing neutron/primary gamma/secondary gamma contributions separately.

Table 7. Shielding rankings of fission products and light elements with greater than $1 \%$ of total dose at a 5 -year cooling time

\begin{tabular}{lcccccc}
\hline & \multicolumn{2}{c}{ Iron cask $^{a}$} & \multicolumn{2}{c}{ Lead cask $^{a}$} & \multicolumn{2}{c}{ Concrete cask $^{a}$} \\
& $20 \mathrm{GWd} / \mathrm{t}$ & $50 \mathrm{GWd} / \mathrm{t}$ & $20 \mathrm{GWd} / \mathrm{t}$ & $50 \mathrm{GWd} / \mathrm{t}$ & $20 \mathrm{GWd} / \mathrm{t}$ & $50 \mathrm{GWd} / \mathrm{t}$ \\
Nuclide & $3.0 \mathrm{wt} \%$ & $4.5 \mathrm{wt} \%$ & $3.0 \mathrm{wt} \%$ & $4.5 \mathrm{wt} \%$ & $3.0 \mathrm{wt} \%$ & $4.5 \mathrm{wt} \%$ \\
\hline Co-60 & $1(49)^{b}$ & $1(33)$ & $1(56)$ & $1(40)$ & $1(50)$ & $1(39)$ \\
Pr-144 & $2(19)$ & $3(8)$ & $2(17)$ & $3(8)$ & $3(12)$ & $5(6)$ \\
Cs-134 & $3(11)$ & $2(15)$ & $3(10)$ & $2(16)$ & $2(14)$ & $2(23)$ \\
Rh-106 & $4(9)$ & $5(6)$ & $4(8)$ & $5(6)$ & $5(7)$ & $6(6)$ \\
Eu-154 & $5(4)$ & $4(7)$ & $5(4)$ & $4(8)$ & $6(5)$ & $3(10)$ \\
Ba-137m & $6(3)$ & $6(3)$ & - & - & $4(9)$ & $4(9)$ \\
Y-90 & $7(1)$ & - & $6(1)$ & - & $7(1)$ & $7(1)$ \\
\hline
\end{tabular}

${ }^{a} \mathrm{Gamma}$ shields consist of $27-\mathrm{cm}$ steel, $12.7-\mathrm{cm}$ lead, and $50-\mathrm{cm}$ concrete for the iron, lead, and concrete casks, respectively.

${ }^{b}$ Percentage contribution to the total dose. 
1. The three cask models studied exhibit similar trends with respect to the neutron-vs-gamma-ray contributions to the total dose. The primary gamma rays dominate the total dose for the first 50 to 100 years; the neutron/secondary gamma contribution dominates the remainder of the time up to 10,000 years. The neutron-vs-secondary-gamma contributions vary appreciably by cask type because of the differing attenuation and secondary particle generation properties of the shield materials.

2. For short cooling times (less than 100 years), ${ }^{244} \mathrm{Cm}$ dominates the actinide contributions to the total dose. However, over the same time period the primary gamma dose dominates the total dose, except for the lead cask, where the neutron doses overtake those due to primary gammas at about 50 years. The fractional contribution of ${ }^{244} \mathrm{Cm}$ to the total dose increases with increasing burnup.

3. For long cooling times (greater than 100 years), the actinides ${ }^{239} \mathrm{Pu},{ }^{240} \mathrm{Pu}$, and ${ }^{242} \mathrm{Pu}$ dominate the total dose. For decay times approaching 10,000 years, ${ }^{214} \mathrm{Bi}$ becomes increasingly important because it is a daughter of several long-lived actinides.

4. The dose contributions for actinides ${ }^{240} \mathrm{Pu},{ }^{242} \mathrm{Pu}$, and ${ }^{214} \mathrm{Bi}$ are relatively insensitive to burnup. The dose contribution due to ${ }^{239} \mathrm{Pu}$ decreases somewhat with increasing burnup because of its tendency to contribute significantly to the reactor power in the latter stages of burnup.

5. ${ }^{60} \mathrm{Co}$ dominates the contribution to the total dose rate from about 3 to 30 years; however, the initial levels of cobalt vary significantly. The initial amount of cobalt assumed in this work was $\mathbf{0 . 5 \%}$ for the Inconel grid spacers, which is typically an upper limit for older assemblies. Most newer assemblies contain significantly lower initial concentrations, effectively lowering the large contributions seen for ${ }^{60} \mathrm{Co}$.

6. $\quad{ }^{144} \mathrm{Pr}$ is a very important contributor to the total dose for decay times of 5 years or less. Thereafter, the contribution decreases rapidly due to the 285 -d half-life of its precursor, ${ }^{144} \mathrm{Ce}$. The ${ }^{144} \mathrm{Pr}$ ranking is insensitive to burnup since it is a direct product of fission and its concentration should grow proportionally to the total burnup.

7. ${ }^{134} \mathrm{Cs}$ is an important contributor to the total dose during the 2- to 10 -year time frame. Its contribution typically peaks at about 5 years. For higher burnups, the relative contribution increases because it is not a direct fission product but rather is produced from ${ }^{133} \mathrm{Cs}$ capture.

8. ${ }^{154}$ Eu contributes substantially to the total dose between 5 and 50 years. The contribution peaks at about 20 years. The contribution to dose also increases with burnup due to its production from capture in ${ }^{153} \mathrm{Eu}$.

9. The importances of the remaining fission products (other than those reasons mentioned in 5 through 7 above) decrease with increasing burnup because of the faster buildup of actinides relative to fission products during extended irradiations.

10. ${ }^{106} \mathrm{Rh}$ is an important contributor to the total dose but only for fairly short cooling times of 2 years or less. 
11. ${ }^{137} \mathrm{~m} \mathrm{Ba}$ can be important for thin shields, but since its energy is somewhat low $(0.66 \mathrm{Mev})$ it becomes less important for thick shields. The enhanced importance is also seen for the concrete cask, where low-energy gamma rays can be passed more readily than in the high-Z iron and lead casks.

\subsection{CURIE RANKINGS}

The curie rankings for this study are given in Table 8 for two burnups $(20 \mathrm{GWd} / \mathrm{t}$ and $50 \mathrm{GWd} / \mathrm{t}$ ) and their corresponding enrichments (3.0 wt \% and $4.5 \mathrm{wt} \%$ ). These rankings are presented for decay times of 5 and 10,000 years after irradiation. Plots of the fractional contribution to the total number of curies for the various actinides, fission products, and light elements are shown in Appendix $\mathrm{C}$ for ten decay times ranging from 2 to 10,000 years.

The curie rankings in Table 8, along with the total curies plots shown in the Appendix, show the domination of the fission products for decay times less than 200 years. After that time, the actinides are the dominant contributor to the total curie levels in the spent fuel. The primary actinide contributors at early decay times $\left({ }^{241} \mathrm{Pu},{ }^{238} \mathrm{Pu}\right.$, and $\left.{ }^{241} \mathrm{Am}\right)$ decay such that at the 10,000 -year period, shown in Table $8,{ }^{239} \mathrm{Pu}$ and ${ }^{240} \mathrm{Pu}$ are the primary contributors. For high burnups, ${ }^{243} \mathrm{Am}$ and its daughter, ${ }^{239} \mathrm{~Np}$, also contribute a few percent to the total curie levels.

The dominant fission-product contributors to the total curie levels at decay times less than 200 years exist primarily in parent-daughter pairs in secular equilibrium (i.e., they have identical activities). These parent-daughter pairs include the ${ }^{137} \mathrm{Cs}-{ }^{137 m} \mathrm{Ba},{ }^{90} \mathrm{Sr}-{ }^{90} \mathrm{Y},{ }^{144} \mathrm{Ce}-{ }^{144} \mathrm{Pr}$, and ${ }^{106} \mathrm{Ru}-{ }^{106} \mathrm{Rh}$ pairs, but ${ }^{147} \mathrm{Pm},{ }^{134} \mathrm{Cs}$, and ${ }^{85} \mathrm{Kr}$ also contribute. All these fission products are essentially decayed out at 200 years. The only fission product that contributes appreciably beyond this time period is ${ }^{99} \mathrm{Tc}$, which has a 213,000 -year half-life.

\subsection{DECAY HEAT RANKINGS}

The decay heat rankings for this study are given in Table 9 for two burnups (20 GWd/t and $50 \mathrm{GWd} / \mathrm{t}$ ) and their corresponding enrichments (3.0 wt \% and $4.5 \mathrm{wt} \%)$. These rankings are presented for decay times of 5 and 10,000 years after irradiation. Plots of the fractional contribution to the total decay heat for the various actinides, fission products, and light elements are shown in Appendix $\mathrm{D}$ for ten decay times ranging from 2 to 10,000 years.

The decay heat rankings in Table 9, along with the total decay heat plots shown in Appendix D, show the domination of the fission products for decay times less than 70 years. After that time, the actinides are the dominant contributor to the total decay heat levels in the spent fuel. For the low-burnup case, the primary actinide contributors at early decay times, ${ }^{238} \mathrm{Pu}$ and ${ }^{241} \mathrm{Am}$, decay until at the 10,000 -year period, shown in Table $9,{ }^{239} \mathrm{Pu}$ and ${ }^{240} \mathrm{Pu}$ are the primary contributors. For high burnups, ${ }^{244} \mathrm{Cm}$ and ${ }^{243} \mathrm{Am}$ also contribute nonnegligible amounts to the total decay heat.

The dominant fission-product contributors to the total decay heat levels at decay times less than 70 years exist largely in parent-daughter pairs in secular equilibrium. These pairs include the ${ }^{137} \mathrm{Cs}-{ }^{137 m} \mathrm{Ba},{ }^{90} \mathrm{Sr}-{ }^{90} \mathrm{Y},{ }^{144} \mathrm{Ce}-{ }^{144} \mathrm{Pr}$, and ${ }^{106} \mathrm{Ru}-{ }^{106} \mathrm{Rh}$ pairs, but ${ }^{134} \mathrm{Cs}$, ${ }^{154} \mathrm{Eu}$, and the light-element ${ }^{60} \mathrm{Co}$ also contribute. These parent-daughter pairs, while at secular equilibrium, have differing contributions to the total decay heat, since the Q-values or the heat generated per decay differ between the parent and daughter nuclides. All these fission products are essentially decayed out at $\mathbf{2 0 0}$ to $\mathbf{3 0 0}$ years. No fission products contribute appreciably to the decay heat beyond this time period. 
Table 8. Curie rankings of actinides, fission products, and light elements with greater than $0.1 \%$ of total curies at 5 and 10,000 years

\begin{tabular}{|c|c|c|c|c|}
\hline \multirow[b]{2}{*}{ Nuclide } & \multicolumn{2}{|c|}{5 years } & \multicolumn{2}{|c|}{10,000 years } \\
\hline & $\begin{array}{l}20 \mathrm{GWd} / \mathrm{t} \\
3.0 \mathrm{wt} \%\end{array}$ & $\begin{array}{l}50 \mathrm{GWd} / \mathrm{t} \\
4.5 \mathrm{wt} \%\end{array}$ & $\begin{array}{l}20 \mathrm{GWd} / \mathrm{t} \\
3.0 \mathrm{wt} \%\end{array}$ & $\begin{array}{l}50 \mathrm{GWd} / \mathrm{t} \\
4.5 \mathrm{wt} \%\end{array}$ \\
\hline \multicolumn{5}{|l|}{ Actinides } \\
\hline $\mathrm{Pu}-241$ & $1(17)^{a}$ & $1(17)$ & - & - \\
\hline $\mathbf{P u}-238$ & $2(0.2)$ & $2(0.7)$ & - & - \\
\hline Am-241 & $3(0.2)$ & $3(0.2)$ & - & - \\
\hline $\mathrm{Pu}-240$ & - & - & $2(32)$ & $2(38)$ \\
\hline Pu-239 & - & - & $1(62)$ & $1(49)$ \\
\hline Am-243 & - & - & - & $3(3)$ \\
\hline Np-239 & - & - & - & $4(3)$ \\
\hline \multicolumn{5}{|c|}{ Fission products and light elements } \\
\hline Cs-137 & $1(15)$ & $1(17)$ & - & - \\
\hline $\mathrm{Ba}-137 \mathrm{~m}$ & $2(14)$ & $2(16)$ & - & - \\
\hline Sr-90 & $3(12)$ & $3(12)$ & - & - \\
\hline Y-90 & $4(12)$ & $4(12)$ & - & - \\
\hline $\mathrm{Pm}-147$ & $5(10)$ & $5(6)$ & - & - \\
\hline Ce-144 & $6(3)$ & $9(2)$ & - & - \\
\hline Pr-144 & $7(3)$ & $10(2)$ & - & - \\
\hline Ru-106 & $8(3)$ & $7(3)$ & - & - \\
\hline Rh-106 & $9(3)$ & $8(3)$ & - & - \\
\hline Cs-134 & $10(3)$ & $6(6)$ & - & - \\
\hline $\mathrm{Kr}-85$ & 11(1) & $11(1)$ & - & - \\
\hline Tc-99 & - & - & $1(2)$ & $1(3)$ \\
\hline
\end{tabular}

${ }^{a}$ Percentage contribution to the total curie levels. 
Table 9. Decay heat rankings of actinides, fission products, and light elements with greater than $1 \%$ of total decay heat at 5 and 10,000 years

\begin{tabular}{lcccc}
\hline \multicolumn{3}{c}{5 years } & \multicolumn{2}{c}{10,000 years } \\
\hline Nuclide & $20 \mathrm{GWd} / \mathrm{t}$ & $50 \mathrm{GWd} / \mathrm{t}$ & $20 \mathrm{GWd} / \mathrm{t}$ & $50 \mathrm{GWd} / \mathrm{t}$ \\
\hline Actinides & $3.0 \mathrm{wt} \%$ & $4.5 \mathrm{wt} \%$ & $3.0 \mathrm{wt} \%$ & $4.5 \mathrm{wt} \%$ \\
\hline Pu-238 & & & & \\
$\mathrm{Am}-241$ & $1(2)^{a}$ & $2(7)$ & - & - \\
$\mathrm{Pu}-240$ & $2(2)$ & $3(2)$ & - & - \\
$\mathrm{Pu}-239$ & - & - & $2(33)$ & $2(41)$ \\
$\mathrm{Cm}-244$ & - & - & $1(65)$ & $1(54)$ \\
Am-243 & - & $1(7)$ & - & - \\
& - & - & - & \\
Fission products and light elements & & & \\
Y-90 & $1(23)$ & $1(19)$ & & - \\
Ba-137m & $2(20)$ & $2(18)$ & - & - \\
Cs-134 & $3(11)$ & $3(17)$ & - & - \\
Rh-106 & $4(10)$ & $4(7)$ & - & - \\
Pr-144 & $5(9)$ & $7(4)$ & - & - \\
Cs-137 & $6(6)$ & $5(5)$ & - & - \\
Sr-90 & $7(5)$ & $6(4)$ & - & - \\
Co-60 & $8(5)$ & $8(3)$ & - & - \\
Eu-154 & $9(1)$ & $9(2)$ & - & - \\
\hline
\end{tabular}

${ }^{a}$ Percentage contribution to the total decay heat levels. 


\subsection{RADIOLOGICAL TOXICITY RANKINGS}

The ranking of radiological toxicity, especially in regard to environmental dose, is a complex problem. A complete analysis must take into account leakage of nuclides from the fuel assemblies and environmental pathway analyses, both of which are beyond the scope of the present study. In this work, the measure of radiological toxicity has been taken to be the potential committed effective dose equivalent for exposure either by ingestion or inhalation. The adjective "potential" is used because the full amount of each isotope present in the assembly is considered when computing the committed effective dose equivalent. No credit has been taken for the retention of a nuclide in the assembly or for losses along an environmental pathway from the assembly location to the location of an exposed individual.

The activity of each nuclide was multiplied by the committed effective dose equivalent per unit intake for the exposure mode of interest. These conversion coefficients were taken from Federal Guidance Report No. $11 .^{8}$ For the inhalation exposure mode, a nuclide generally has two or three conversion coefficients corresponding to compounds that have different clearance times from the lung. For ingestion exposure, some nuclides have more than one conversion coefficient because different compounds containing the nuclide will have a different fraction of the compound reaching body fluids after ingestion. For those nuclides that have more than one conversion coefficient, the coefficient used was the one that yields the largest effective dose equivalent.

Effective dose equivalent ${ }^{10}$ is a weighted sum of doses to individual organs and tissues of the body. The weighting factor for an individual organ or tissue corresponds to the fractional contribution of that organ or tissue to the total risk of stochastic effects when the entire body is uniformly irradiated. The committed dose is the sum of all doses projected to be received in the future from an intake at a given time. By convention, the sum is taken over 50 years, which represents the arbitrarily assumed remaining lifetime of an exposed adult worker. The conversion coefficients are derived from (1) metabolic models that represent chemical transport of compounds within, and excretion from the body; and (2) studies of radiation transport between pairs of source and target organs for radiations emitted by the nuclides of interest, including alphas, betas, discrete electrons, $\mathbf{X}$ rays, and gamma rays. Radioactive decay within the body is explicitly included. The details of these calculations can be found in Federal Guidance Report No. $11,{ }^{8}$ ICRP Publication $26,{ }^{10}$ and ICRP Publication 30 (ref. 11).

The rankings do not include elemental tritium, or any noble gas (argon, krypton, and xenon) nuclides. The primary exposure mode for these nuclides is submersion dose. To estimate submersion dose, the concentration of the nuclide in air is required. Since there is no way to relate a unit concentration of nuclide in air to the amount in the fuel assembly, no rankings can be computed here. In addition, the rankings do not include ${ }^{220} \mathrm{Rn},{ }^{222} \mathrm{Rn}$, and their daughter products. Dose from these nuclides and their daughters is particularly difficult to calculate, and radiation protection for these nuclides is expressed in terms of exposure to the chain of parent and daughters in units of Working Level Months. ${ }^{8}$

The radiological toxicity rankings for exposure by ingestion and inhalation are given in Tables 10 and 11, respectively. Each table has rankings for two burnups $(20 \mathrm{GWd} / \mathrm{t}$ and $50 \mathrm{GWd} / \mathrm{t})$ and the corresponding enrichments (3.0 wt \% and $4.5 \mathrm{wt} \%$ ), presented for decay times of 5 and 10,000 years. Plots of the fractional contribution to the potential committed effective dose equivalent from ingestion and inhalation are shown in Appendix $E$ for actinides and for fission products plus ${ }^{60} \mathrm{Co}$ at decay times from 2 through 100,000 years. 
Table 10. Ingestion toxicity rankings of actinides and fission products with greater than $0.1 \%$ of total potential committed effective dose equivalent at 5 and 10,000 years

\begin{tabular}{|c|c|c|c|c|}
\hline \multirow[b]{2}{*}{ Nuclide } & \multicolumn{2}{|c|}{5 years } & \multicolumn{2}{|c|}{10,000 years } \\
\hline & $\begin{array}{c}20 \mathrm{GWd} / \mathrm{t} \\
3.0 \mathrm{wt} \%\end{array}$ & $\begin{array}{l}50 \mathrm{GWd} / \mathrm{t} \\
4.5 \mathrm{wt} \%\end{array}$ & $\begin{array}{c}20 \mathrm{GWd} / \mathrm{t} \\
3.0 \mathrm{wt} \%\end{array}$ & $\begin{array}{c}50 \mathrm{GWd} / \mathrm{t} \\
4.5 \mathrm{wt} \%\end{array}$ \\
\hline \multicolumn{5}{|l|}{ Actinides } \\
\hline $\begin{array}{l}\text { Pu-241 } \\
\text { Pu-238 } \\
\text { Am-241 } \\
\text { Pu-240 } \\
\text { Pu-239 } \\
\text { Cm-244 } \\
\text { Am-243 } \\
\text { Cm-243 } \\
\text { Am-242m } \\
\text { Np-237 } \\
\text { Pu-242 } \\
\text { U-234 }\end{array}$ & $\begin{array}{c}1(35)^{a} \\
2(20) \\
3(18) \\
4(9) \\
5(8) \\
6(4) \\
7(0.1) \\
- \\
- \\
- \\
- \\
-\end{array}$ & $\begin{array}{c}3(18) \\
1(37) \\
4(11) \\
5(4) \\
6(3) \\
2(24) \\
7(0.3) \\
8(0.2) \\
9(0.1) \\
- \\
- \\
-\end{array}$ & $\begin{array}{c}- \\
- \\
- \\
2(33) \\
1(66) \\
- \\
3(0.5) \\
- \\
- \\
4(0.3) \\
5(0.2) \\
6(0.1)\end{array}$ & $\begin{array}{c}- \\
- \\
- \\
2(41) \\
1(54) \\
- \\
3(3) \\
- \\
- \\
5(0.4) \\
4(0.6) \\
6(0.2)\end{array}$ \\
\hline \multicolumn{5}{|c|}{ Fission Products } \\
\hline $\begin{array}{l}\text { Sr-90 } \\
\text { Ru-106 } \\
\text { Ce-144 } \\
\text { Cs-137 } \\
\text { Pm-147 }\end{array}$ & $\begin{array}{c}1(4) \\
2(0.4) \\
3(0.3) \\
4(0.1) \\
5(0.1)\end{array}$ & $\begin{array}{c}1(2) \\
2(0.2) \\
- \\
- \\
-\end{array}$ & $\begin{array}{l}- \\
- \\
- \\
-\end{array}$ & $\begin{array}{l}- \\
- \\
- \\
-\end{array}$ \\
\hline
\end{tabular}

${ }^{a}$ Percentage contribution to the total potential committed effective dose equivalent. 
Table 11. Inhalation toxicity rankings of actinides, fission products, and light elements with greater than $0.1 \%$ of total potential committed effective dose equivalent at 5 and 10,000 years

\begin{tabular}{|c|c|c|c|c|}
\hline \multirow[b]{2}{*}{ Nuclide } & \multicolumn{2}{|c|}{5 years } & \multicolumn{2}{|c|}{10,000 years } \\
\hline & $\begin{array}{l}20 \mathrm{GWd} / \mathrm{t} \\
3.0 \mathrm{wt} \%\end{array}$ & $\begin{array}{c}50 \mathrm{GWd} / \mathrm{t} \\
4.5 \mathrm{wt} \%\end{array}$ & $\begin{array}{l}20 \mathrm{GWd} / \mathrm{t} \\
3.0 \mathrm{wt} \%\end{array}$ & $\begin{array}{c}50 \mathrm{GWd} / \mathrm{t} \\
4.5 \mathrm{wt} \%\end{array}$ \\
\hline \multicolumn{5}{|c|}{ Actinides } \\
\hline $\begin{array}{l}\text { Pu-241 } \\
\text { Pu-238 } \\
\text { Am-241 } \\
\text { Pu-240 } \\
\text { Pu-239 } \\
\text { Cm-244 } \\
\text { Am-243 } \\
\text { Cm-243 } \\
\text { Np-237 } \\
\text { Pu-242 }\end{array}$ & $\begin{array}{c}1(19)^{a} \\
2(11) \\
3(10) \\
4(5) \\
5(4) \\
6(2) \\
= \\
- \\
- \\
-\end{array}$ & $\begin{array}{c}3(13) \\
1(25) \\
4(7) \\
5(3) \\
6(2) \\
2(16) \\
7(0.2) \\
8(0.1) \\
- \\
-\end{array}$ & $\begin{array}{c}- \\
- \\
- \\
2(33) \\
1(66) \\
- \\
3(0.5) \\
- \\
4(0.3) \\
5(0.2)\end{array}$ & $\begin{array}{c}- \\
- \\
- \\
2(41) \\
1(54) \\
- \\
3(3) \\
- \\
5(0.4) \\
4(0.6)\end{array}$ \\
\hline \multicolumn{5}{|c|}{ Fission Products and Light Elements } \\
\hline $\begin{array}{l}\text { Sr-90 } \\
\text { Cs-137 } \\
\text { Cs-134 } \\
\text { Y-90 } \\
\text { Ru-106 } \\
\text { Ce-144 } \\
\text { Co-60 } \\
\text { Pm-147 }\end{array}$ & $\begin{array}{c}1(27) \\
2(12) \\
3(4) \\
4(2) \\
5(1) \\
6(1) \\
7(0.4) \\
8(0.2)\end{array}$ & $\begin{array}{c}1(18) \\
2(9) \\
3(4) \\
4(1) \\
5(0.8) \\
6(0.4) \\
7(0.2) \\
-\end{array}$ & $\begin{array}{l}- \\
- \\
- \\
- \\
- \\
- \\
- \\
-\end{array}$ & $\begin{array}{l}- \\
- \\
- \\
- \\
- \\
- \\
- \\
-\end{array}$ \\
\hline
\end{tabular}

${ }^{a}$ Percentage contribution to the total potential committed effective dose equivalent. 
In addition, Appendix $\mathrm{E}$ contains plots of the relative contributions of the light-element, actinide, and fission-product groups to the total for the same range of decay times. It is clear from the latter plots that the actinides are the primary contributors to the potential committed effective dose equivalent. For ingestion exposure, the actinide group is the only major contributor for all decay times from 2 through 100,000 years. For inhalation exposure, the actinide group is the only major contributor from 100 through 100,000 years. For times less than 5 years, the fission-product group is a larger contributor than the actinide group for low-enrichment, low-burnup fuel. From 10 to 100 years, it remains a major contributor to inhalation exposure, but rapidly decreases in importance between 100 and 200 years. The light-element group is never a significant contributor to radiological toxicity.

In the light-element group, ${ }^{60} \mathrm{Co}$ is the only noticeable contributor for inhalation exposure, and only for decay times less than 10 years. It is negligible for greater decay times. No light-element nuclide makes a contribution greater than $0.1 \%$ for ingestion exposure at any decay time.

No fission product makes a significant contribution after 200 years decay time. Among the fission products, ${ }^{90} \mathrm{Sr}$ is the largest contributor for both exposure modes, except for the ingestion of ${ }^{144} \mathrm{Ce}$ at 2 years from low-enrichment, low-burnup fuel. For decay times less than 5 years, ${ }^{144} \mathrm{Ce}$ and ${ }^{106} \mathrm{Ru}$ are of interest for both exposure modes. For inhalation exposure, ${ }^{137} \mathrm{Cs}$ is of moderate importance until 100 years, but is barely of interest for ingestion exposure at decay times of 10 years or less and only for low-enrichment, low-burnup fuel. From 2 to 10 years decay time, ${ }^{134} \mathrm{Cs}$ is moderately important for inhalation exposure. At times of 5 years or less, ${ }^{147} \mathrm{Pm}$ is noticeable, but of small importance for both exposure modes.

As mentioned earlier, the actinide group contains the principal contributors to committed effective dose equivalent for all except the shortest decay times. For decay times from 2 through 100 years, ${ }^{238} \mathrm{Pu}$ is important for both exposure modes. During this same time period, ${ }^{241} \mathrm{Am}$ steadily increases in importance, remains the principal contributor for both exposure modes until 1,000 years, then rapidly decreases, becoming of no interest after 3,000 years decay. For times less than 20 years, ${ }^{241} \mathrm{Pu}$ is important for both exposure modes, but loses importance rapidly, becoming of no interest after 100 years. The importance of ${ }^{240} \mathrm{Pu}$ is moderate at decay times less than 100 years, but it becomes a major contributor at times between 200 and 30,000 years, with a peak at 3,000 years decay. The behavior of ${ }^{239} \mathrm{Pu}$ is the same as that of ${ }^{240} \mathrm{Pu}$ out to a decay time of 3,000 years. However, it keeps on increasing in importance, becoming the most important contributor for decay times greater than 10,000 years. For high-enrichment, high-burnup fuel, ${ }^{243} \mathrm{Am}$ makes a modest contribution in the period from 1,000 to 30,000 years; for low-enrichment, low-burnup fuel, it makes only a small contribution during this period. At the maximum decay time of 100,000 years, there are a number of moderate contributors: ${ }^{237} \mathrm{~Np},{ }^{242} \mathrm{Pu}$, and ${ }^{229} \mathrm{Th}$ for both exposure modes; ${ }^{210} \mathrm{~Pb}$, ${ }^{210} \mathrm{Po}$, and ${ }^{226} \mathrm{Ra}$ only for inhalation exposure; and ${ }^{234} \mathrm{U}$ and ${ }^{230} \mathrm{Th}$ only for ingestion exposure. The other nuclides shown on the actinide plots make only small contributions at this time.

Note that conversion factors relating committed effective dose equivalent to ingestion or inhalation are not available for all radioactive isotopes in the ORIGEN-S decay library; therefore, some unknown fraction of the total committed effective dose equivalent is being neglected for both exposure modes. Given the energies and intensities of all radiations emitted by a nuclide, it is possible to derive conversion factors for that nuclide. When only the total alpha, beta, gamma, and neutron energy emitted by a nuclide is known, it should still be possible to derive a conservative conversion factor for that nuclide. However, the effort required to derive the additional conversion factors is far beyond the scope of the current work. In an effort to gain some basic understanding of the effect of neglecting those nuclides having no conversion factors, plots have been included in Appendix $E$ that give the fraction of activity neglected in computing the committed effective dose equivalents. It can be seen from these plots that no light-element activity of consequence has been omitted. The neglected fraction of actinide activity is less than $1 \%$ for times less than 30,000 years, and reaches a maximum of about $9 \%$ at 100,000 years. The neglected fraction of fission product 
activity, is roughly $20 \%$ at 2 years decay time, slowly increases to a maximum of about $30 \%$ at 200 years decay time, and decreases rapidly (becoming negligible) at times of 1,000 years or greater. Considering the time dependence of the actinide and fission-product group contributions to the committed effective dose equivalent (also shown in Appendix E), the effect of the neglected isotopes should be relatively small, since conversion factors have been tabulated for most nuclides of radiological significance. That is, the estimates of the total committed effective dose equivalent are low by some unknown (but probably fairly small) factor, and the relative rankings of nuclides that are significant contributors should not change.

\subsection{SUMMARY}

The previous sections have described the rankings of the various actinides, fission products, and light elements with respect to five different analysis areas. Tables 12 and 13 present these rankings in summary form. Table 12 gives the rankings for the actinides, and Table 13 gives rankings for the fission products and light elements. A scheme for easy selection of the most important nuclides for either short or long cooling times was chosen to represent these rankings in the two tables. The use is made of a high, medium, and low ranking, where high is defined to be a $10 \%$ or greater contribution to the total response; a medium ranking falls between 1 and $10 \%$ of the total response; and a low ranking corresponds to 0.1 to $1 \%$ contribution to the total response. To account for the variation in nuclide importance with decay, separate rankings are tabulated for short and long cooling times. For the purposes of this designation, short cooling times are assumed to be 100 years or less.

For the actinides, a number of nuclides, primarily the major plutonium, americium, and curium isotopes, have high-to-medium rankings in most or all of the analysis areas. The uranium isotopes are largely important only for criticality.

For the fission-product and light-element isotopes shown in Table 13, very few nuclides have importances in several areas. The shielding, curies, decay heat, and radiological toxicity categories are closely related and have several important isotopes in common. For the criticality rankings, there are no high importances for fission products, and only four isotopes have medium importances. However, there are some 16 nuclides with low importances, the sum of which would be a medium or high importance. This fact can complicate the validation process for these materials because of the large number of isotopes that must be characterized.

These importance rankings should facilitate validation efforts for radionuclide generation/depletion codes by indicating the nuclides that have the most significant effect on the responses of interest, and allowing experimental efforts to be emphasized for those nuclides. Furthermore, although good measurement accuracy is needed to minimize uncertainty in the validation process, the degree of accuracy needed may vary from nuclide to nuclide. These differing nuclide requirements are due to the differing accuracy requirements in the various analysis areas (e.g., acceptable criticality predictions are expected to be within a percent of $k_{\text {eff }}$ measurements, whereas agreement within $10 \%$ could be acceptable for shielding applications). These rankings by analysis area should allow the varying accuracy requirements to be met in the most efficient manner. Indeed, certain groups of elements are more amenable to accurate measurements than others. For example, shown in Table 14 are applicable measurement techniques (see ref. 12) for a number of isotopes and their corresponding target accuracies. The highly accurate thermal-emission, isotopic dilution mass spectrometry (TEIDMS) method appears to be suitable for most of the important actinide absorbers and fission-product absorbers. For the important fission products where the TEIDMS method has not been applied, the radiochemical analysis (RCA) method appears to be of sufficient accuracy for the shielding and decay heat verification studies. 
Table 12 . Summary rankings by analysis area (actinides) ${ }^{a}$

\begin{tabular}{|c|c|c|c|c|c|c|c|c|c|c|c|c|}
\hline \multirow{3}{*}{ Actinides } & & & & & & & & & \multicolumn{4}{|c|}{ Toxicity } \\
\hline & \multicolumn{2}{|c|}{ Absorption } & \multicolumn{2}{|c|}{ Shielding } & \multicolumn{2}{|c|}{ Curies } & \multicolumn{2}{|c|}{ Watts } & \multicolumn{2}{|c|}{ Ingestion } & \multicolumn{2}{|c|}{ Inhalation } \\
\hline & Short ${ }^{b}$ & Long $^{c}$ & Short & Long & Short & Long & Short & Long & Short & Long & Short & Long \\
\hline Pb-210 & & & & & & & & & & L & & $\mathbf{M}$ \\
\hline $\mathrm{Bi}-214$ & & & $\mathbf{M}$ & & & & & & & & & \\
\hline Po-210 & & & & & & & & & & $\mathrm{L}$ & & $\mathbf{M}$ \\
\hline Ra-225 & & & & & & & & & & & & $\mathbf{L}$ \\
\hline Ra-226 & & & & & & & & & & $\mathbf{L}$ & & $\mathbf{M}$ \\
\hline Ac-227 & & & & & & & & & & $\mathbf{M}$ & & $\mathbf{L}$ \\
\hline Th-229 & & & & & & & & & & $\mathbf{M}$ & & $\mathbf{M}$ \\
\hline Th-230 & & & & & & & & & & $\mathbf{M}$ & & $\mathbf{L}$ \\
\hline $\mathrm{Pa}-231$ & & & & & & & & & & L & & $\mathbf{L}$ \\
\hline U-233 & & & & & & & & & & $\mathrm{L}$ & & L \\
\hline U-234 & $\mathbf{L}$ & $\mathbf{L}$ & & & & & & & & $\mathbf{M}$ & & $\mathbf{L}$ \\
\hline U-235 & $\mathbf{H}$ & $\mathbf{H}$ & & & & & & & & & & \\
\hline U-238 & $\mathbf{H}$ & $\mathbf{H}$ & & & & & & & & L & & L \\
\hline Np-237 & $\mathbf{L}$ & $\mathbf{M}$ & & & & & & & & $\mathbf{M}$ & & $\mathbf{M}$ \\
\hline Np-239 & & & & & & $\mathbf{M}$ & & & & & & \\
\hline Pu-238 & & & $\mathbf{M}$ & & $\mathbf{M}$ & & $\mathbf{H}$ & & $\mathbf{H}$ & $\mathbf{M}$ & $\mathbf{H}$ & $\mathbf{H}$ \\
\hline Pu-239 & $\mathbf{H}$ & $\mathbf{H}$ & $\mathbf{L}$ & $\mathbf{M}$ & $\mathbf{L}$ & $\mathbf{H}$ & $\mathbf{M}$ & $\mathbf{H}$ & $\mathbf{M}$ & $\mathbf{H}$ & $\mathbf{M}$ & $\mathbf{H}$ \\
\hline $\mathrm{Pu}-240$ & $\mathbf{M}$ & $\mathbf{M}$ & $\mathbf{M}$ & $\mathbf{H}$ & $\mathbf{L}$ & $\mathbf{H}$ & $\mathbf{M}$ & $\mathbf{H}$ & $\mathbf{M}$ & $\mathbf{H}$ & $\mathbf{M}$ & $\mathbf{H}$ \\
\hline Pu-241 & $\mathbf{M}$ & & & & $\mathbf{H}$ & & & & $\mathbf{H}$ & & $\mathbf{H}$ & \\
\hline Pu-242 & L & $\mathbf{L}$ & $\mathbf{L}$ & $\mathbf{H}$ & & & & & & $\mathbf{M}$ & & $\mathbf{M}$ \\
\hline Am-241 & $\mathbf{M}$ & & $\mathbf{M}$ & & $\mathbf{M}$ & $\mathbf{H}$ & $\mathrm{H}$ & $\mathbf{H}$ & $\mathrm{H}$ & $\mathbf{H}$ & $\mathbf{H}$ & $\mathbf{H}$ \\
\hline Am-242m & & & & & & & & & $\mathbf{L}$ & & & \\
\hline Am-243 & & & & $\mathbf{L}$ & & $\mathbf{M}$ & & $\mathbf{M}$ & $\mathbf{L}$ & $\mathbf{M}$ & $\mathbf{L}$ & $\mathbf{M}$ \\
\hline $\mathrm{Cm}-242$ & & & & & & & L & & $\mathbf{L}$ & & L & \\
\hline $\mathrm{Cm}-243$ & & & & & & & & & L & & $\mathbf{L}$ & \\
\hline $\mathrm{Cm}-244$ & & & $\mathbf{H}$ & & & & $\mathbf{M}$ & & $\mathbf{H}$ & & $\mathbf{H}$ & \\
\hline
\end{tabular}

H-High ranking ( $>10 \%$ of total); M-medium ranking ( 1 to $10 \%$ of total); L-low ranking ( 0.1 to $1 \%$ of total). The sum of all $H, M$, and $L$ rankings should include virtually all ( $>95 \%$ ) of the total response.

Short cooling times ( $<100$ years).

Long cooling times ( $>100$ years). 
Table 13. Summary rankings by analysis areas (fission products and light elements) ${ }^{a}$

\begin{tabular}{|c|c|c|c|c|c|c|c|c|c|c|c|c|}
\hline \multirow{3}{*}{ Isotope } & & & & & & & & & \multicolumn{4}{|c|}{ Toxicity } \\
\hline & \multicolumn{2}{|c|}{ Absorption } & \multicolumn{2}{|c|}{ Shielding } & \multicolumn{2}{|c|}{ Curies } & \multicolumn{2}{|c|}{ Watts } & \multicolumn{2}{|c|}{ Ingestion } & \multicolumn{2}{|c|}{ Inhalation } \\
\hline & Short $^{b}$ & Long ${ }^{c}$ & Short & Long & Short & Long & Short & Long & Short & Long & Short & Long \\
\hline H-3 & & & & & & & & & $\mathbf{S} 1^{d}$ & & S1 & \\
\hline C-14 & & & & & & & & & $\mathbf{S} 2^{d}$ & S2 & S2 & S2 \\
\hline$C 0-60$ & & & $\mathbf{H}$ & & & & $\mathbf{M}$ & & $\mathbf{L}$ & & $\mathbf{L}$ & \\
\hline Ni-59 & & & & & $\mathbf{S} 3^{d}$ & S3 & & & & & & \\
\hline $\mathrm{Ni}-63$ & & & & & S3 & S3 & & & & & & \\
\hline $\mathrm{Kr}-85$ & & & & & $\mathbf{L}$ & & & & & & & \\
\hline Sr-90 & & & & & $\mathbf{H}$ & & $\mathbf{M}$ & & $\mathbf{M}$ & . & $\mathbf{H}$ & L \\
\hline Y-90 & & & $\mathbf{M}$ & & $\mathbf{H}$ & & $\mathbf{H}$ & & L & & $\mathbf{M}$ & \\
\hline Nb-94 & & & & & $\mathbf{L}$ & & & & & & & \\
\hline Mo-95 & & $\mathbf{L}$ & & & & & & & & & & \\
\hline Tc-99 & L & $\mathbf{L}$ & & & & $\mathbf{M}$ & & & & & & \\
\hline Ru-101 & $\mathbf{L}$ & $\mathbf{L}$ & & & & & & & & & & \\
\hline Ru-106 & & & & & $\mathbf{M}$ & & & & $\mathbf{M}$ & & $\mathbf{M}$ & \\
\hline Rh-103 & $\mathbf{M}$ & $\mathbf{M}$ & & & & & & & & & & \\
\hline Rh-106 & & & H & & $\mathbf{M}$ & & $\mathbf{H}$ & & & & & \\
\hline Pd-105 & $\mathbf{L}$ & L & & & & & & & & & & \\
\hline Ag-109 & L & L & & & & & & & & & & \\
\hline Ag-110m & & & $\mathbf{L}$ & & $\mathbf{M}$ & & & & & & & \\
\hline $\mathrm{Xe}-131$ & $\mathbf{L}$ & $\mathbf{L}$ & & & & & & & & & & \\
\hline Cs-133 & & L & & & & & & & & & & \\
\hline Cs-134 & & & $\mathbf{H}$ & & & & $\mathbf{H}$ & & & & $\mathbf{M}$ & \\
\hline Cs-137 & & & & & $\mathbf{H}$ & & $\mathbf{M}$ & & L & & $\mathbf{H}$ & $\mathbf{L}$ \\
\hline Ba-137m & & & $\mathbf{H}$ & & $\mathrm{H}$ & & $\mathbf{H}$ & & & & & \\
\hline Ce-144 & & & & & $\mathbf{M}$ & & $L$ & & $\mathbf{M}$ & & & \\
\hline $\operatorname{Pr}-141$ & L & $\mathbf{L}$ & & & & & & & & & & \\
\hline Pr-144 & & & $\mathbf{H}$ & & & & $\mathbf{H}$ & & & & L & \\
\hline Nd-143 & $\mathbf{M}$ & $\mathbf{M}$ & & & & & & & & & & \\
\hline Nd-145 & L & L & & & & & & & & & & \\
\hline Pm-147 & & & & & $\mathbf{M}$ & & $\mathbf{M}$ & & $\mathbf{L}$ & & L & \\
\hline Sm-147 & L & L & & & & & & & & & & \\
\hline Sm-149 & $\mathbf{M}$ & $\mathbf{M}$ & & & & & & & & & & \\
\hline Sm-150 & L & L & & & & & & & & & & \\
\hline Sm-151 & L & L & & & $\mathbf{L}$ & & & & & & & \\
\hline Sm-152 & L & L & & & & & & & & & & \\
\hline Eu-151 & L & $\mathbf{L}$ & & & & & & & & & & \\
\hline Eu-153 & $\mathbf{L}$ & $\mathbf{L}$ & & & & & & & & & & \\
\hline Eu-154 & & & $\mathbf{M}$ & & $\mathbf{M}$ & & $\mathbf{M}$ & & & & & \\
\hline Gd-155 & $\mathbf{M}$ & $\mathbf{M}$ & & & & & & & & & & \\
\hline Gd-157 & L & L & & & & & & & & & & \\
\hline
\end{tabular}

H-high ranking ( $>10 \%$ of total); $M-$ medium ranking ( $1 \%$ to $10 \%$ of total); $L-$ low ranking ( $0.1 \%$ to $1 \%$ of total). The sum of all $H, M$, and $L$ rankings should include virtually all $(>95 \%)$ of the total response.

tShort cooling times ( $<100$ years).

Long cooling times ( $>100$ years).

Special categories inciude the following:

S1 - Included due to special status in dosimetry studies.

S2 - Included because of importance to long-term waste package performance assessment.

S3 - These nuclides were not specifically identified in the analysis as important, but are included because of their special status in determining greater than Class $C$ disposal limits of waste storage. 
Table 14. Accuracy and applicability of current analytical methods

\begin{tabular}{|c|c|c|c|c|c|c|c|}
\hline $\begin{array}{l}\text { Element or } \\
\text { radioisotope }\end{array}$ & SSMS $^{a}$ & TEIDMS $^{b}$ & $\mathrm{RCA}^{c}$ & $\begin{array}{l}\text { Element or } \\
\text { radioisotope }\end{array}$ & SSMS $^{a}$ & TEIDMS $^{b}$ & $\mathrm{RCA}^{\mathrm{c}}$ \\
\hline $\mathrm{Li}$ & $\mathbf{x}$ & & & Sm-154 & $\mathbf{X}$ & $\mathrm{X}$ & \\
\hline $\mathrm{Ti}$ & $\mathbf{x}$ & & & Eu-153 & $\mathrm{X}$ & $\mathrm{X}$ & \\
\hline $\mathrm{Cr}$ & $\mathbf{X}$ & & & $\mathrm{Eu}-154$ & $\mathbf{X}$ & $\mathbf{X}$ & \\
\hline $\mathrm{Fe}$ & $\mathbf{x}$ & & & Eu-155 & $\mathbf{X}$ & $\mathrm{X}$ & \\
\hline $\mathrm{Ni}$ & $\mathbf{X}$ & & & Nd-143 & $\mathbf{X}$ & $\mathrm{X}$ & \\
\hline Mo & $\mathrm{X}$ & & & Nd-144 & $\mathbf{X}$ & $\mathrm{X}$ & \\
\hline Th & $\mathrm{X}$ & & & Nd-145 & $\mathrm{X}$ & $\mathbf{X}$ & \\
\hline B & $\mathrm{X}$ & & & Nd-146 & $X$ & $\mathrm{X}$ & \\
\hline V & $\mathrm{x}$ & & & Nd-148 & $\mathrm{X}$ & $\mathrm{X}$ & \\
\hline $\mathrm{Mn}$ & $\mathbf{X}$ & & & Nd-150 & $\mathbf{X}$ & $\mathrm{X}$ & \\
\hline Co & $\mathbf{X}$ & & & Th-232 & $\mathrm{X}$ & & \\
\hline $\mathbf{N b}$ & $\mathbf{X}$ & & & U-232 & & & $\mathbf{X}$ \\
\hline $\mathrm{U}^{d}$ & $\mathrm{X}$ & & & U-233 & $\mathbf{X}$ & $\mathbf{X}$ & \\
\hline $\mathrm{Pu}$ & & $\mathbf{X}$ & & U-234 & & $\mathbf{X}$ & \\
\hline Se-79 & $\mathbf{x}$ & & & U-235 & & $\mathrm{X}$ & \\
\hline Sr-90 & $\mathbf{X}$ & & $\mathbf{X}$ & U-236 & & $\mathrm{X}$ & \\
\hline Zr-93 & $\mathbf{X}$ & & & U-238 & & $\mathbf{x}$ & \\
\hline $\mathrm{Nb}-94$ & $\mathbf{X}$ & & & $\mathrm{Np}-237$ & $\mathbf{x}$ & & $\mathrm{X}$ \\
\hline Tc-99 & $\mathbf{X}$ & $\mathbf{X}$ & & $\mathrm{Pu}-238$ & & $\mathrm{X}$ & \\
\hline Ru-106 & $\mathbf{X}$ & & $\mathbf{X}$ & Pu-239 & & $\mathbf{X}$ & \\
\hline Pd-107 & $\mathrm{X}$ & & $\mathbf{X}$ & $\mathrm{Pu}-240$ & & $\mathrm{X}$ & \\
\hline Sb-125 & $\mathbf{X}$ & & $\mathbf{X}$ & $\mathrm{Pu}-241$ & & $\mathbf{X}$ & \\
\hline Sn-126 & $\mathbf{X}$ & & & $\mathrm{Pu}-242$ & & $\mathbf{X}$ & \\
\hline I-129 & $\mathbf{x}$ & & $\mathbf{x}$ & Pu-244 & & $\mathbf{x}$ & \\
\hline Cs-133 & $\mathbf{X}$ & & & Am-241 & & & $\mathrm{x}$ \\
\hline Cs-134 & $\mathbf{X}$ & & $\mathbf{X}$ & Am-242 & & & $\mathrm{X}$ \\
\hline Cs-135 & $\mathbf{X}$ & & & Am-242m & & & $X$ \\
\hline Cs-137 & $\mathbf{X}$ & & $\mathbf{X}$ & Am-243 & & & $\mathbf{X}$ \\
\hline Ce-144 & $\mathbf{X}$ & $\mathbf{X}$ & $\mathbf{x}$ & $\mathrm{Cm}-242$ & & & $\mathrm{X}$ \\
\hline Pm-147 & $\mathbf{x}$ & & & $\mathrm{Cm}-243$ & & & $\mathbf{X}$ \\
\hline Sm-147 & $\mathbf{X}$ & $\mathbf{X}$ & & $\mathrm{Cm}-244$ & & & $\mathbf{X}$ \\
\hline Sm-148 & $\mathbf{X}$ & $\mathbf{X}$ & & $\mathrm{Cm}-245$ & & & $X$ \\
\hline Sm-149 & $\mathbf{X}$ & $\mathbf{X}$ & & $\mathrm{Cm}-246$ & & & $\mathrm{X}$ \\
\hline Sm-150 & $\mathbf{X}$ & $\mathbf{X}$ & & Cm-247 & & & $\mathbf{X}$ \\
\hline Sm-151 & $\mathbf{x}$ & $\mathbf{X}$ & & $\mathrm{Cm}-248$ & & & $\mathrm{X}$ \\
\hline Sm-152 & $\mathrm{X}$ & $\mathbf{X}$ & & & & & \\
\hline
\end{tabular}

${ }^{\circ}$ Beta-gamma spark-source mass spectrometry, $\pm 25 \%$. Isotope dilution, in cases where an enriched spike is available, can be used to obtain $\pm 10 \%$ precision. Chemical separations from elements with the same mass numbers may be necessary.

'Thermal-emission, isotopic dilution mass spectrometry, \pm 1 to $2 \%$.

Radiochemical analyses, \pm 5 to $10 \%$.

${ }^{d}$ Uranium is often analyzed by extraction and a Davies-Gray potentiometric titration, $\pm 1 \%$. 


\section{CONCLUSIONS}

This study has investigated the relative importances of the various actinide, fission-product, and light-element isotopes with respect to five analysis areas: criticality safety (absorption fractions), shielding (dose rate fractions), curies (fractional curie levels), decay heat (fraction of total watts), and radiological toxicity (fraction of committed effective dose equivalent). These rankings were presented for up to six different burnup/enrichment scenarios and at decay times from 2 to 100,000 years. For completeness, rankings in each of these analysis areas are plotted in the appendixes, as well as being summarized in Tables 2 through 11 in the main body of the report. In addition, Tables 12 and 13 give summary rankings in terms of high (greater than $10 \%$ contribution to the total), medium (between 1 and $10 \%$ contribution), and low ( 0.1 to $1 \%$ contribution) for both short- and long-term cooling. When compared with the target measurement accuracies given in Table 14, these rankings show that most of the important isotopes can be characterized sufficiently for the purpose of radionuclide generation/depletion code validation in each of the analysis areas. 


\section{REFERENCES}

1. U. S. Department of Energy, Characteristics of Potential Repository Wastes, DOE/RW-0184-R1 (Vols. 1-4), July 1992.

2. A. G. Croff, ORIGEN2 - A Revised and Updated Version of the Oak Ridge Isotope Generation and Depletion Code, ORNL-5621, Union Carbide Corp., Nucl. Div., Oak Ridge Natl. Lab., July 1980.

3. S. B. Ludwig and J. P. Renier, Standard-and Extended-Burnup PWR and BWR Reactor Models for the ORIGEN2 Computer Codes, ORNL/TM-11018, Martin Marietta Energy Systems, Inc., Oak Ridge Natl. Lab., December 1989.

4. O. W. Hermann and R. M. Westfall, "SCALE System Module to Calculate Fuel Depletion; Actinide Transmutation, Fission Product Buildup and Decay, and Associated Radiation Source Terms," Sect. F7 of SCALE: A Modular Code System for Performing Standardized Computer Analyses for Licensing Evaluation, NUREG/CR-0200, Revision 4 (ORNL/NUREG/CSD-2/R4), Vols. I, II, and III (draft February 1990). Available from Radiation Shielding Information Center as CCC-545.

5. O. W. Hermann, "SAS2(H): A Coupled One-Dimensional Depletion and Shielding Analysis Code," Sect. S2 of SCALE: A Modular Code System for Performing Standardized Computer Analyses for Licensing Evaluation, NUREG/CR-0200, Revision 4 (ORNL/NUREG/CSD-2/R4), Vols. I, II, and III (draft February 1990). Available from Radiation Shielding Information Center as CCC-545.

6. M. D. DeHart, Validation of the SCALE Broad Structure 44-Group ENDF/B-V Cross-Section Library for Use in Criticality Safety Analyses, NUREG/CR-6102 (ORNL/TM-12460), U.S. Nuclear Regulatory Commission, September 1994.

7. J. R. Knight, C. V. Parks, S. M. Bowman, L. M. Petrie, and J. A. Bucholz, SAS1: A OneDimensional Shielding Analysis Module, Sect. S1 of SCALE: A Modular Code System for Performing Standardized Computer Analyses for Licensing Evaluation, NUREG/CR-0200, Revision 4 (ORNL/NUREG/CSD-2/R4), Vols. I, II, and III (draft February 1990). Available from Radiation Shielding Information Center as CCC-545.

8. K. F. Eckerman, A. B. Wolbarst, and A. C. B. Richardson, Limiting Values of Radionuclide Intake and Air Concentration and Dose Conversion Factors for Inhalation, Submersion, and Ingestion, Federal Guidance Report No. 11, EPA-520/1-88-020, U.S. Environmental Protection Agency, Washington, D.C., 1988.

9. R. Q. Wright, "Fission Product Evaluations for ENDF/B-VI," Trans. Am. Nucl. Soc. 61, 398 (1990).

10. International Commission on Radiological Protection, "Recommendations of the International Commission on Radiological Protection," ICRP Publication 26, Annals of the ICRP Vol. 1, No. 3, 1977. 
11. International Commission on Radiological Protection, "Limits for Intakes of Radionuclides by Workers," ICRP Publication 30, Annals of the ICRP Vol. 2, Nos. 3/4, 1979.

12. J. W. Roddy and J. C. Mailen, Radiological Characteristics of Light-Water-Reactor Spent Fuel: $A$ Literature Survey of Experimental Data, ORNL/TM-10105, Martin Marietta Energy Systems, Inc., Oak Ridge Natl. Lab., December 1987. 


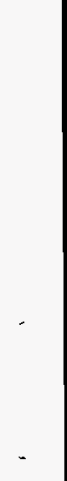




\section{APPENDIX A}

\section{CRITICALITY SAFETY PLOTS}

This appendix contains complete listings of all plots generated in this ranking study. For the criticality safety rankings, plots of the fractional absorption by nuclide over decay times from 2 to 100,000 years are included. For each of the six enrichment/burnup groups, there are three plots corresponding to:

1. the fractional absorption of both actinides and fission products, and the total number of absorptions, for cooling times from 2 to 100,000 years;

2. the fractional absorption in each of the top actinides for cooling times of 2 to 100,000 years; the legend gives the ranking (in terms of absorptions) of the actinides at 5 and 30,000 years;

3. the fractional absorption in each of the top fission products for cooling times of 2 to 100,000 years; the legend gives the ranking (in terms of absorptions) of the fission products at 5 and 30,000 years. 


\section{Absorptions vs Cooling Time}

$3.0 \mathrm{wt} \% \mathrm{U}-235,20 \mathrm{GWd} / \mathrm{t}$

Results with SCALE 44GROUPNDF5

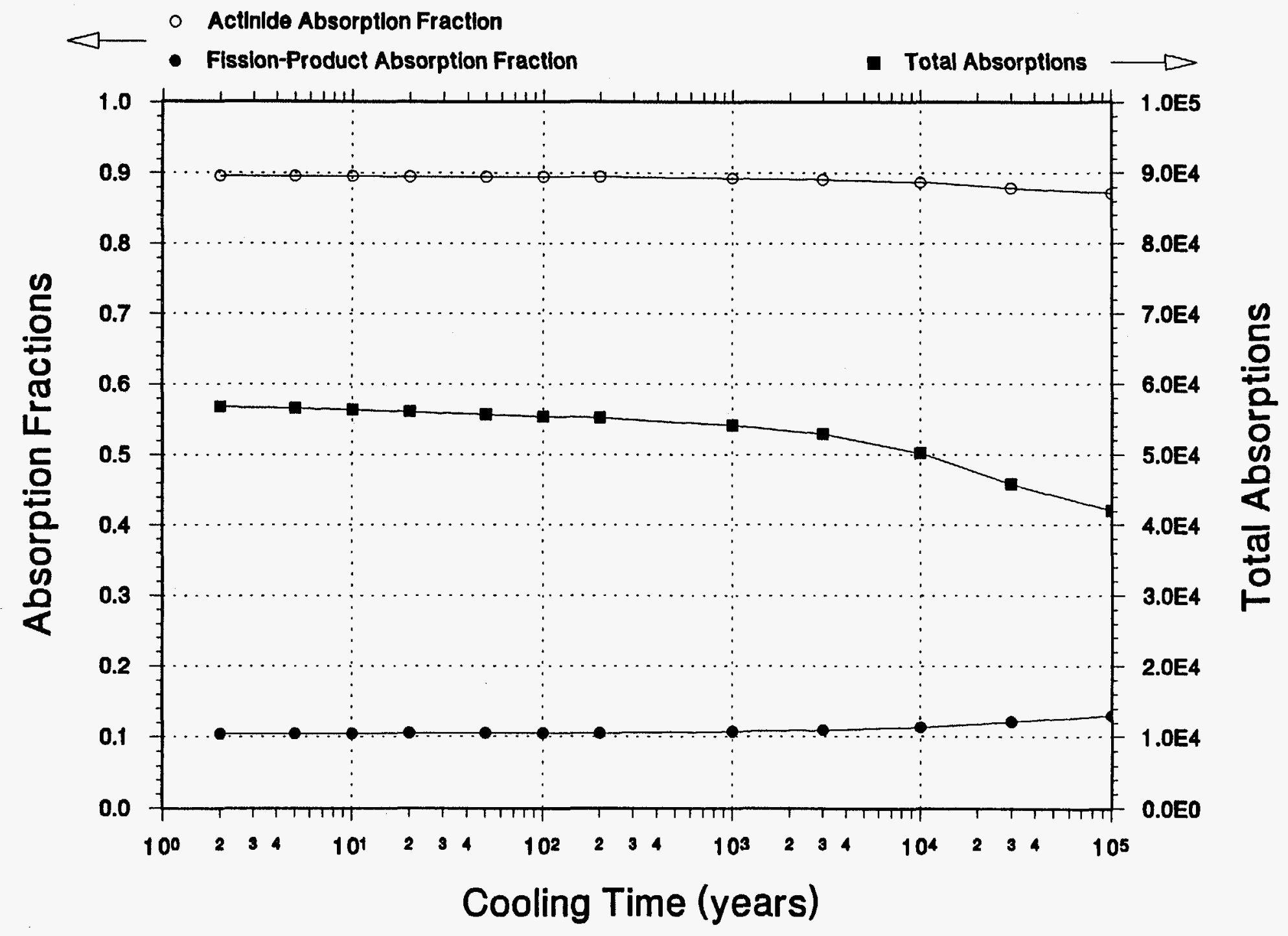


Fraction of Neutrons Absorbed by Major Actinides At Various Cooling Times; 3.0 wt $\%$ U-235, 20 GWd/t

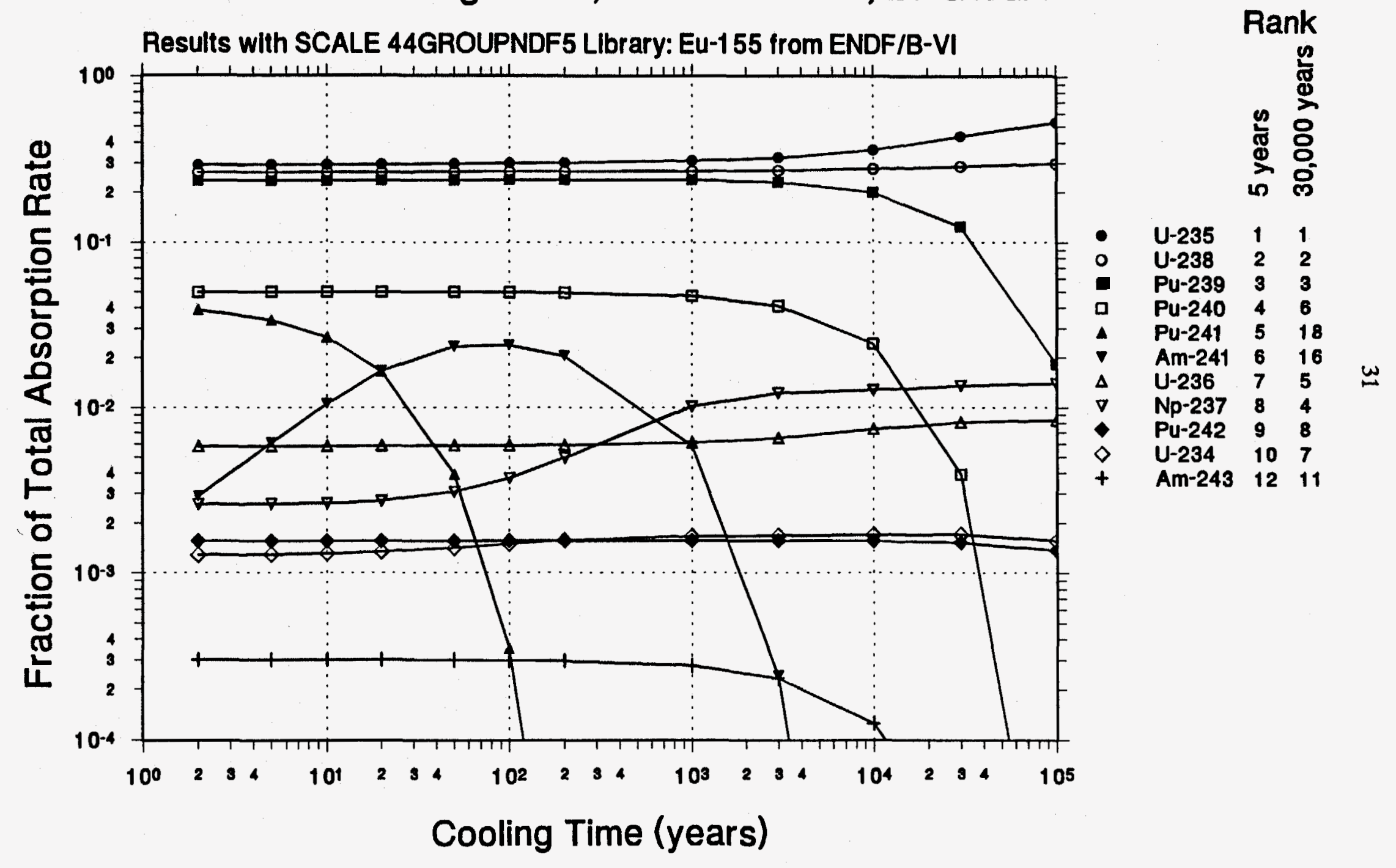


Fraction of Neutrons Absorbed by Major Fission Products At Various Cooling Times; $3.0 \mathrm{wt} \% \mathrm{U}-235,20 \mathrm{GWd} / \mathrm{t}$

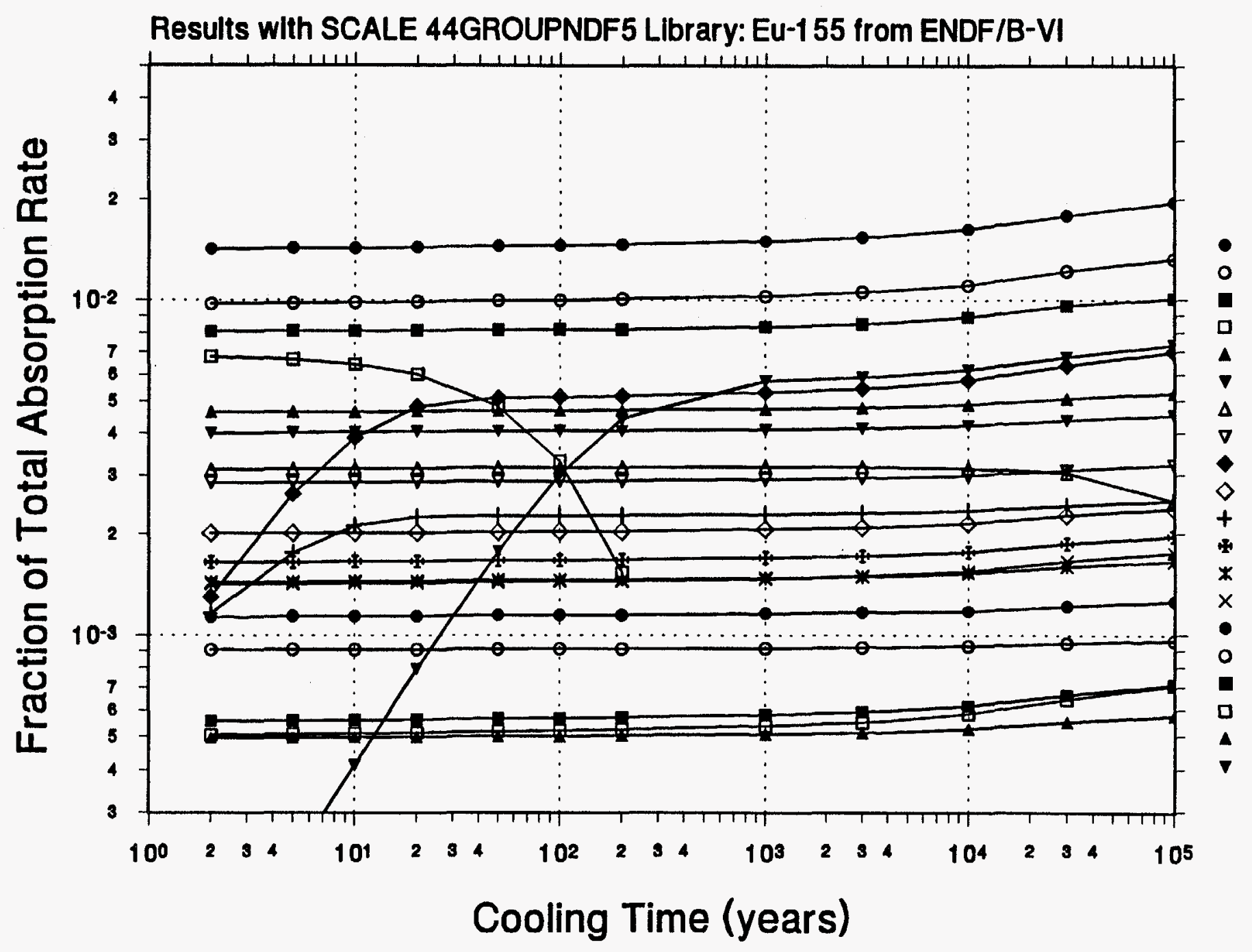

Rank

in

Sm-149 11 Nd-143 2 2 2

Rh-103 33

Sm-151 4 ...

$\mathrm{Xe}-13156$

Cs-133 67

Tc-99 7 9

$\mathrm{Sm}-15288$

Gd-155 95

Nd-145 $10 \quad 11$

Sm-147 $11 \quad 10$

Eu-153 $12 \quad 12$

Mo-95 $13 \quad 14$

Sm-150 $14 \quad 13$

Ag-109 $16 \quad 15$

Ru-101 $17 \quad 16$

$\begin{array}{lll}\text { Pr-141 } 21 & 18\end{array}$

Gd-157 $22 \quad 18$

Pd-105 $23 \quad 20$

$\begin{array}{lll}\text { Eu-151 } & 30 & 4\end{array}$ 


\section{Absorptions vs Cooling Time}

\section{$3.0 \mathrm{wt} \% \mathrm{U}-235,35 \mathrm{GWd} / \mathrm{t}$}

Results with SCALE 44GROUPNDF5

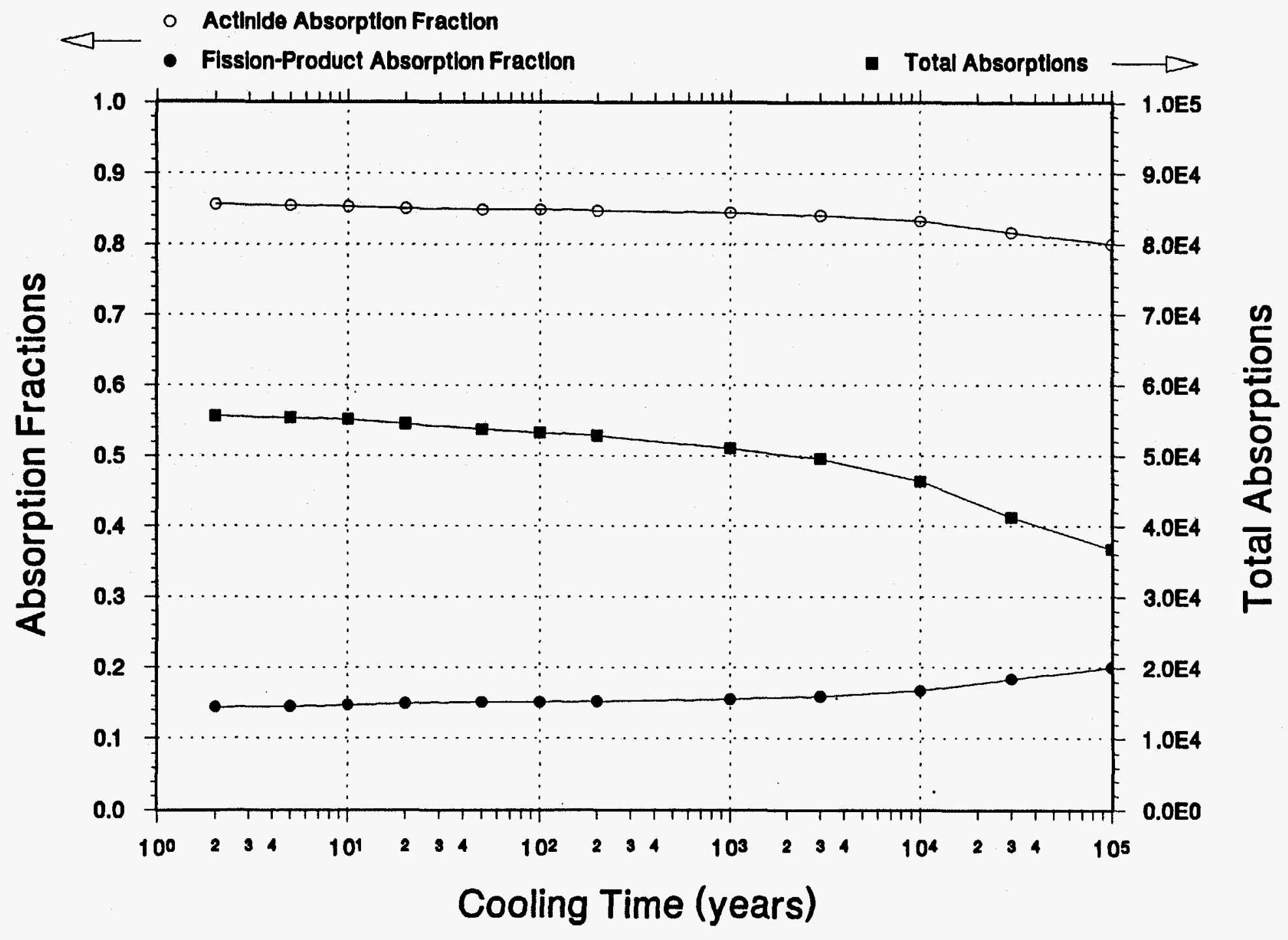




\section{Fraction of Neutrons Absorbed by Major Actinides}

At Various Cooling Times; 3.0 wt\% U-235, 35 GWd/t

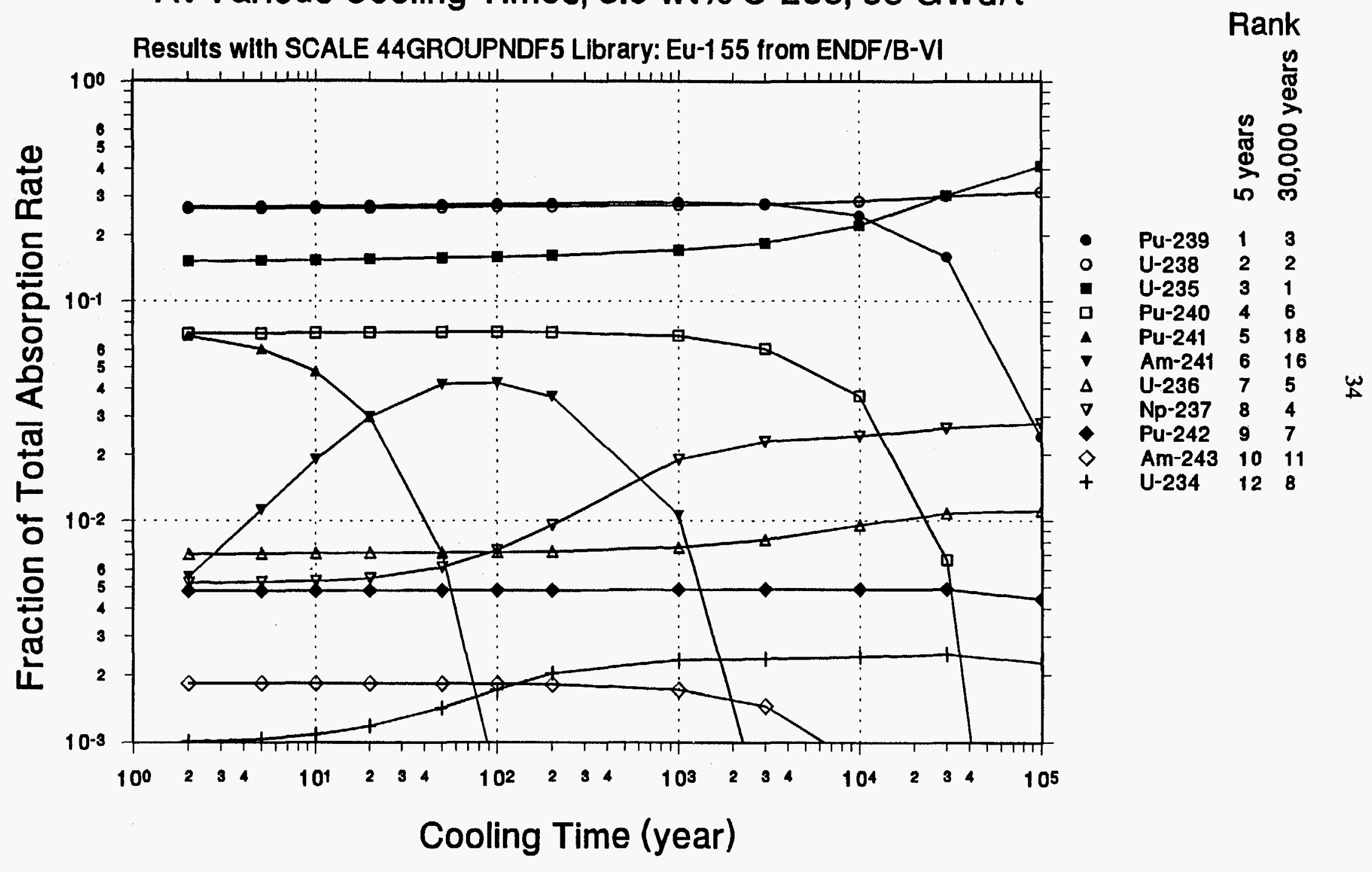


Fraction of Neutrons Absorbed by Major Fission Products At Various Cooling Times; $3.0 \mathrm{wt} \% \mathrm{U}-235,35 \mathrm{GWd} / \mathrm{t}$

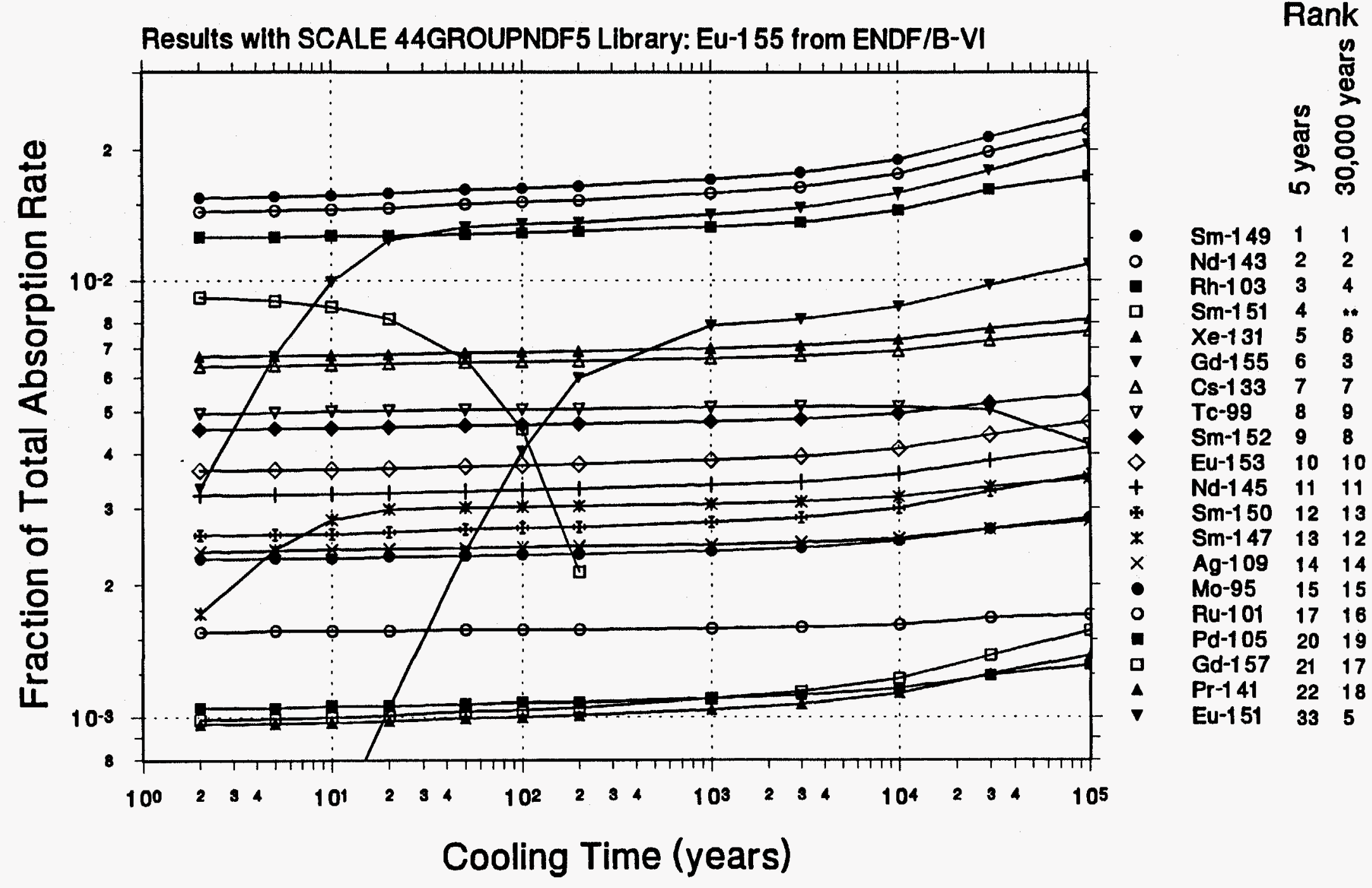




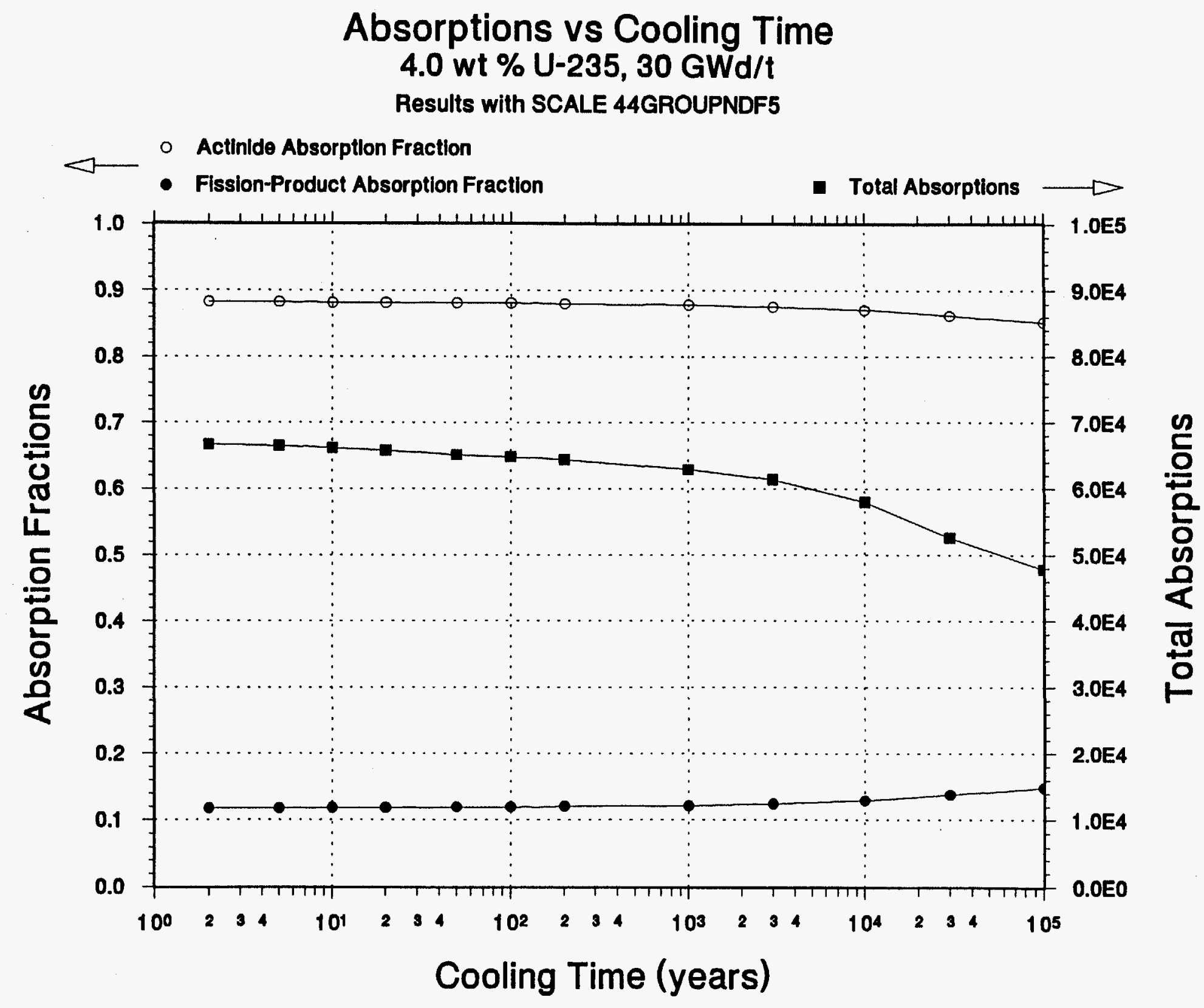


Fraction of Neutrons Absorbed by Major Actinides At Various Cooling Times; $4.0 \mathrm{wt} \% \mathrm{U}-235,30 \mathrm{GWd} / \mathrm{t}$

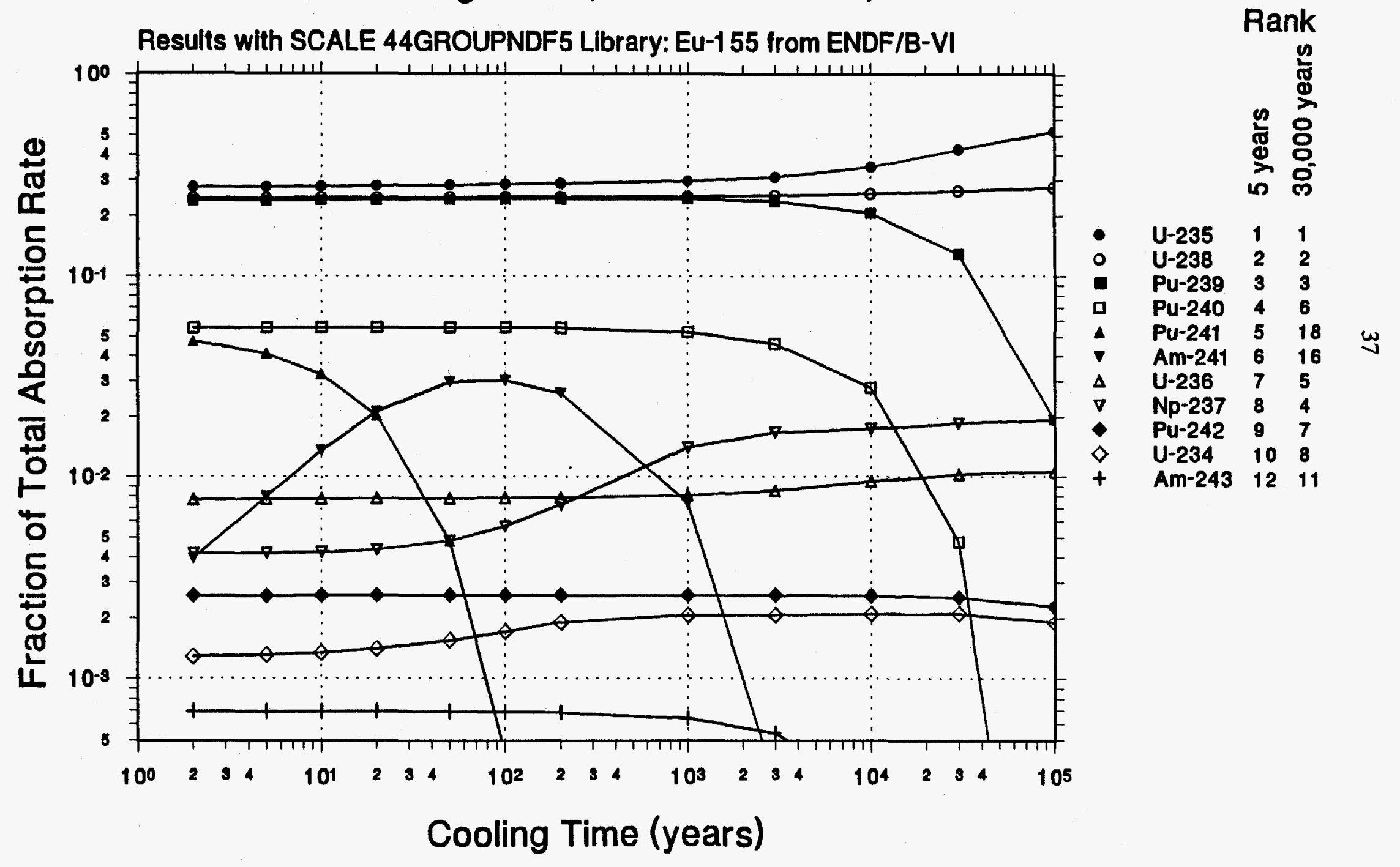


Fraction of Neutrons Absorbed by Major Fission Products At Various Cooling Times; $4.0 \mathrm{wt} \% \mathrm{U}-235,30 \mathrm{GWd} / \mathrm{t}$

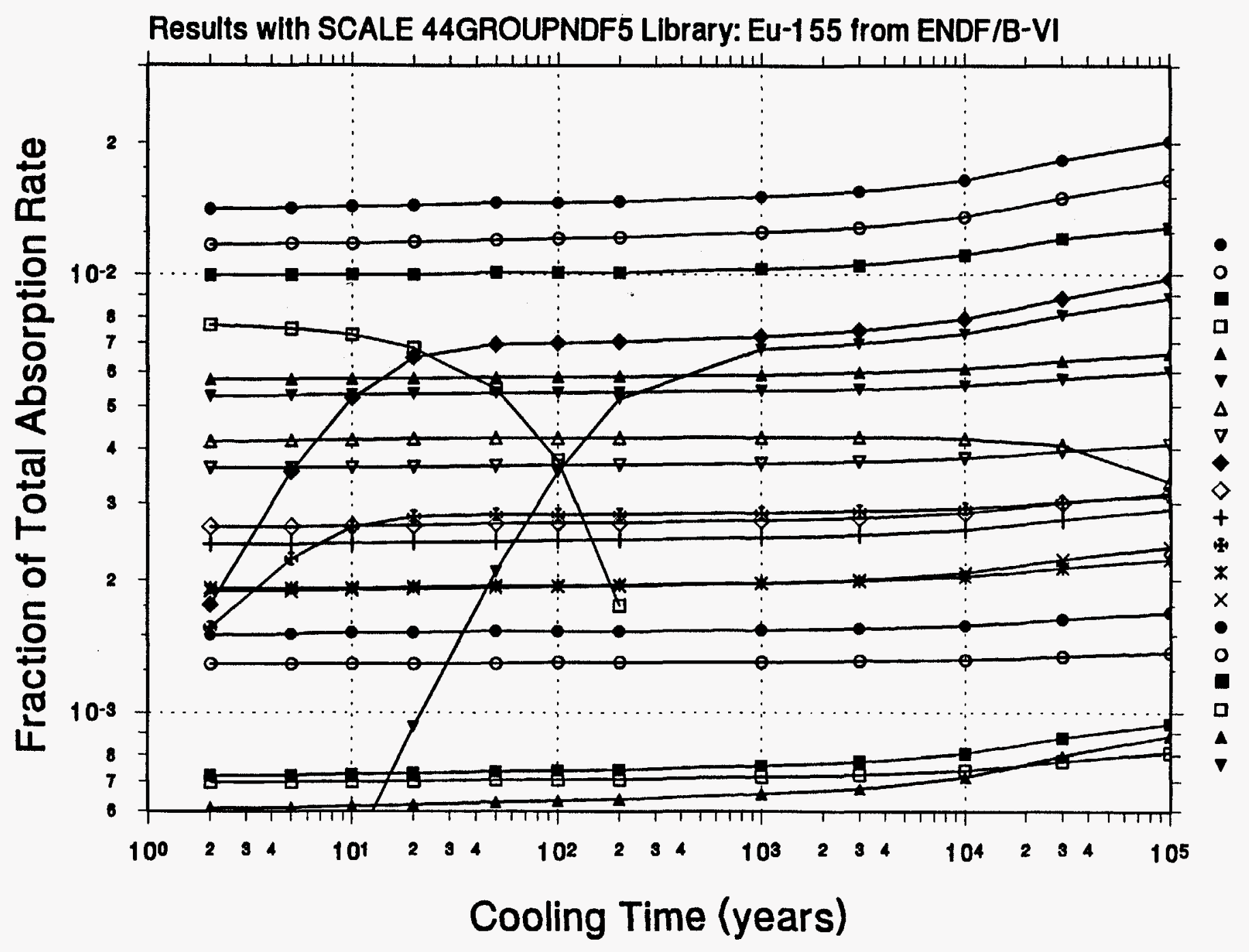

Rank

แn

Sm-149 11 Nd-143 22

Rh-103 33

Sm-151 $4 \quad$

$\mathrm{Xe}-131 \quad 5 \quad 8$

Cs-133 67

$\begin{array}{lll}10-99 & 7\end{array}$

$\mathrm{Sm}-152 \quad 8 \quad 9$

Gd-155 994

Nd-145 $10 \quad 11$

Eu-153 $11 \quad 12$

Sm-147 $12 \quad 10$

Mo-95 $13 \quad 14$

Sm-150 $14 \quad 13$

Ag-109 $15 \quad 15$

Ru-101 $17 \quad 16$

$\begin{array}{lll}P r-141 \quad 21 & 18\end{array}$

Pd-105 $22 \quad 20$

Gd-157 $23 \quad 19$

Eu-151 325 


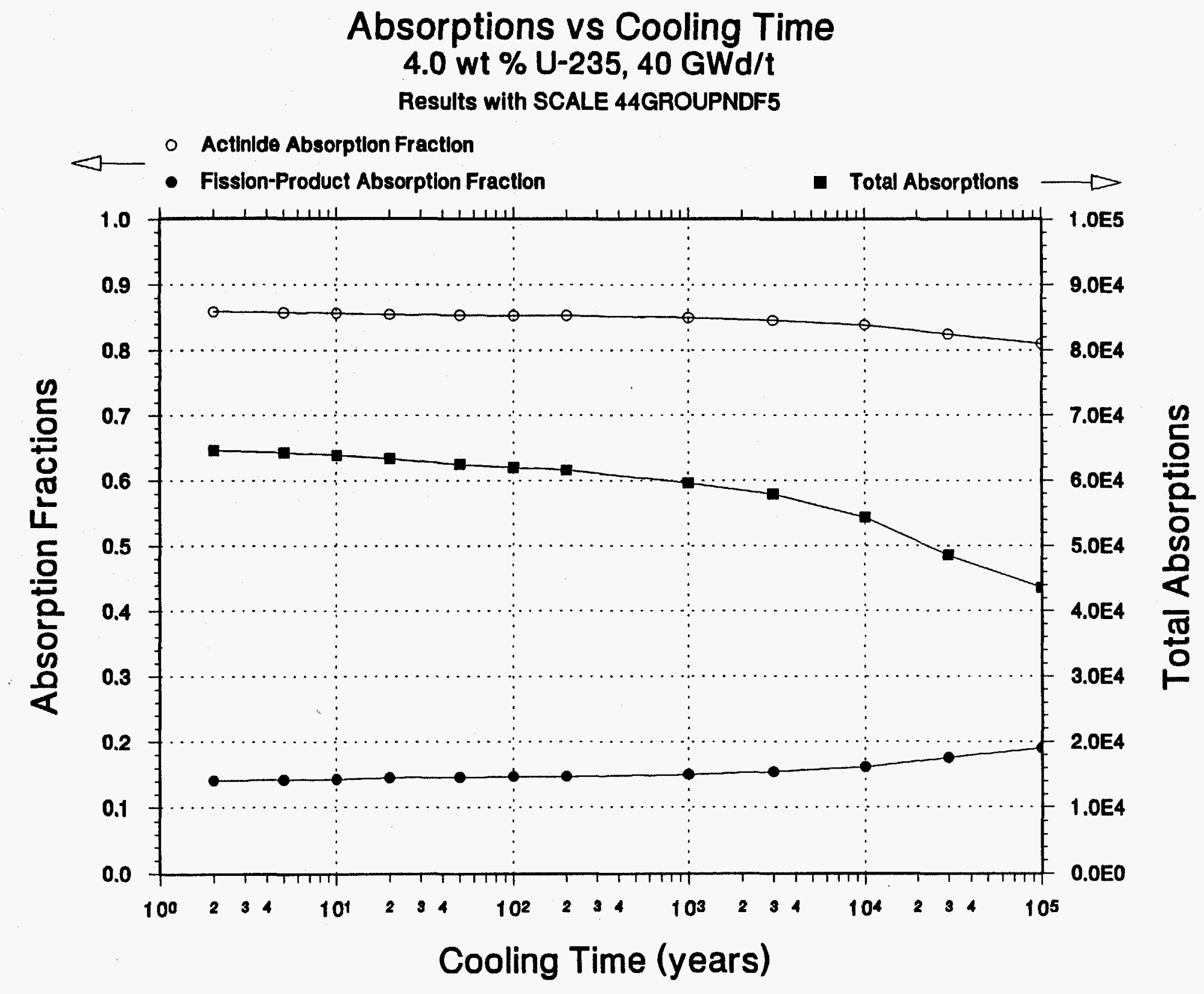


Fraction of Neutrons Absorbed by Major Actinides At Various Cooling Times; 4.0 wt $\%$ U-235, $40 \mathrm{GWd} / \mathrm{t}$

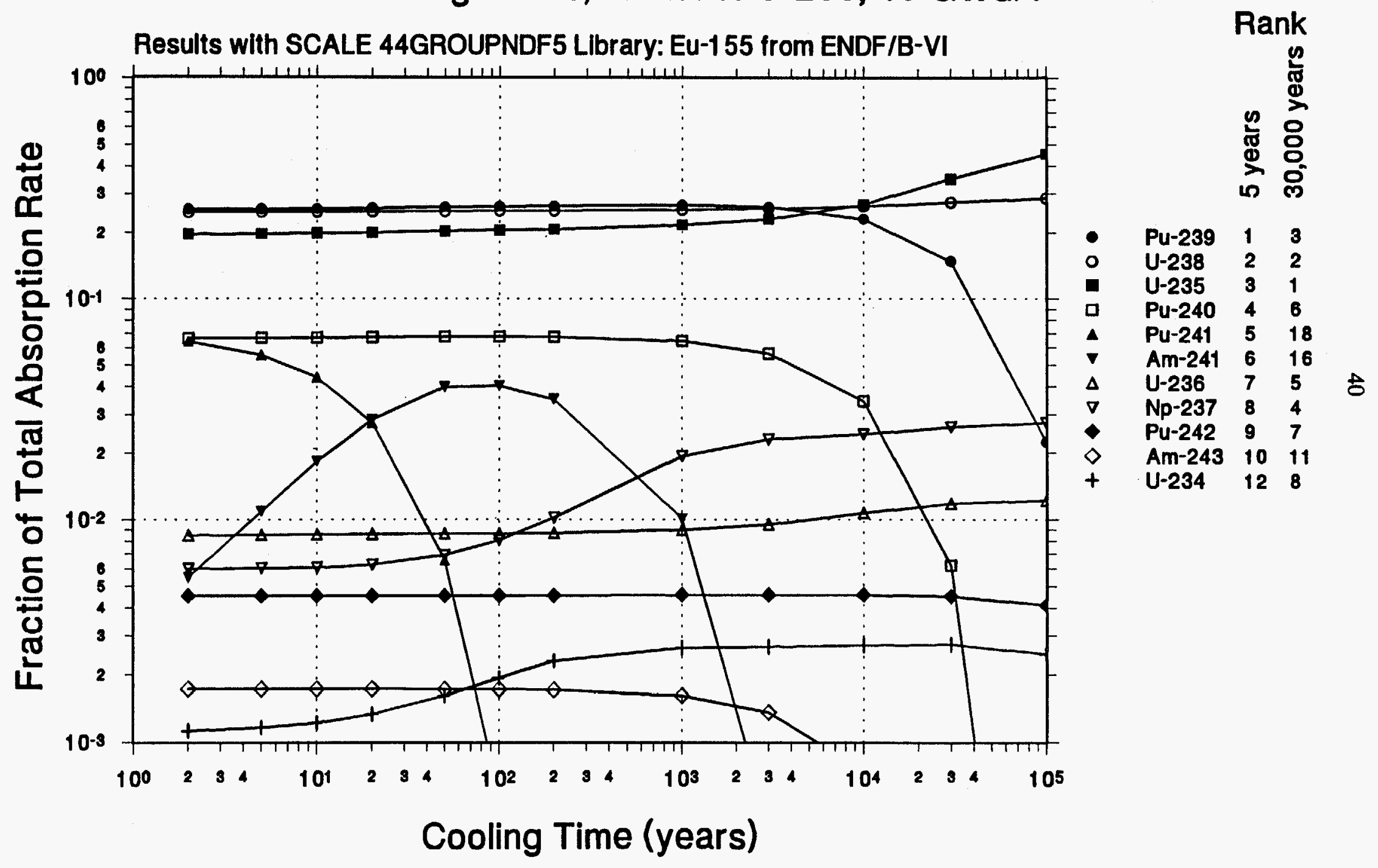


Fraction of Neutrons Absorbed by Major Fission Products At Various Cooling Times; $4.0 \mathrm{wt} \% \mathrm{U}-235,40 \mathrm{GWd} / \mathrm{t}$

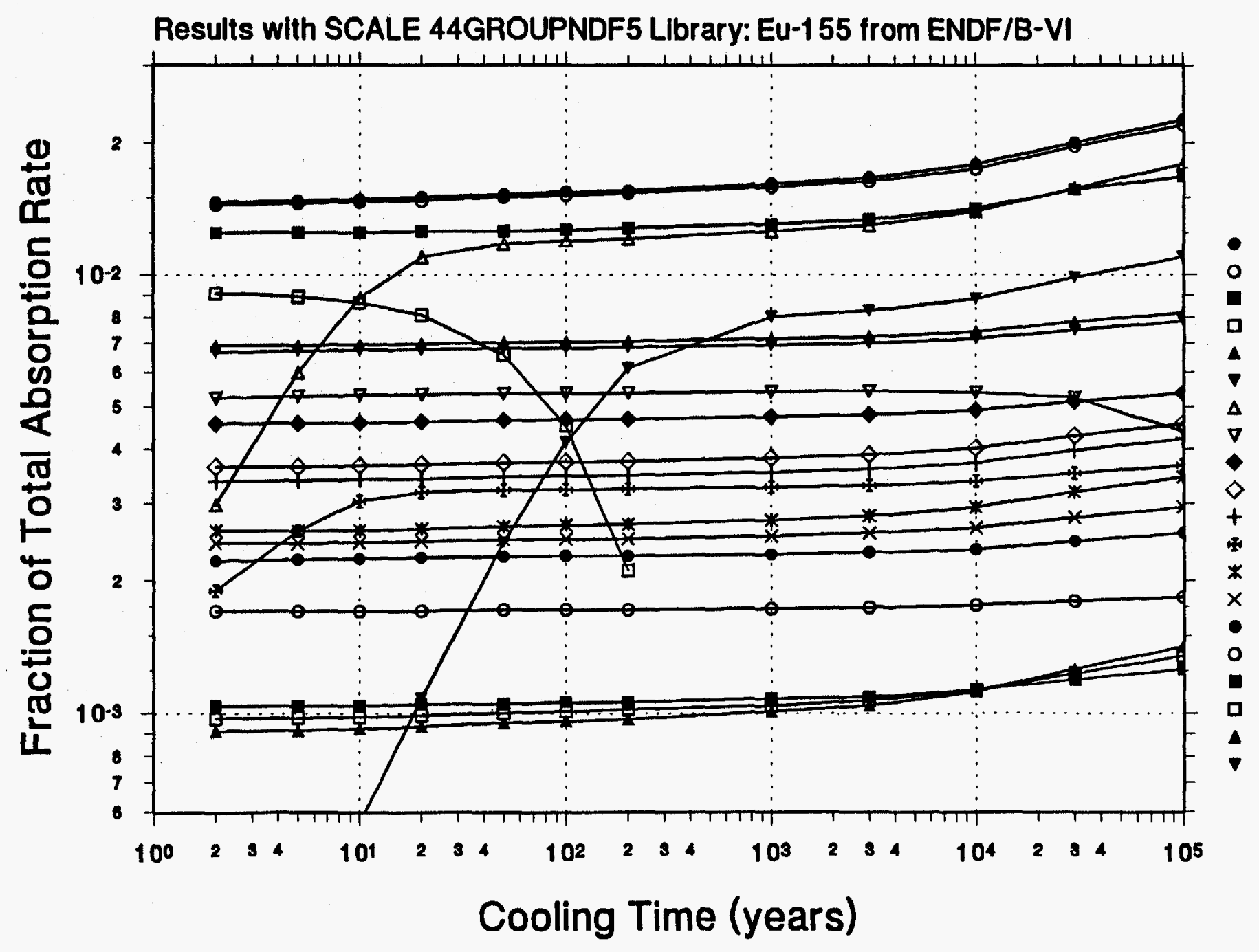

Rank

is

Sm-149 11 Nd-143 22 Rh-103 34 $\mathrm{Sm}-151 \quad 4 \quad$ $\mathrm{Xe}-13155$ Cs-133 67 Gd-155 73 TC-99 88 Sm-152 99 Eu-153 $10 \quad 10$ Nd-145 $11 \quad 11$ Sm-147 $12 \quad 12$ Sm-150 $13 \quad 13$ Mo-95 $14 \quad 14$ Ag-109 $15 \quad 15$ Ru-101 $17 \quad 16$ Pd-105 $20 \quad 20$ $\begin{array}{lll}\text { Pr-141 } 21 & 18\end{array}$ Gd-157 $22 \quad 17$ Eu-151 $33 \quad 5$ 


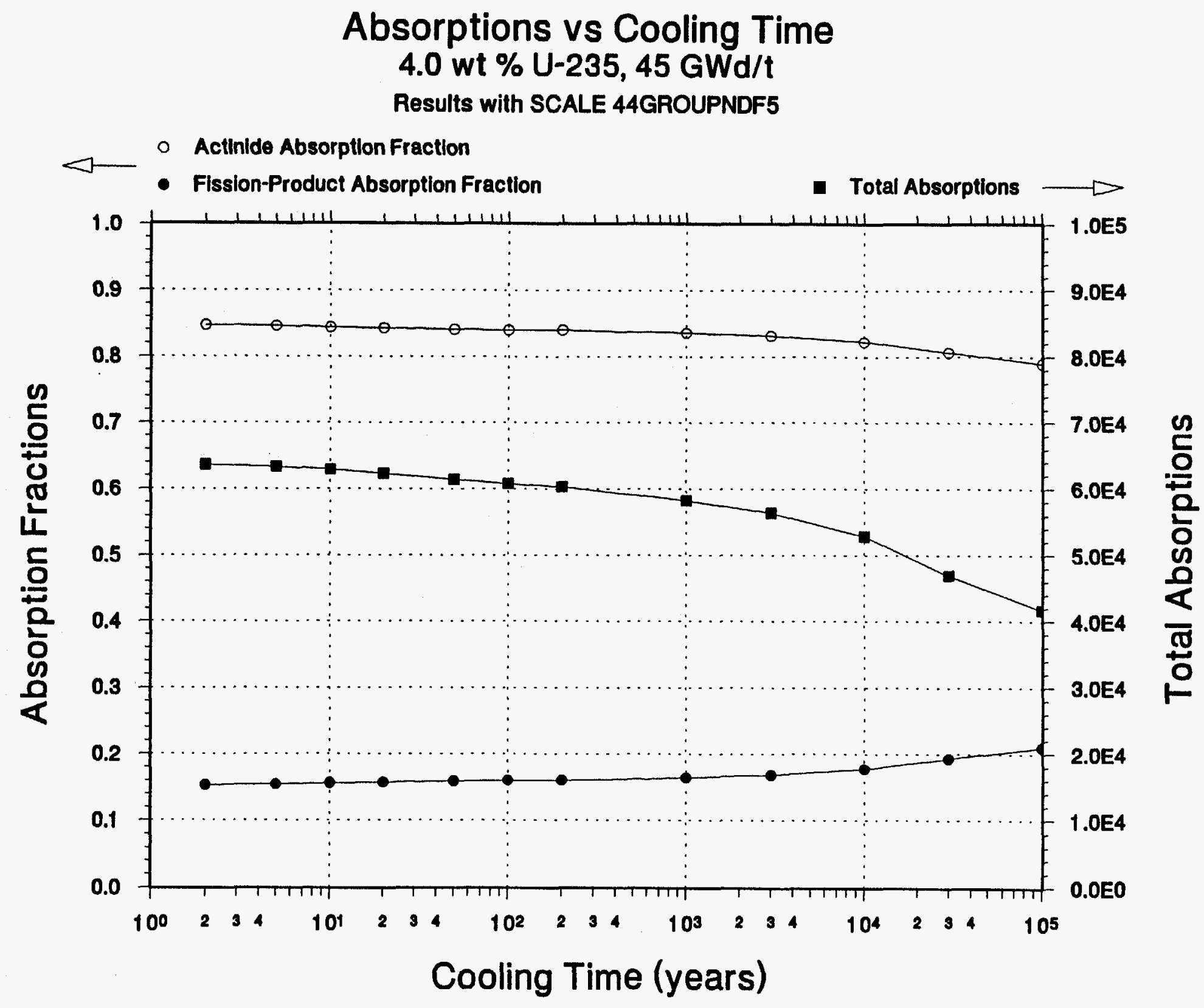


Fraction of Neutrons Absorbed by Major Actinides At Various Cooling Times; 4.0 wt \% U-235, 45 GWd/t

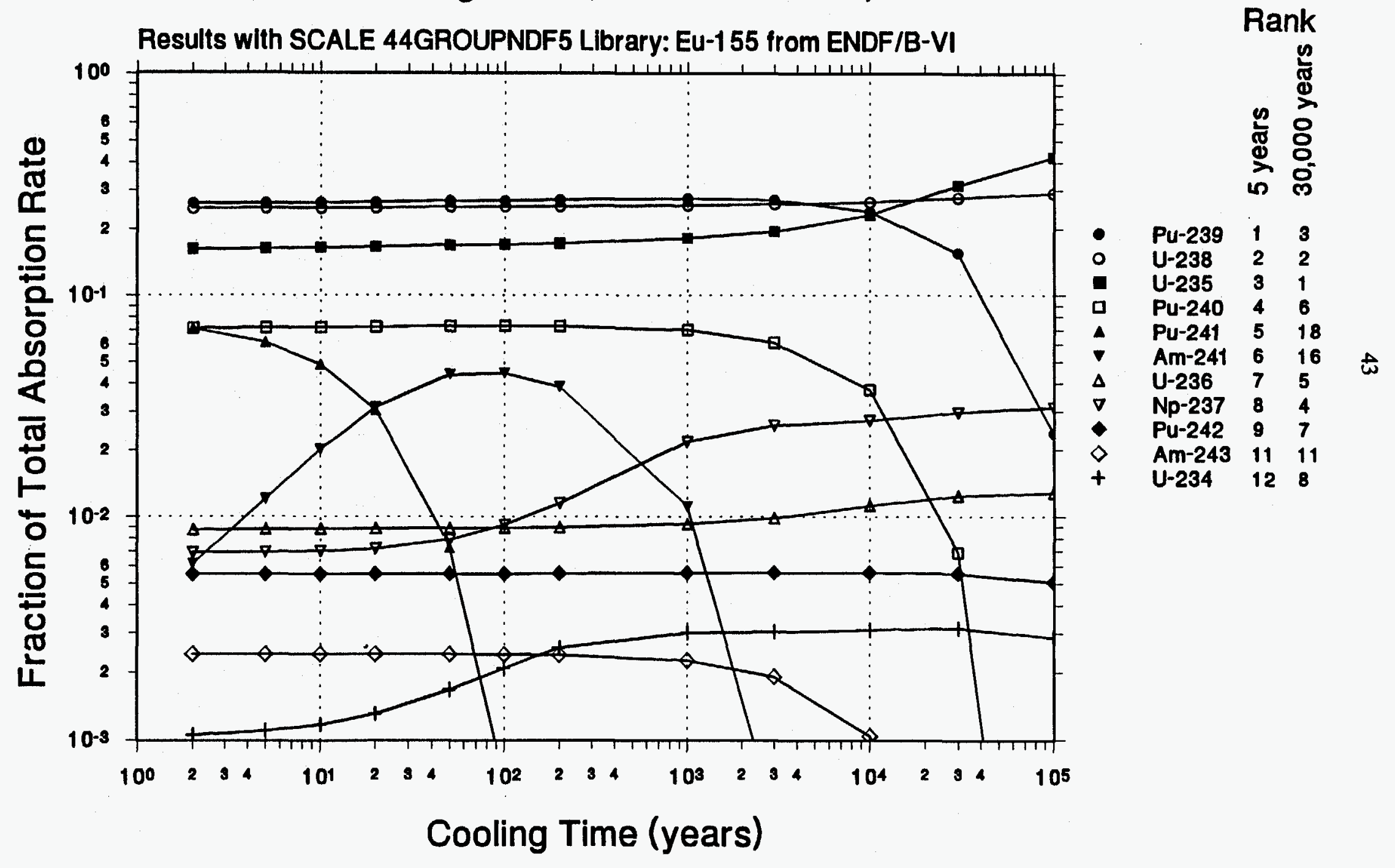


Fraction of Neutrons Absorbed by Major Fission Products At Various Cooling Times; $4.0 \mathrm{wt} \% \mathrm{U}-235,45 \mathrm{GWd} / \mathrm{t}$

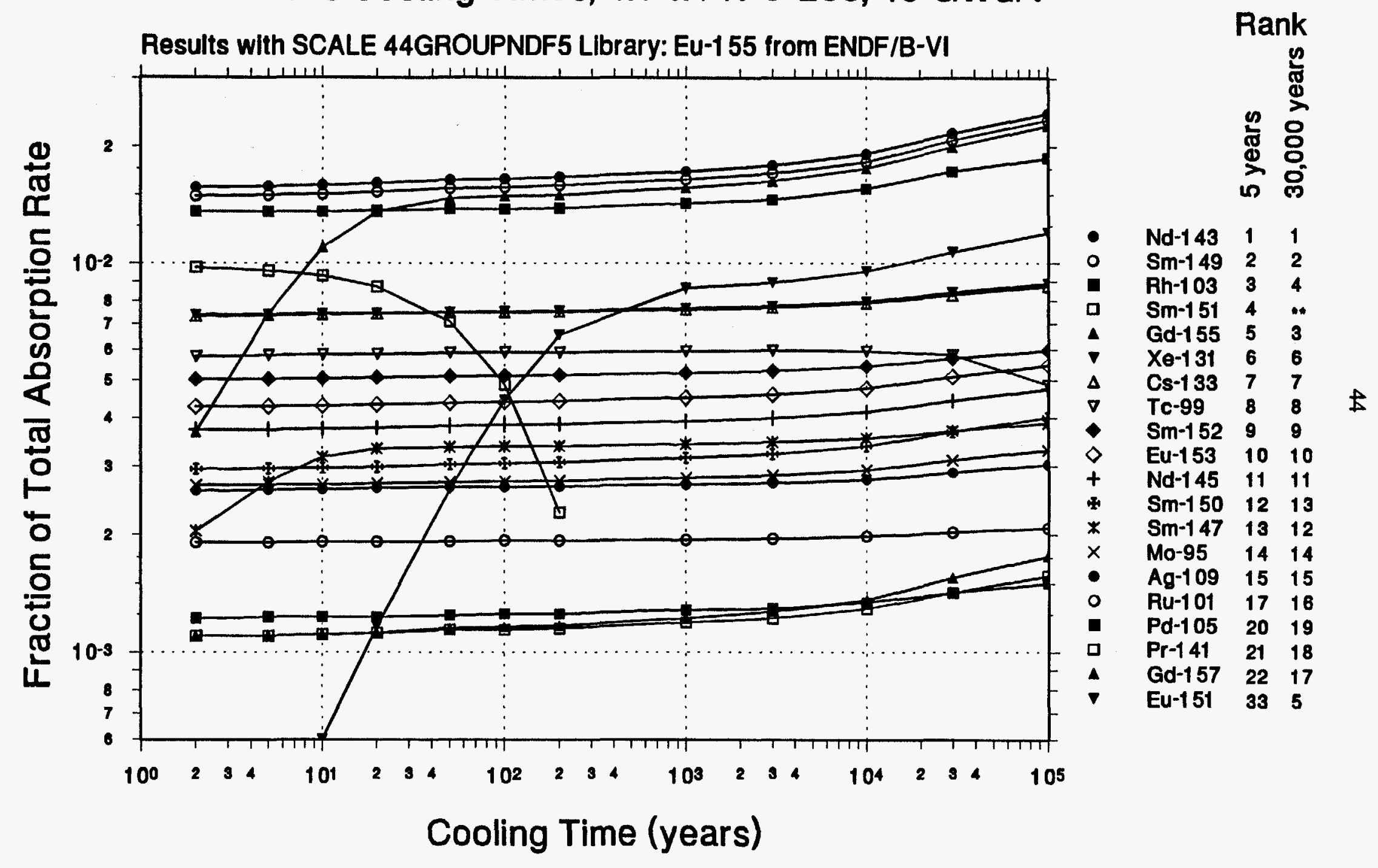




\section{Absorptions vs Cooling Time \\ $4.5 \mathrm{wt} \% \mathrm{U}-235,50 \mathrm{GWd} / \mathrm{t}$ \\ Results with SCALE 44GROUPNDF5}

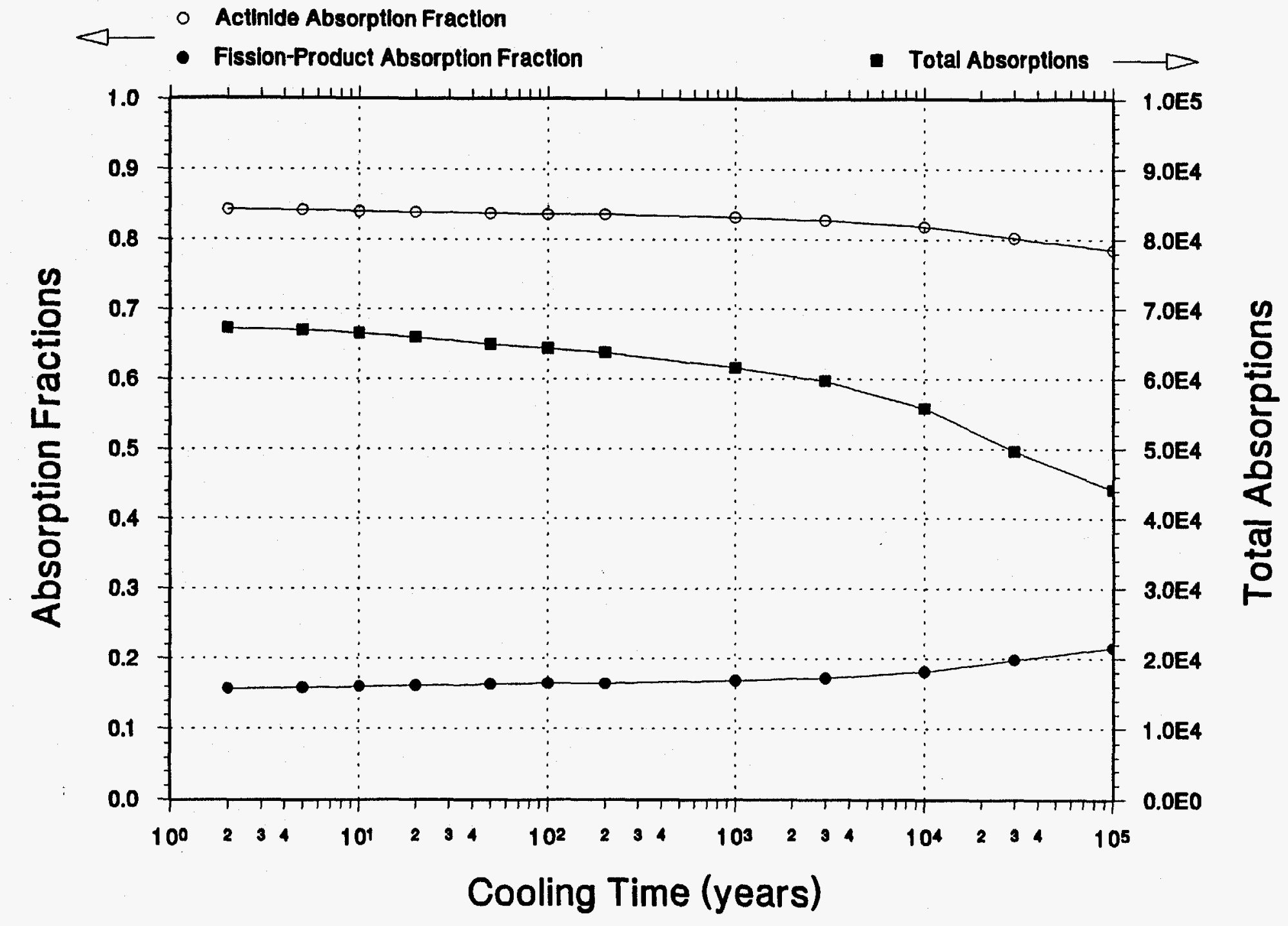


Fraction of Neutrons Absorbed by Major Actinides At Various Cooling Times; $4.5 \mathrm{wt} \% \mathrm{U}-235,50 \mathrm{GWd} / \mathrm{t}$

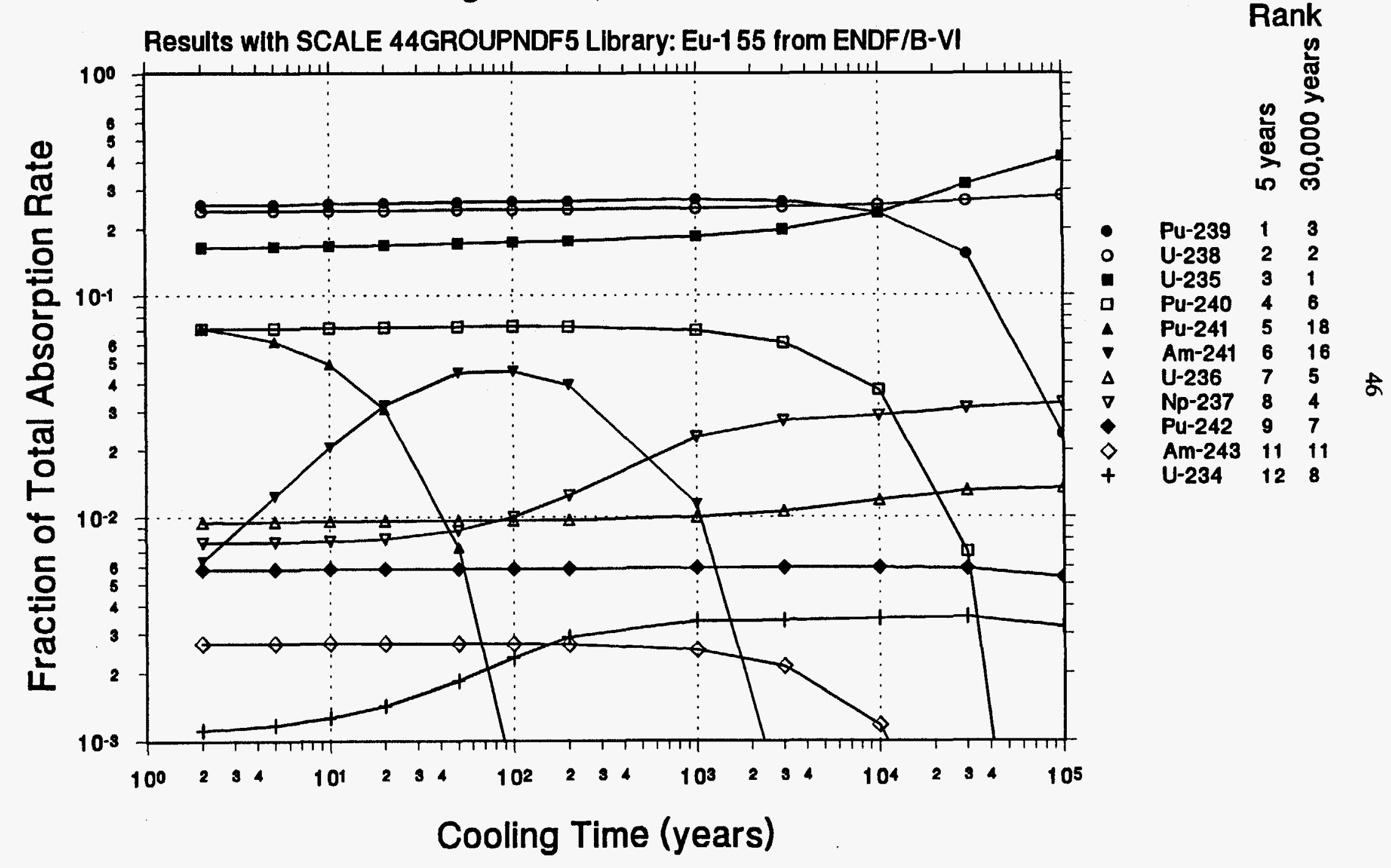


Fraction of Neutrons Absorbed by Major Fission Products At Various Cooling Times; $4.5 \mathrm{wt} \% \mathrm{U}-235,50 \mathrm{GWd} / \mathrm{t}$

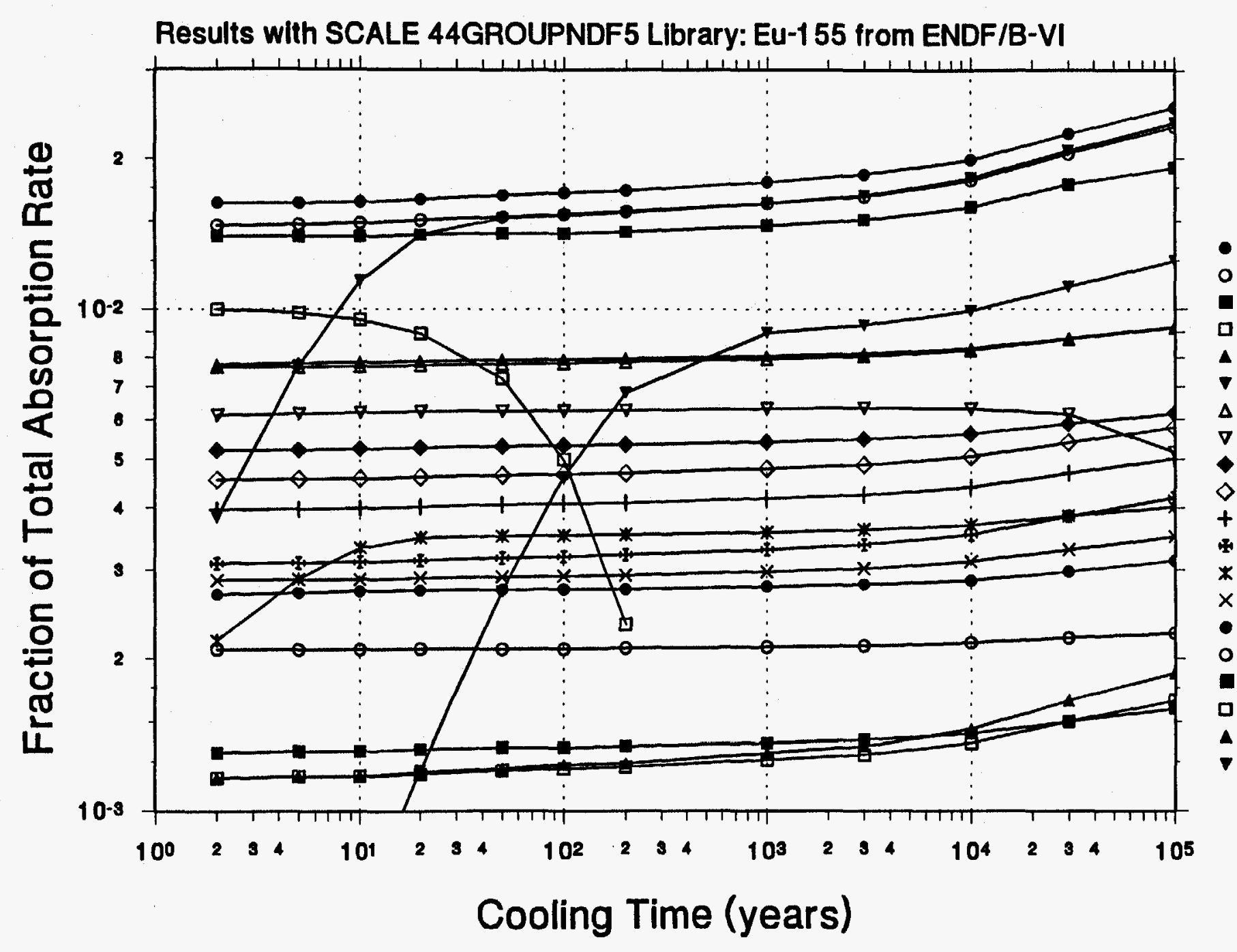

Rank

is

Nd-143 11 Sm-149 23

Rh-1 $03 \quad 3 \quad 4$

Sm-151 4

Cs-133 56

Gd-155 62

$\begin{array}{lll}\mathrm{X}-131 & 7 & 7\end{array}$

Tc-99 88

Sm-152 99

Eu-153 $10 \quad 10$

Nd-145 $11 \quad 11$

Sm-150 $12 \quad 13$

Sm-147 $13 \quad 12$

Mo-95 $14 \quad 14$

Ag-109 $15 \quad 15$

Ru-101 $17 \quad 16$

Pd-105 $20 \quad 18$

$\begin{array}{lll}\text { Pr-1 } 14 & 21 & 19\end{array}$

Gd-157 $22 \quad 17$

Eu-151 335

Cooling Time (years) 


\section{APPENDIX B}

\section{DOSE RATE FRACTION PLOTS}

This section contains the complete listing of all plots generated for the shielding ranking portion of this work. Plots are given for three cask types: iron, lead, and concrete for two burnup/enrichment combinations $-3.0 \mathrm{wt} \%, 20 \mathrm{GWd} / \mathrm{t}$, and $4.5 \mathrm{wt} \%, 50 \mathrm{GWd} / \mathrm{t}$. Five plots are given for each of these six cases corresponding to:

1. the variation in the total dose rate $(\mathrm{mrem} / \mathrm{h})$ over the entire cooling time of 2 to 10,000 years, followed by the fraction of the total doses due to neutrons, primary gammas, and secondary gammas;

2. the fraction of the total dose rates due to neutrons from selected actinides; the legend gives the relative rankings for these actinides at 5 and 10,000 years;

3. the fraction of the total dose rate $(\mathrm{mrem} / \mathrm{h})$ due to primary gammas from selected actinides; the legend gives the relative rankings for these actinides at 5 and 10,000 years;

4. the fraction of the total dose rate $(\mathrm{mrem} / \mathrm{h})$ due to primary gammas from selected fission products and light elements; the legend gives the relative rankings for these isotopes at 5 and 10,000 years;

5. the fraction of the total dose rate $(\mathrm{mrem} / \mathrm{h})$ due to secondary gammas from selected actinides; the legend gives the relative rankings for these isotopes at 5 and 10,000 years. 


\section{Dose Rate vs Cooling Time}

\section{TN-24 Cask; 3.0 wt \% U-235, 20 GWd/t}

Results with SCALE 44GROUPNDF5

- Primary Gamma Dose

- Secondary Gamma Dose

- Neutron Dose

A Total Dose
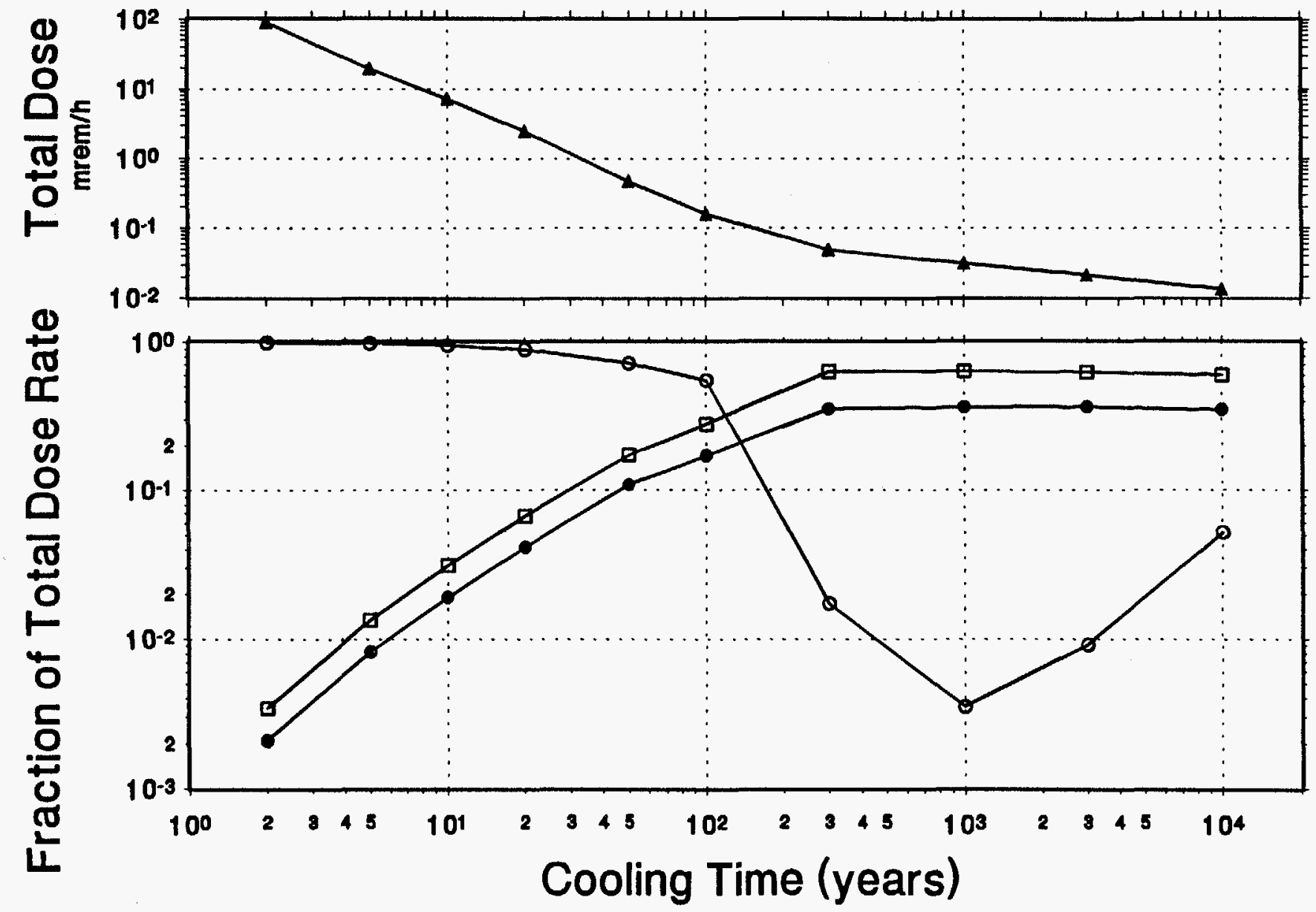
Neutron Dose Fraction vs. Cooling Time for Tn-24; 3.0 wt \% U-235, $20 \mathrm{GWd} / \mathrm{t}$

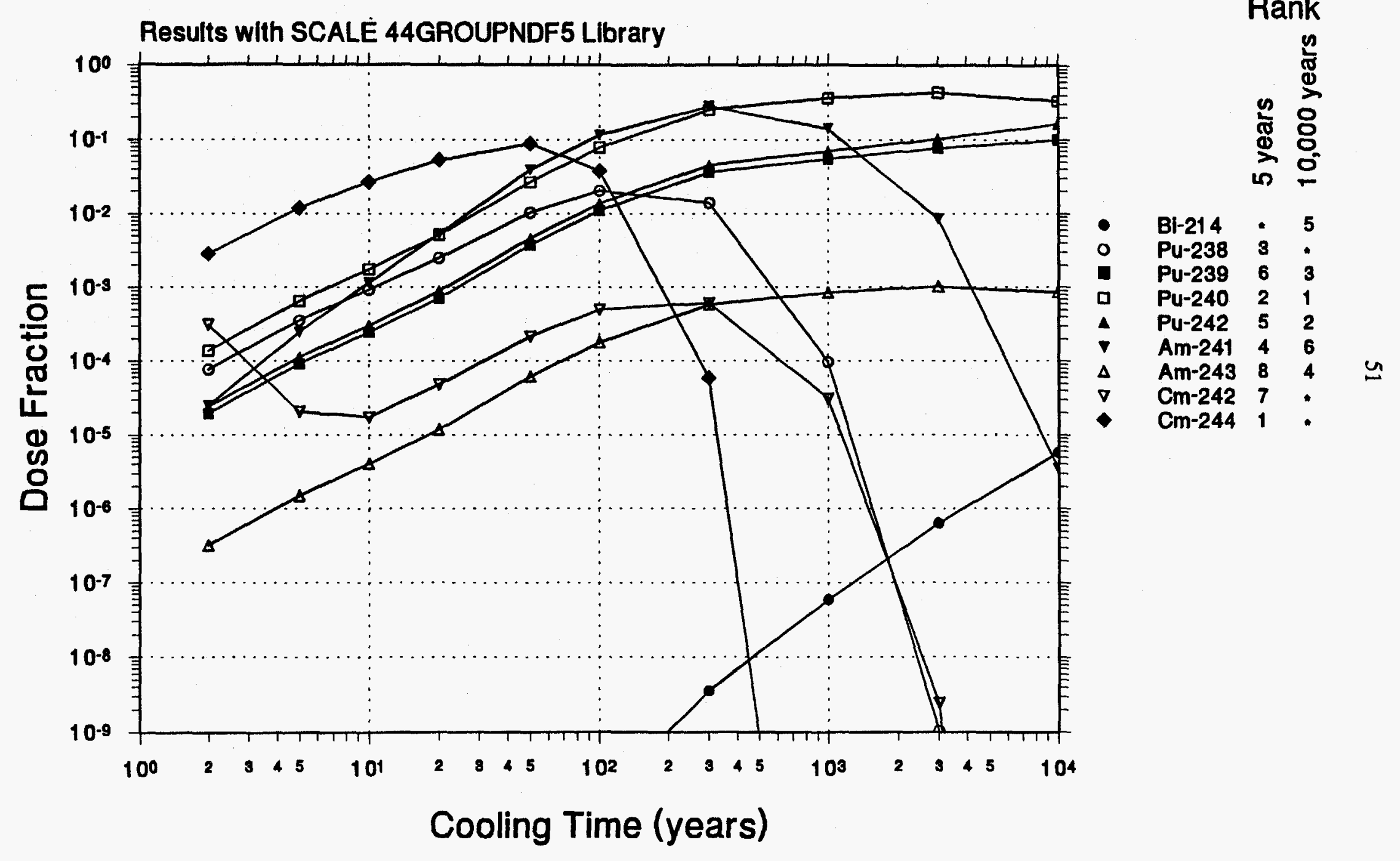




\section{Primary Gamma Dose Fraction vs Cooling Time for Tn-24; 3.0 wt \% U-235, $20 \mathrm{GWd} / \mathrm{t}$ \\ Actinides}

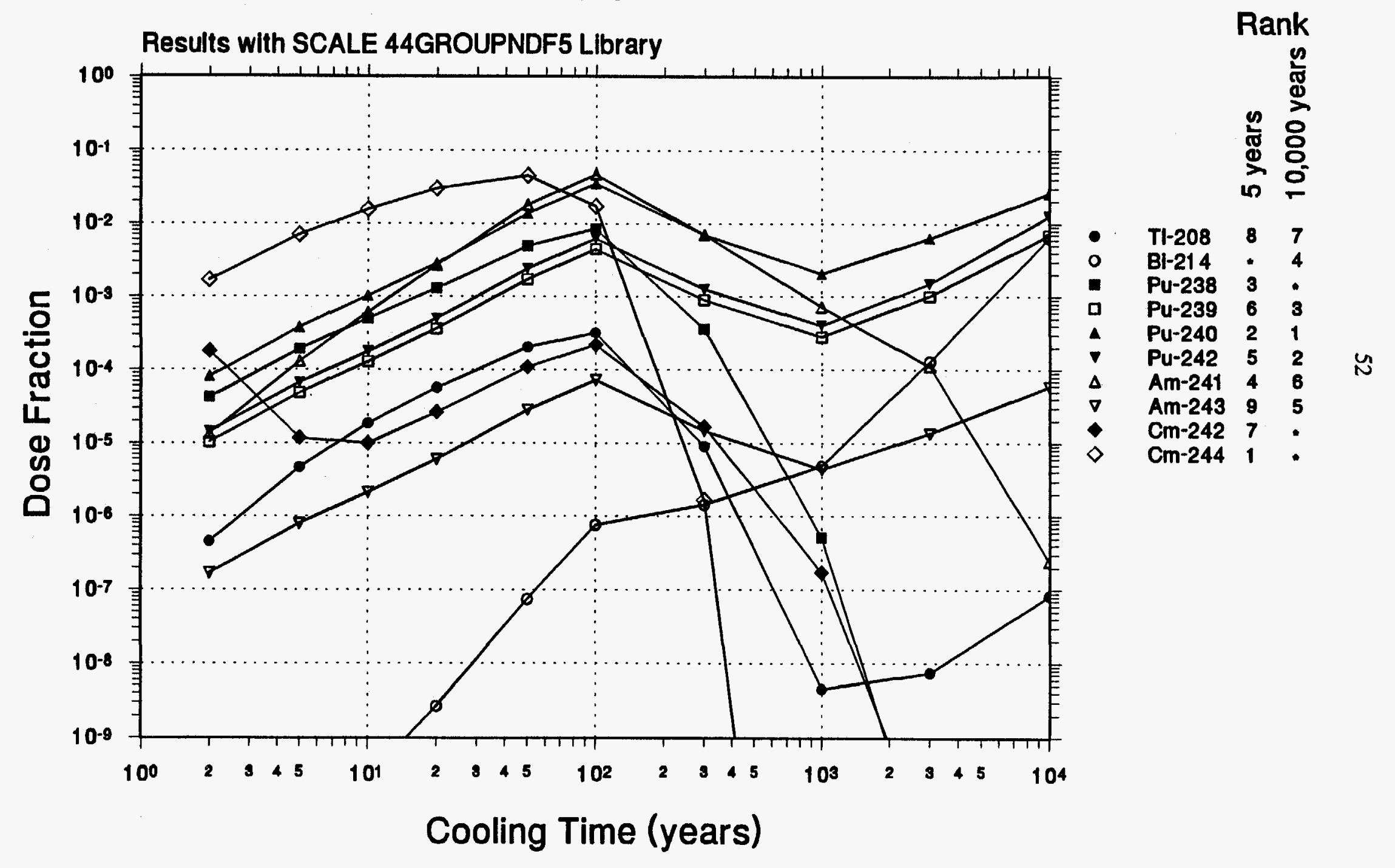




\section{Primary Gamma Dose Fraction vs. Cooling Time for $\mathrm{Tn}-24 ; 3.0 \mathrm{wt} \% \mathrm{U}-235,20 \mathrm{GWd} / \mathrm{t}$ \\ Fission Products and Light Elements}

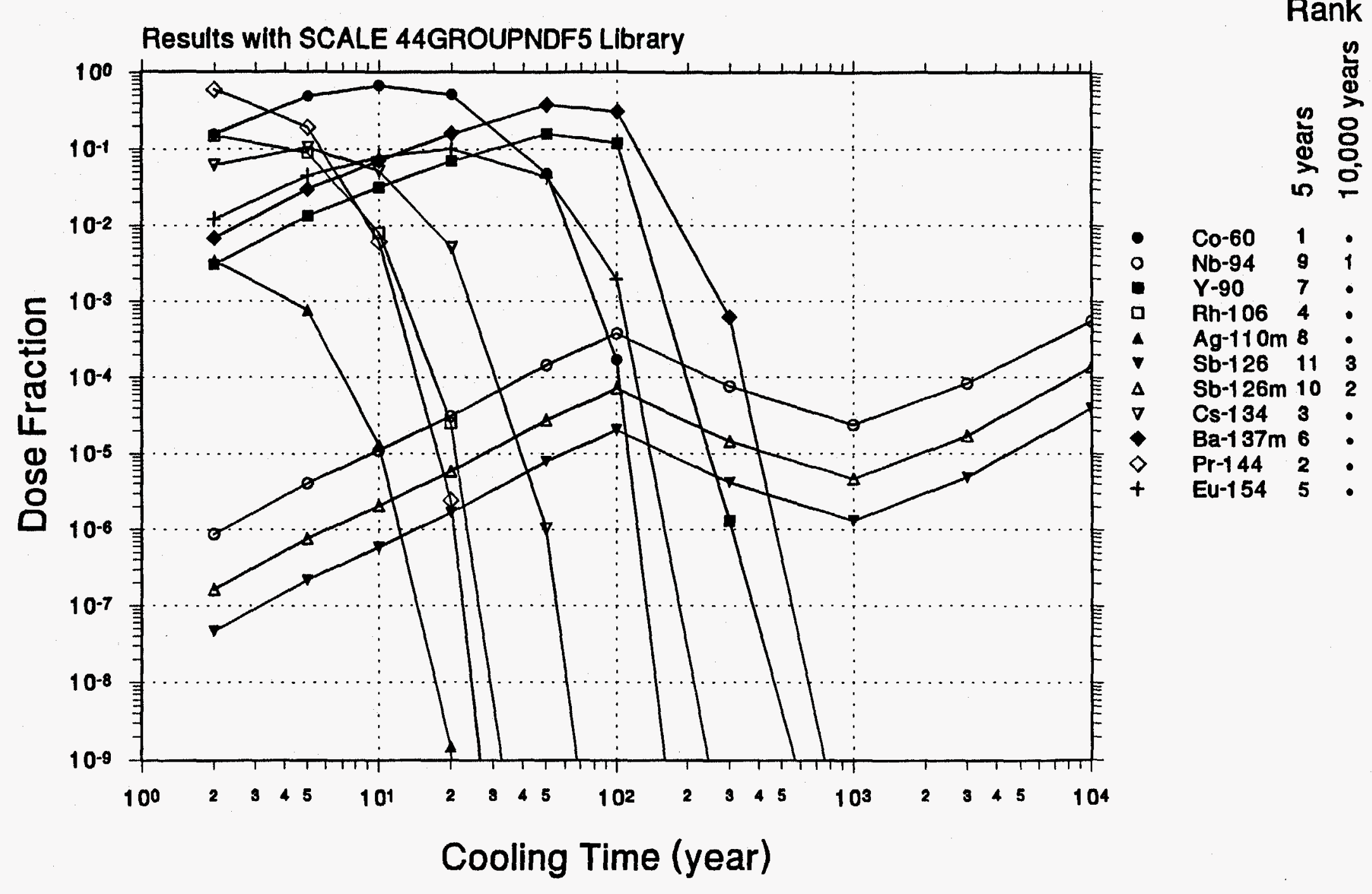




\section{Secondary Gamma Dose Fraction vs Cooling Time}

for $\mathrm{Tn}-24 ; 3.0 \mathrm{wt} \% \mathrm{U}-235,20 \mathrm{GWd} / \mathrm{t}$

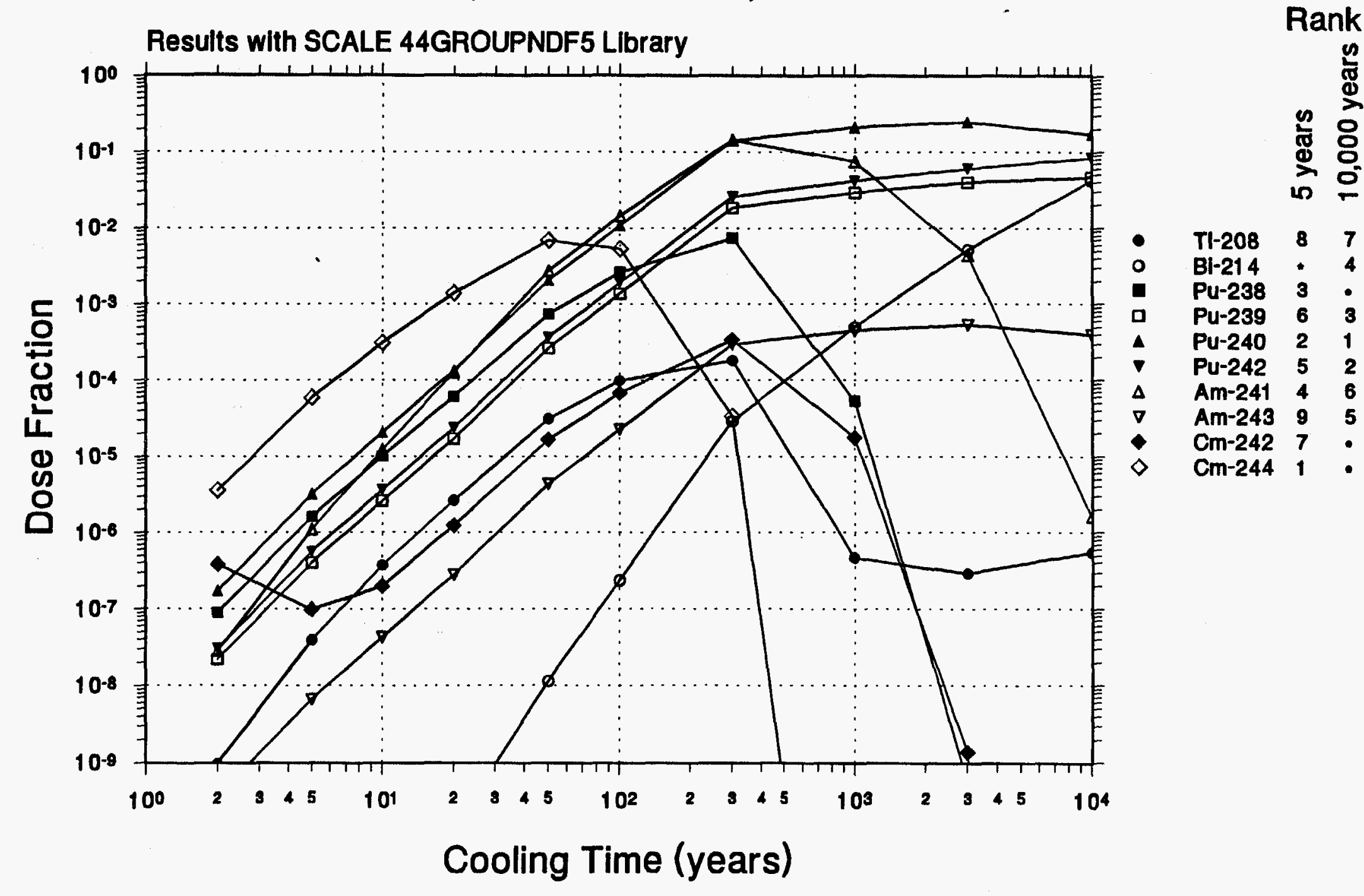




\section{Dose Rate vs Cooling Time Lead Cask; 3.0 wt \% U-235, 20 GWd/t}

Results with SCALE 44GROUPNDF5

- Primary Gamma Dose

- Secondary Gamma Dose

- Neutron Dose

- Total Dose
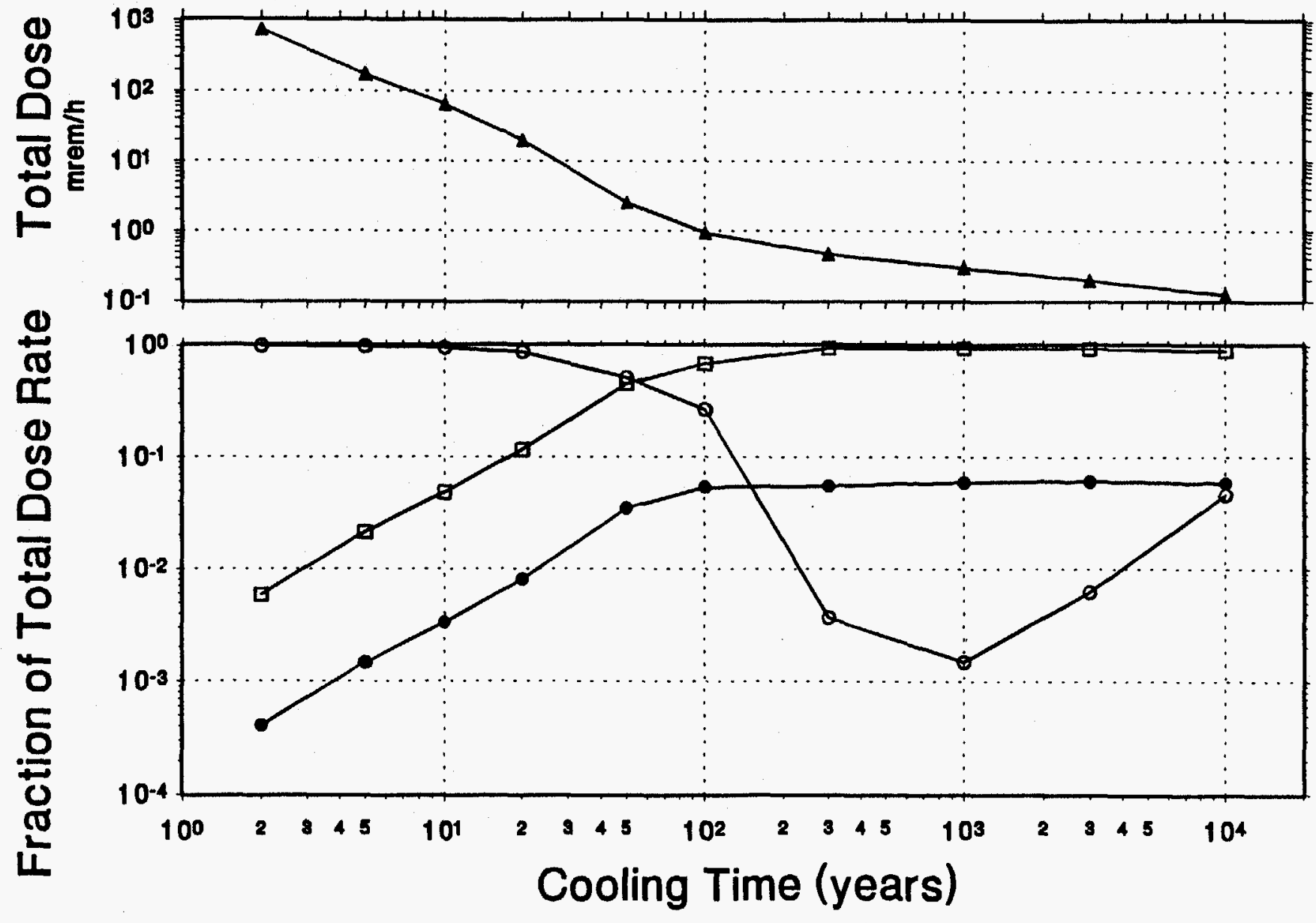
Neutron Dose Fraction vs Cooling Time for Lead; 3.0 wt \% U-235, $20 \mathrm{GWd/t}$

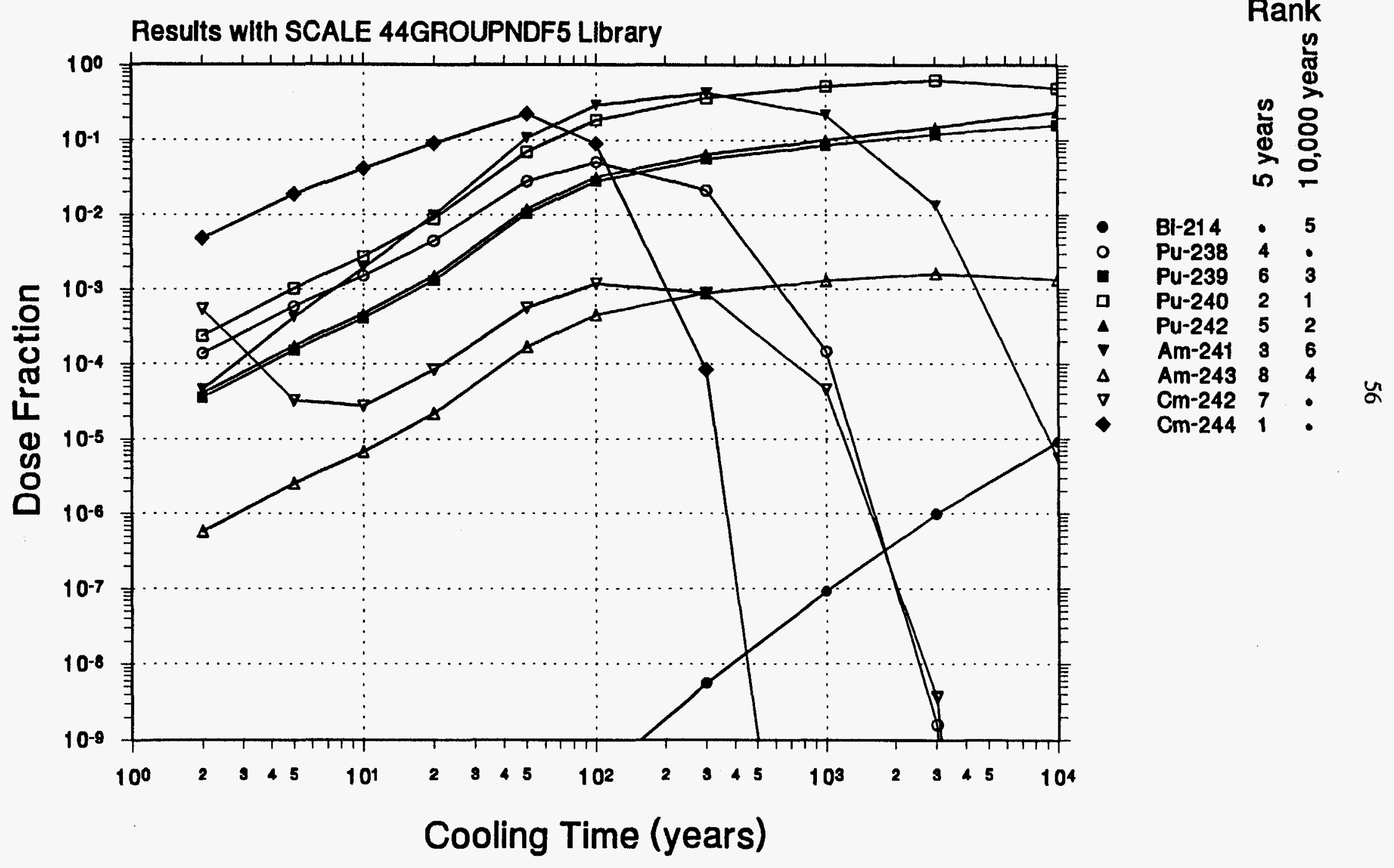




\section{Primary Gamma Dose Fraction vs Cooling Time for Lead; 3.0 wt \% U-235, $20 \mathrm{GWd} / \mathrm{t}$}

Actinides

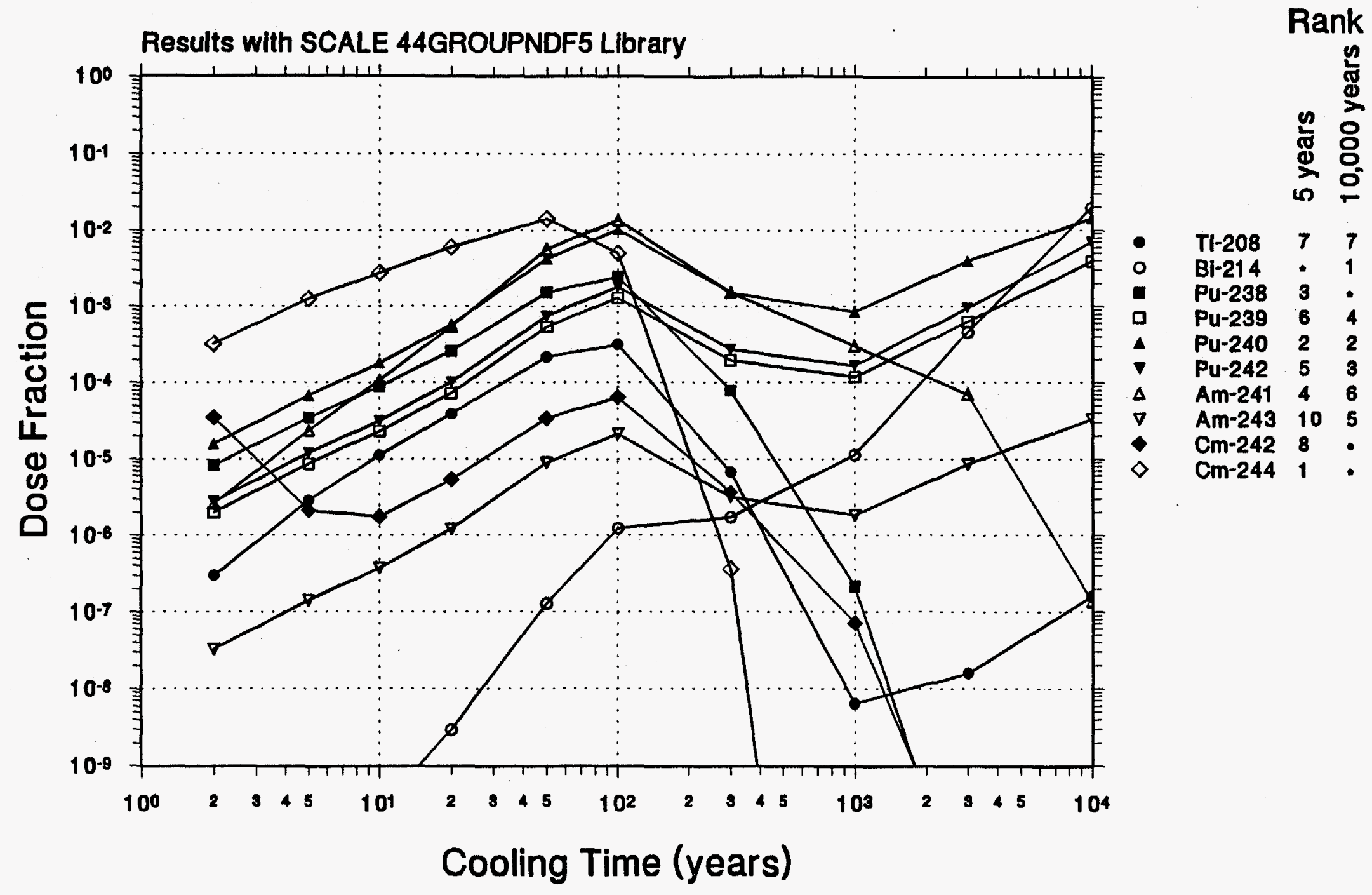




\section{Primary Gamma Dose Fraction vs Cooling Time}

for Lead; $3.0 \mathrm{wt} \% \mathrm{U}-235,20 \mathrm{GWd} / \mathrm{t}$

\section{Fission Products and Light Elements}

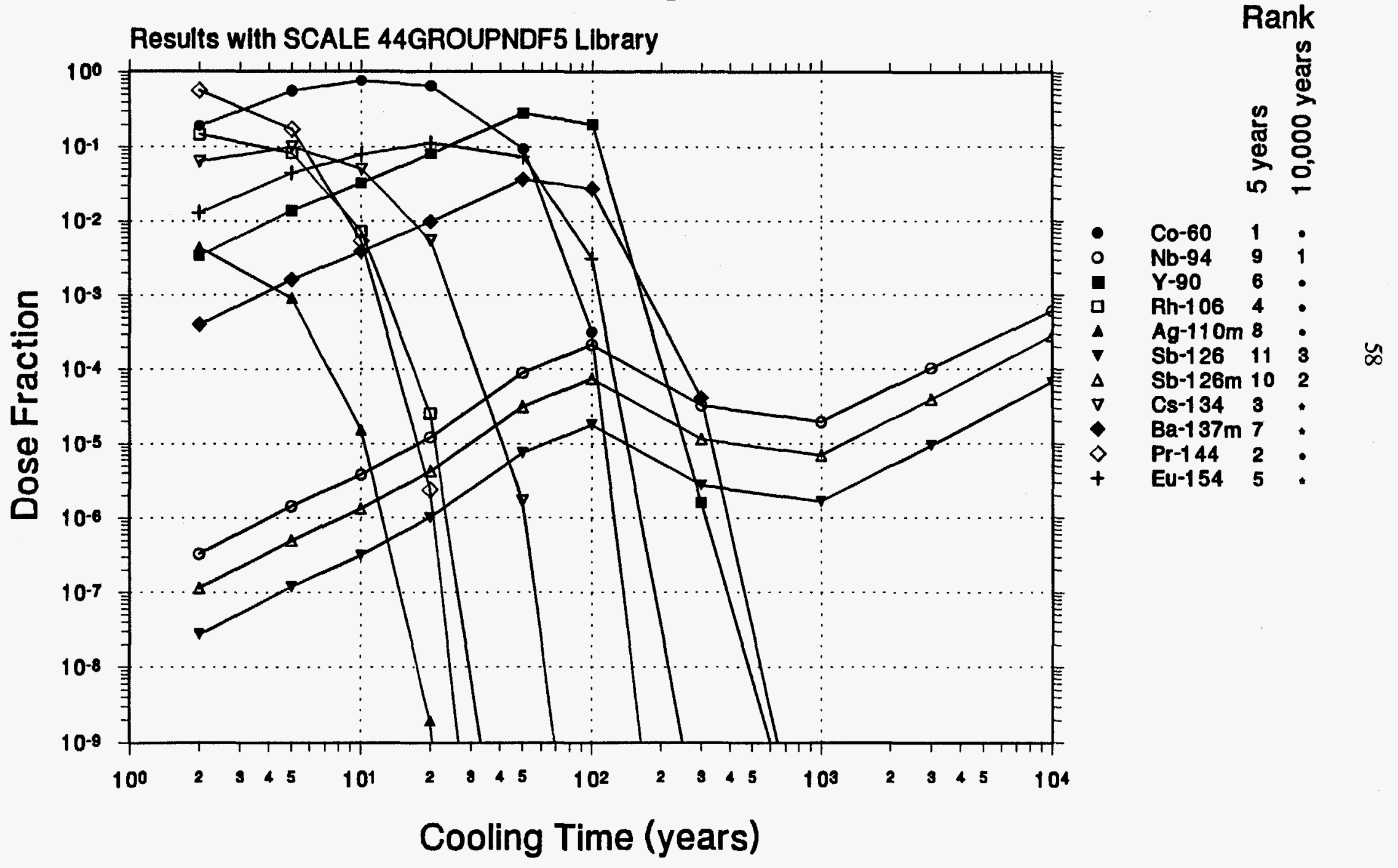




\section{Secondary Gamma Dose Fraction vs Cooling Time}

for Lead; $3.0 \mathrm{wt} \% \mathrm{U}-235,20 \mathrm{GWd} / \mathrm{t}$

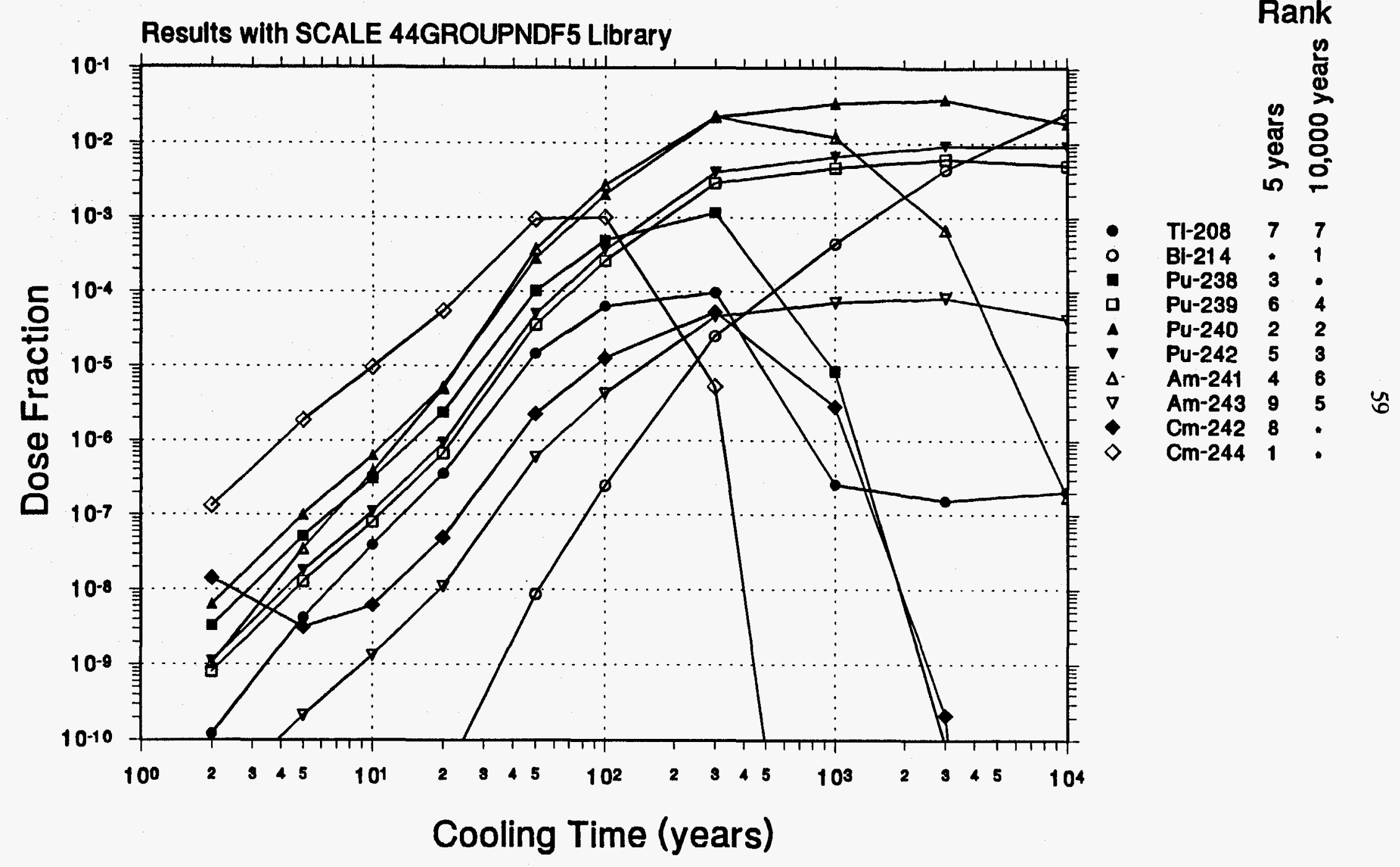




\section{Dose Rate vs Cooling Time \\ VSC Cask; 3.0 wt \% U-235, 20 GWd/t \\ Results with SCALE 44GROUPNDF5}

- Primary Gamma Dose

- Secondary Gamma Dose

- Neutron Dose

- Total Dose

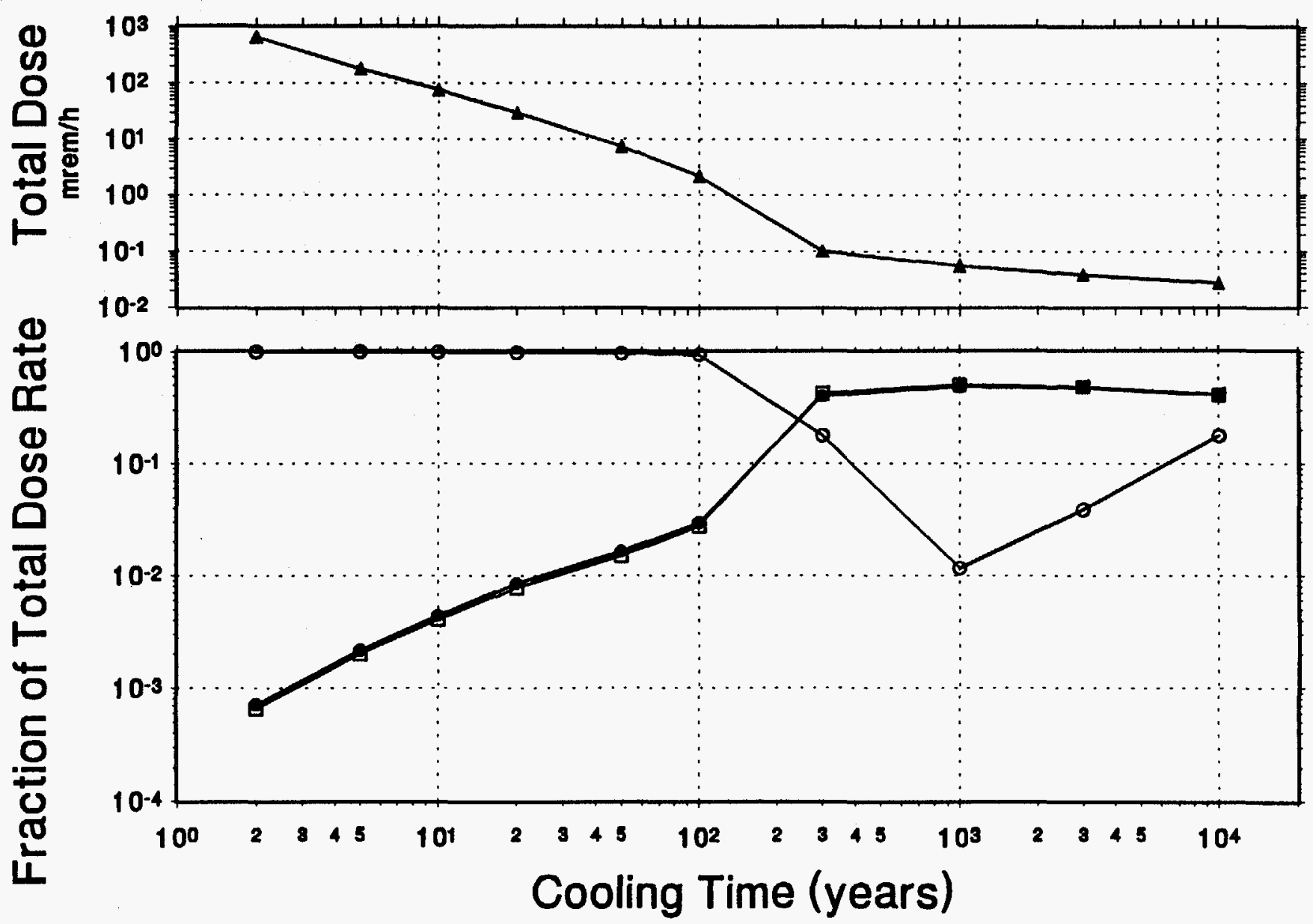




\section{Neutron Dose Fraction vs Cooling Time}

for VSC; 3.0 wt \% U-235, $20 \mathrm{GWd} / \mathrm{t}$

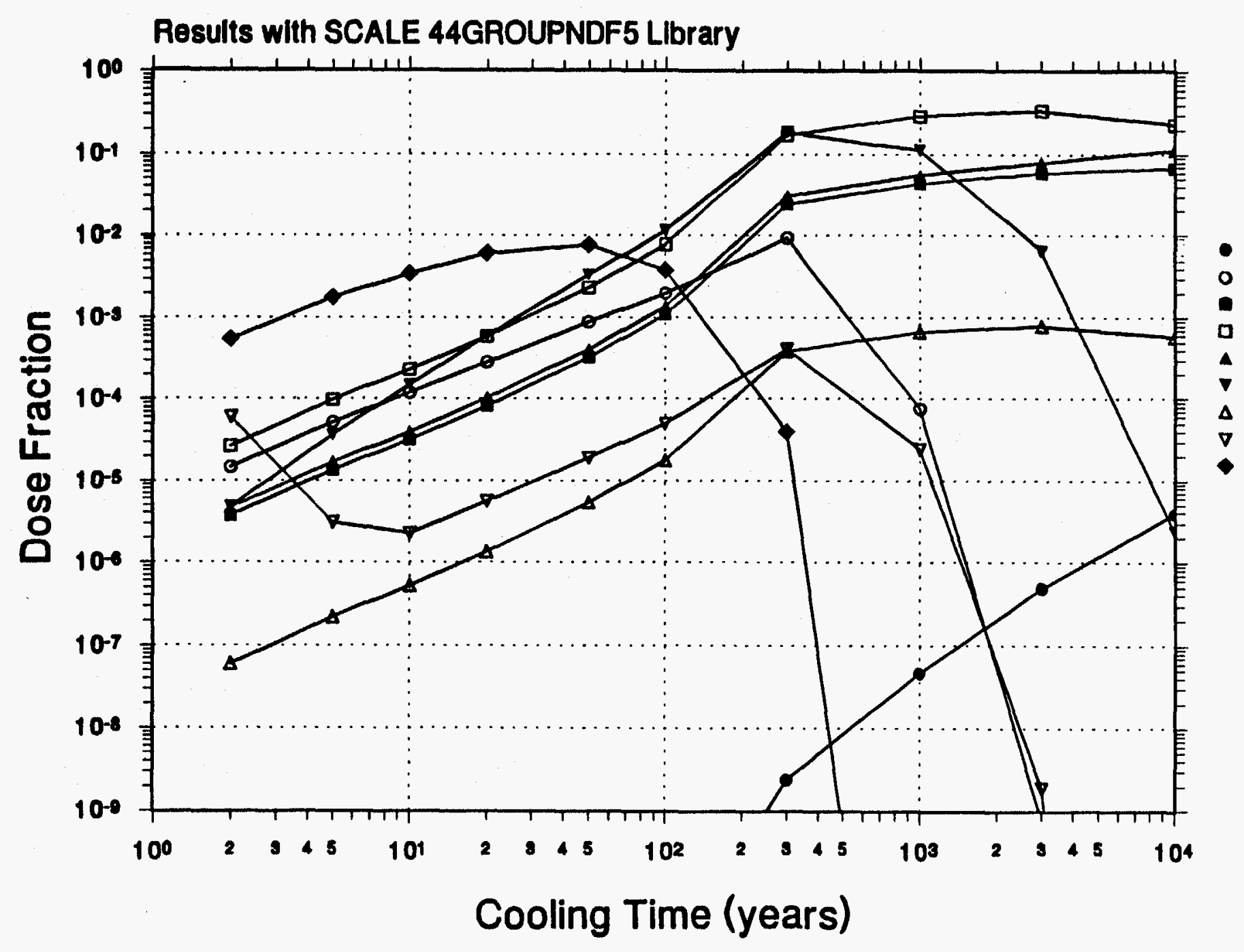

Rank

赵

$\mathrm{BI}-214 \cdot 5$

Pu-238 4 .

Pu-239 $6 \quad 3$

Pu-240 21

Pu-242 52

Am-241 36

Am-243 8 \&

$\mathrm{Cm}-242 ?$ 


\section{Primary Gamma Dose Fraction vs Cooling Time}

for VSC; $3.0 \mathrm{wt} \% \mathrm{U}-235,20 \mathrm{GWd} / \mathrm{t}$

\section{Actinides}

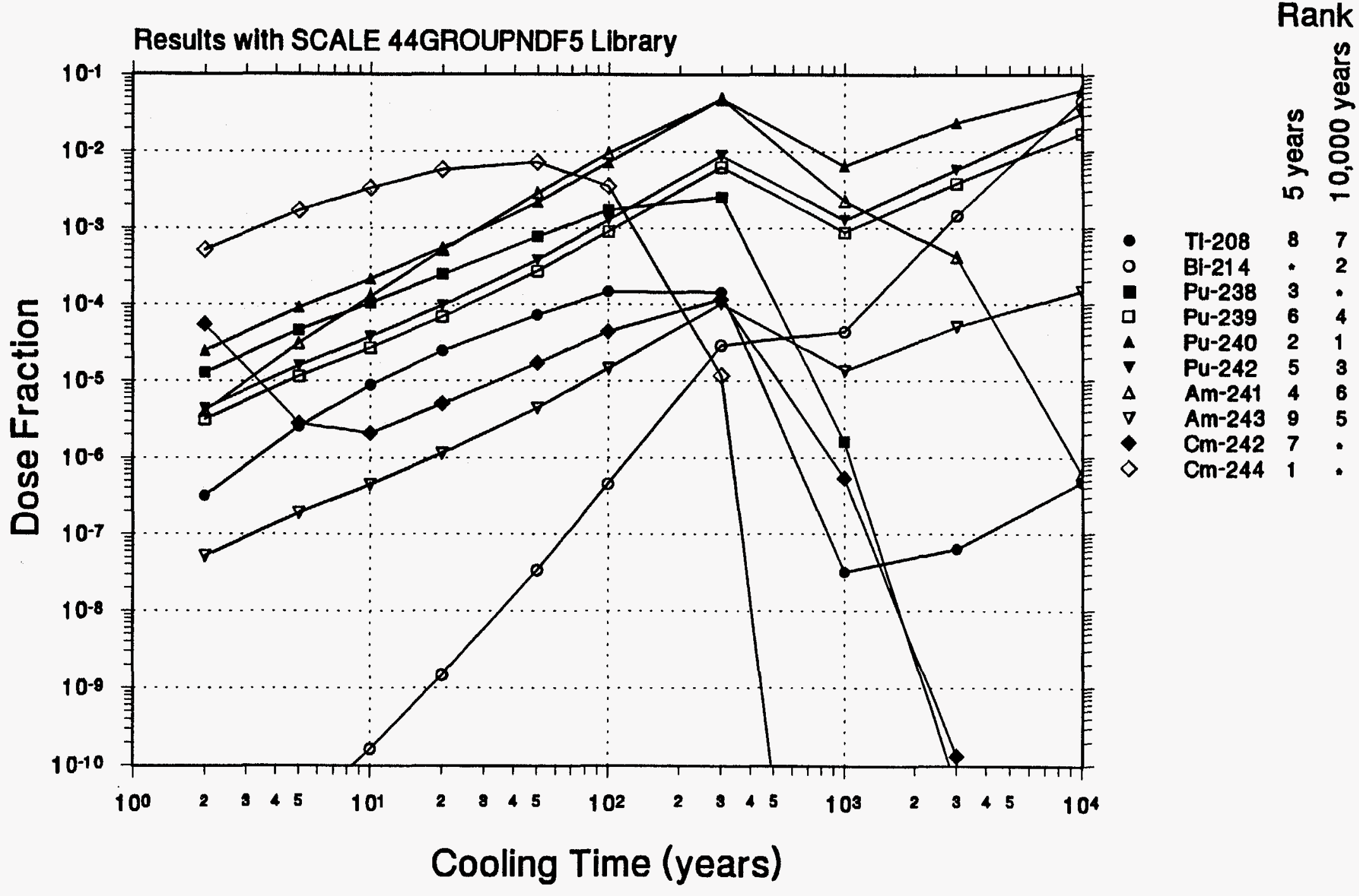




\section{Primary Gamma Dose Fraction vs Cooling Time}

for VSC; $3.0 \mathrm{wt} \% \mathrm{U}-235,20 \mathrm{GWd} / \mathrm{t}$

Fission Products and Light Elements

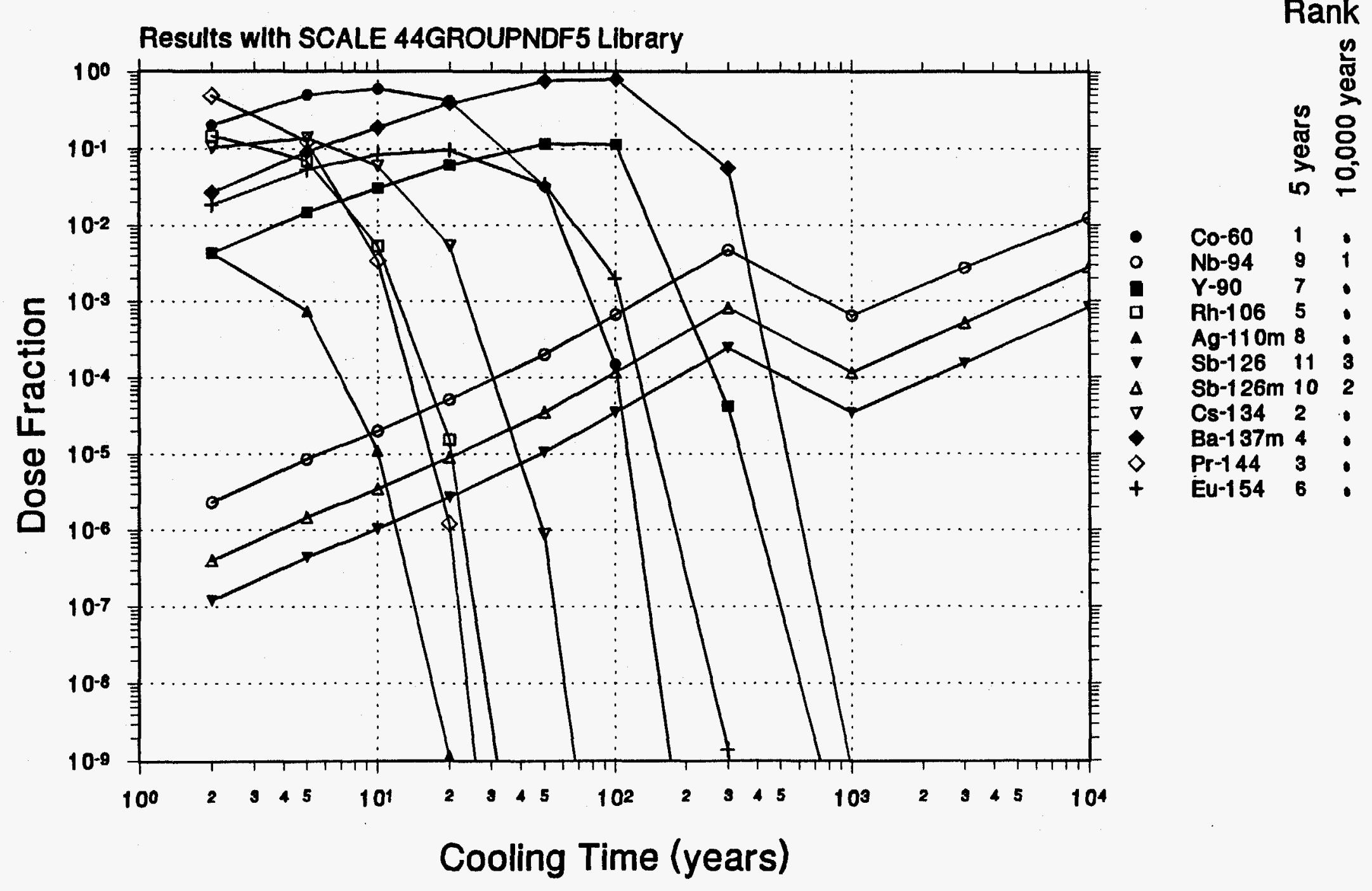


Secondary Gamma Dose Fraction vs Cooling Time for VSC; $3.0 \mathrm{wt} \% \mathrm{U}-235,20 \mathrm{GWd} / \mathrm{t}$

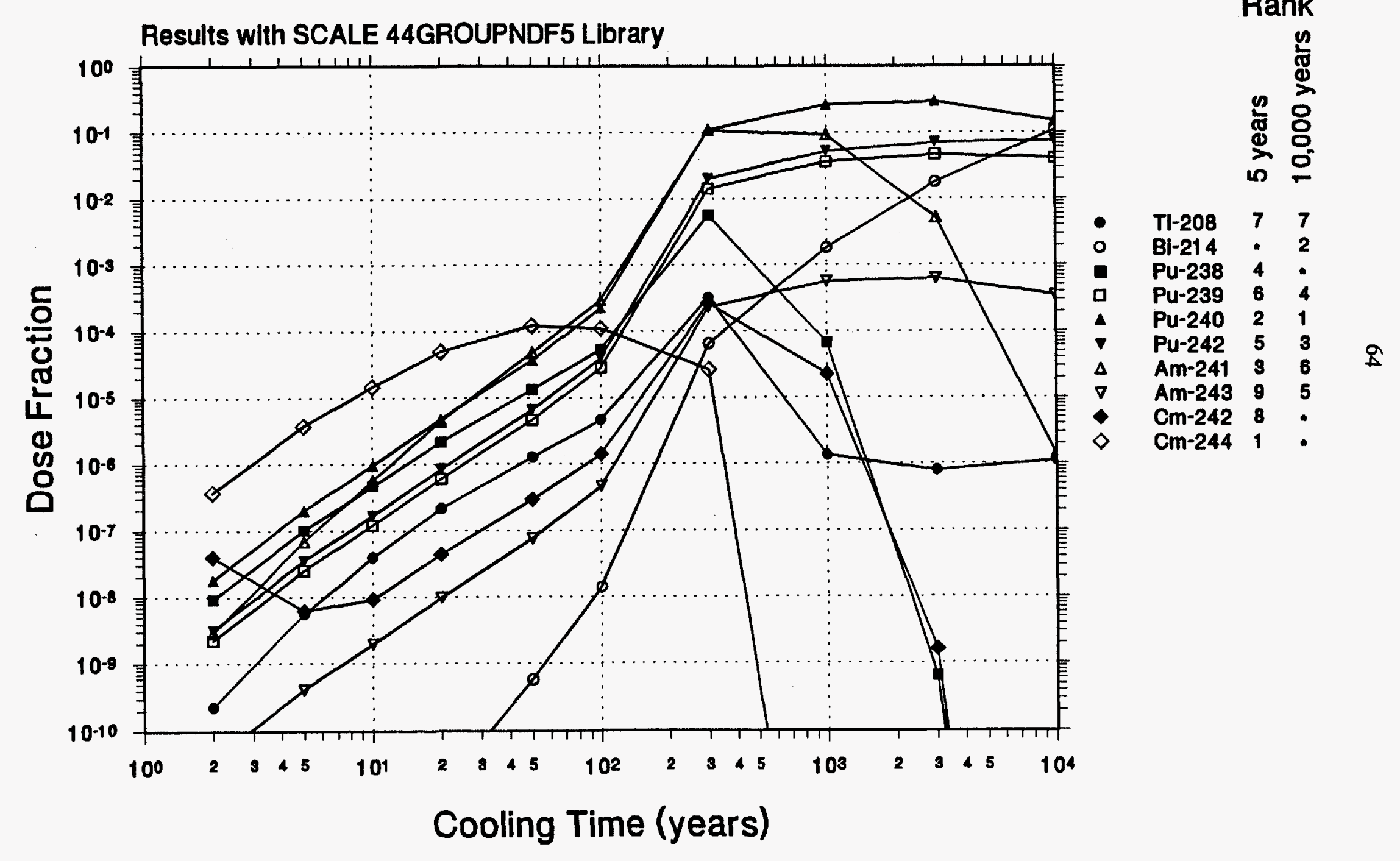




\section{Dose Rate vs Cooling Time}

\section{TN-24 Cask; $4.5 \mathrm{wt} \% \mathrm{U}-235,50 \mathrm{gwd} / \mathrm{t}$}

Results with SCALE 44GROUPNDF5

- Primary Gamma Dose

- Secondary Gamma Dose

- Neutron Dose

- Total Dose

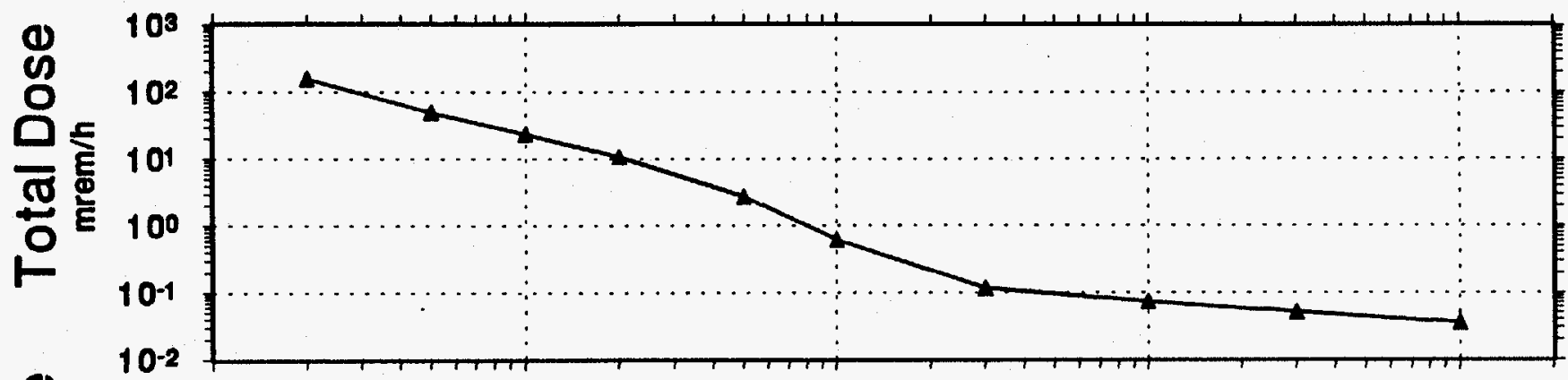

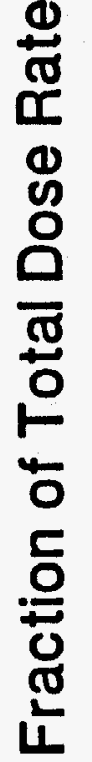

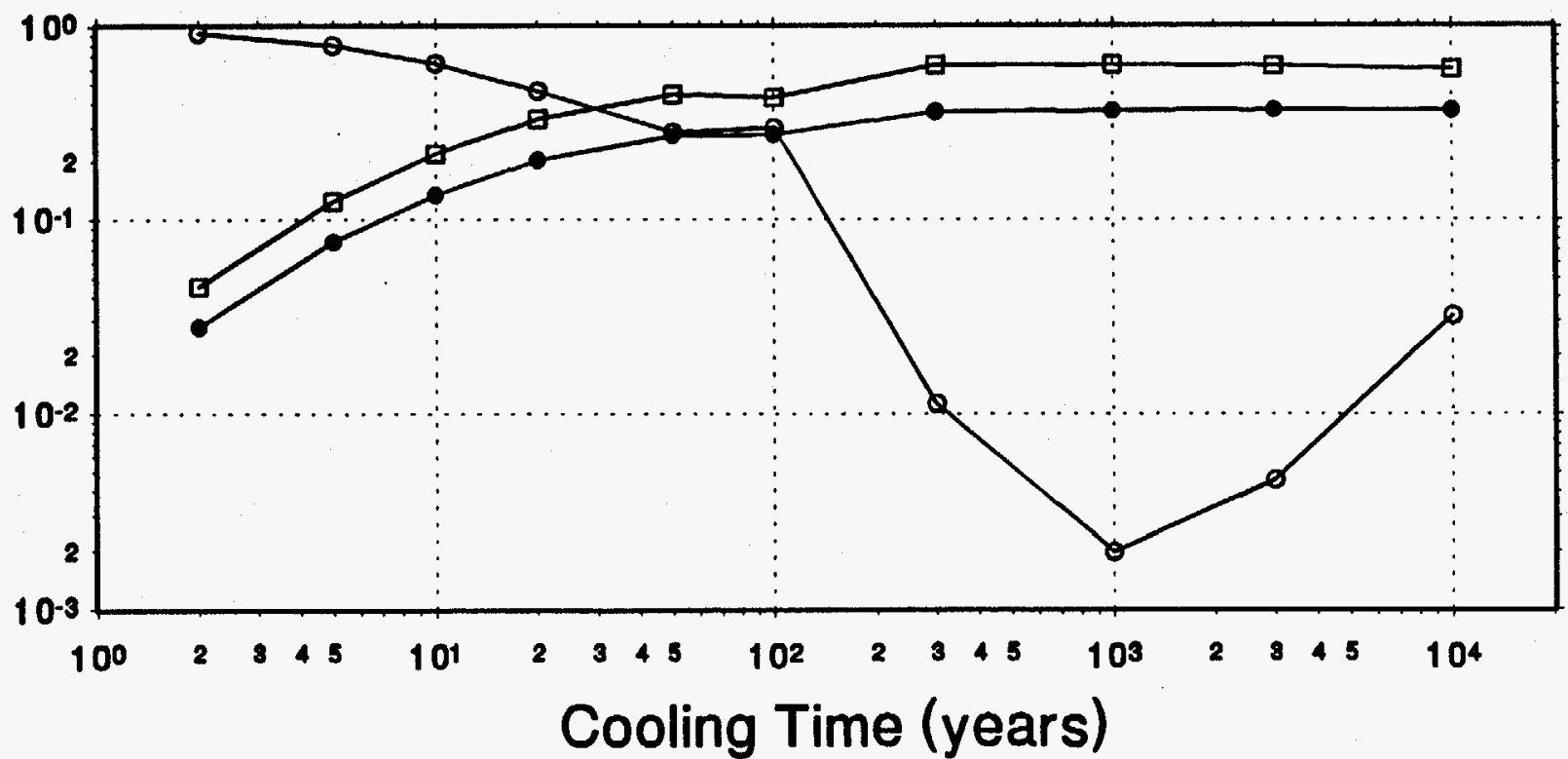



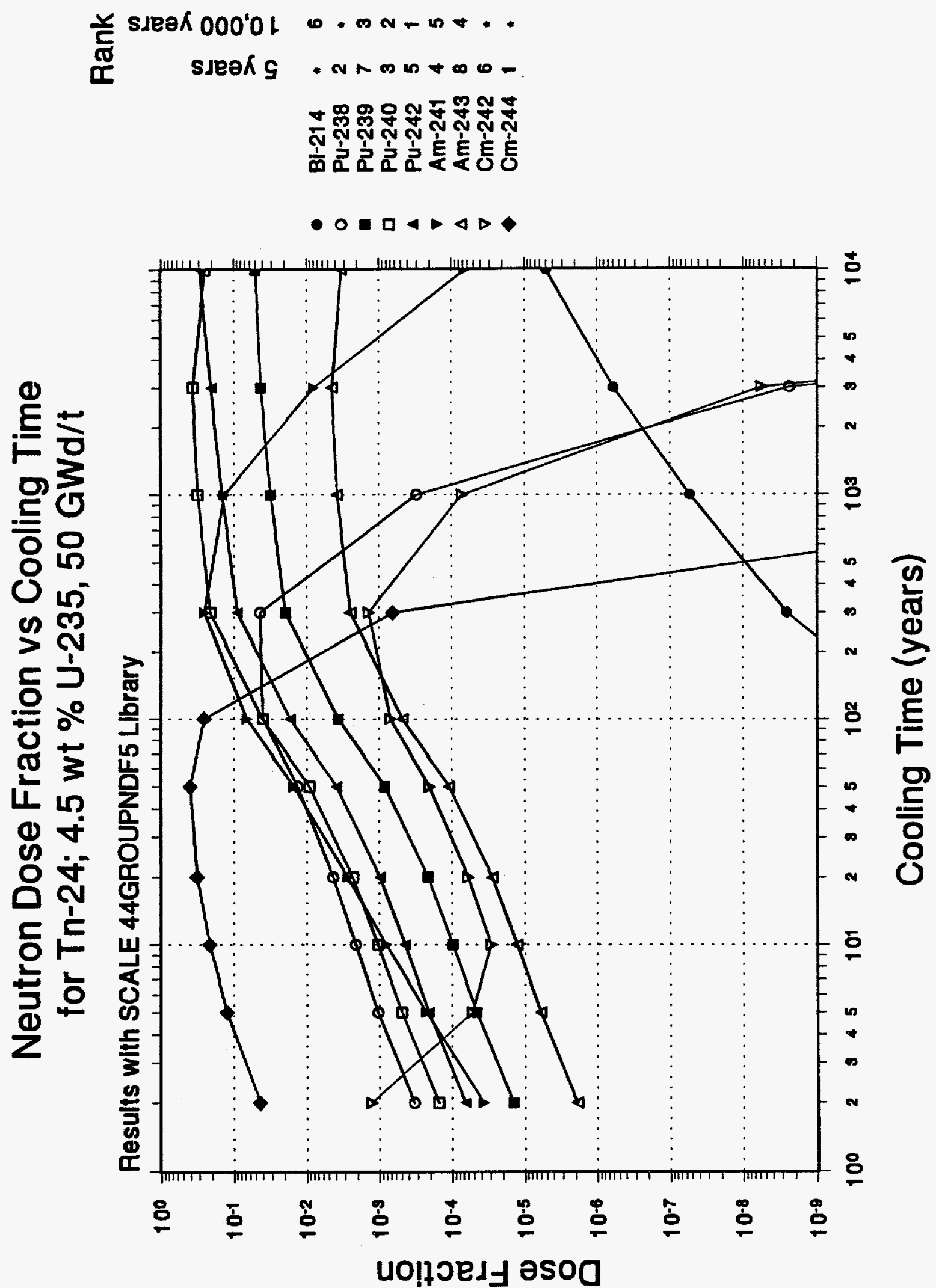
Primary Gamma Dose Fraction vs Cooling Time

\section{for Tn-24; 4.5 wt \% U-235, $50 \mathrm{GWd} / \mathrm{t}$} Actinides

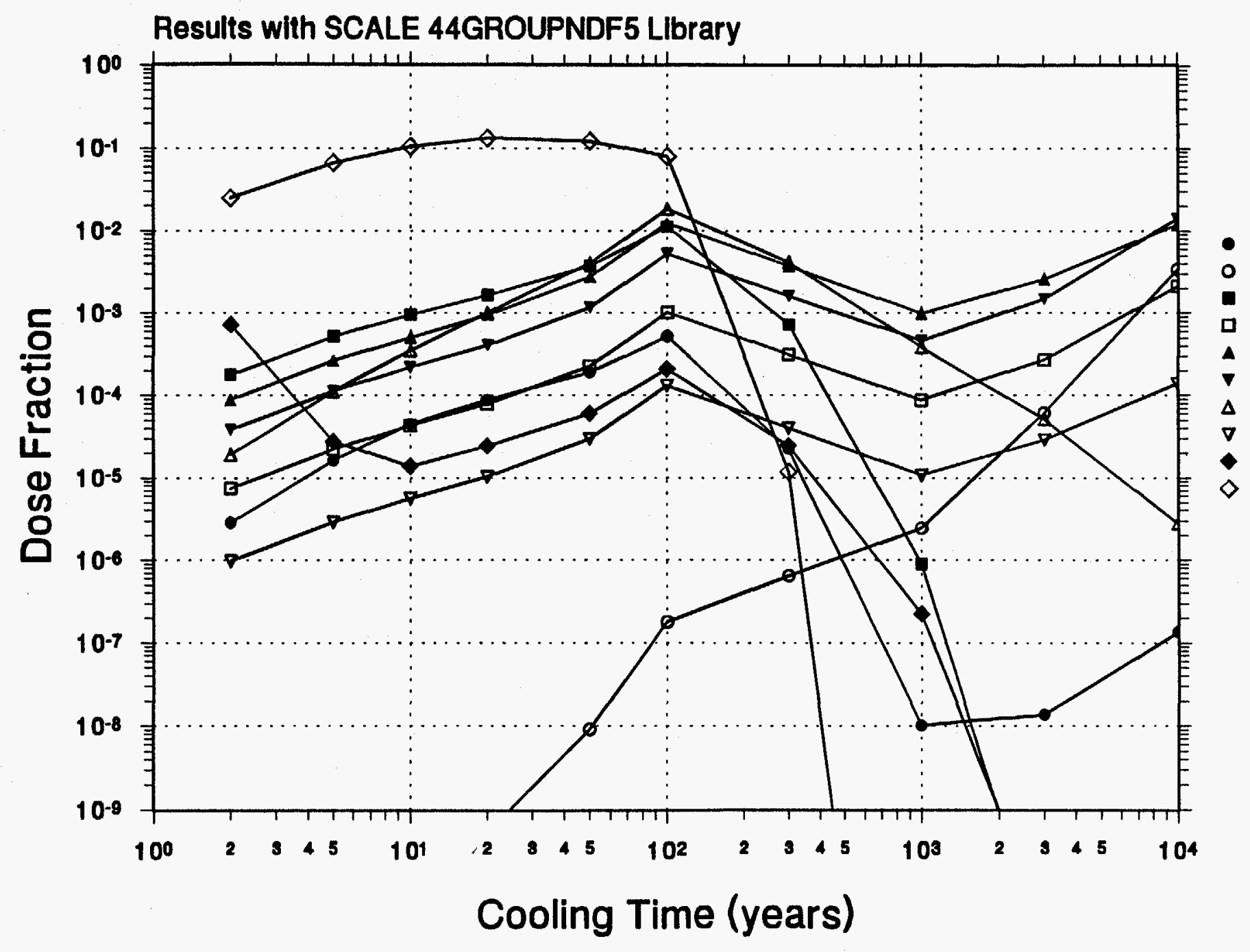

Rank

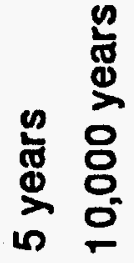

TH-208 87

$\mathrm{Bl}-214$ - 3

Pu-238 2.

Pu-239 74

Pu-240

Pu-242

Am-241

Am-243 90

$\mathrm{Cm}-2426$. 


\section{Primary Gamma Dose Fraction vs Cooling Time for Tn-24; 4.5 wt \% U-235, $50 \mathrm{GWd} / \mathrm{t}$ \\ Fission Products and Light Elements}

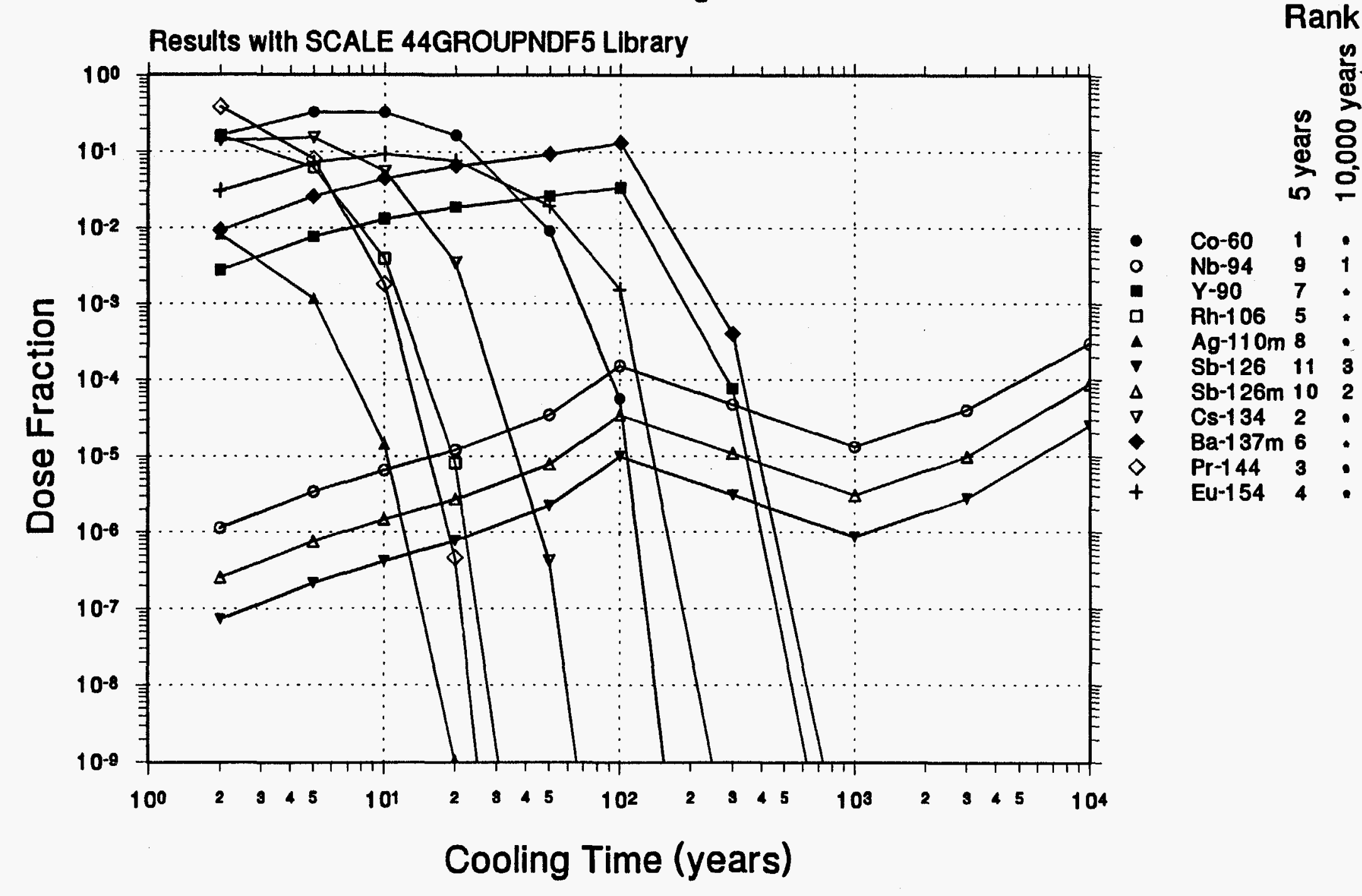




\section{Secondary Gamma Dose Fraction vs Cooling Time}

for Tn-24; $4.5 \mathrm{wt} \% \mathrm{U}-235,50 \mathrm{GWd} / \mathrm{t}$

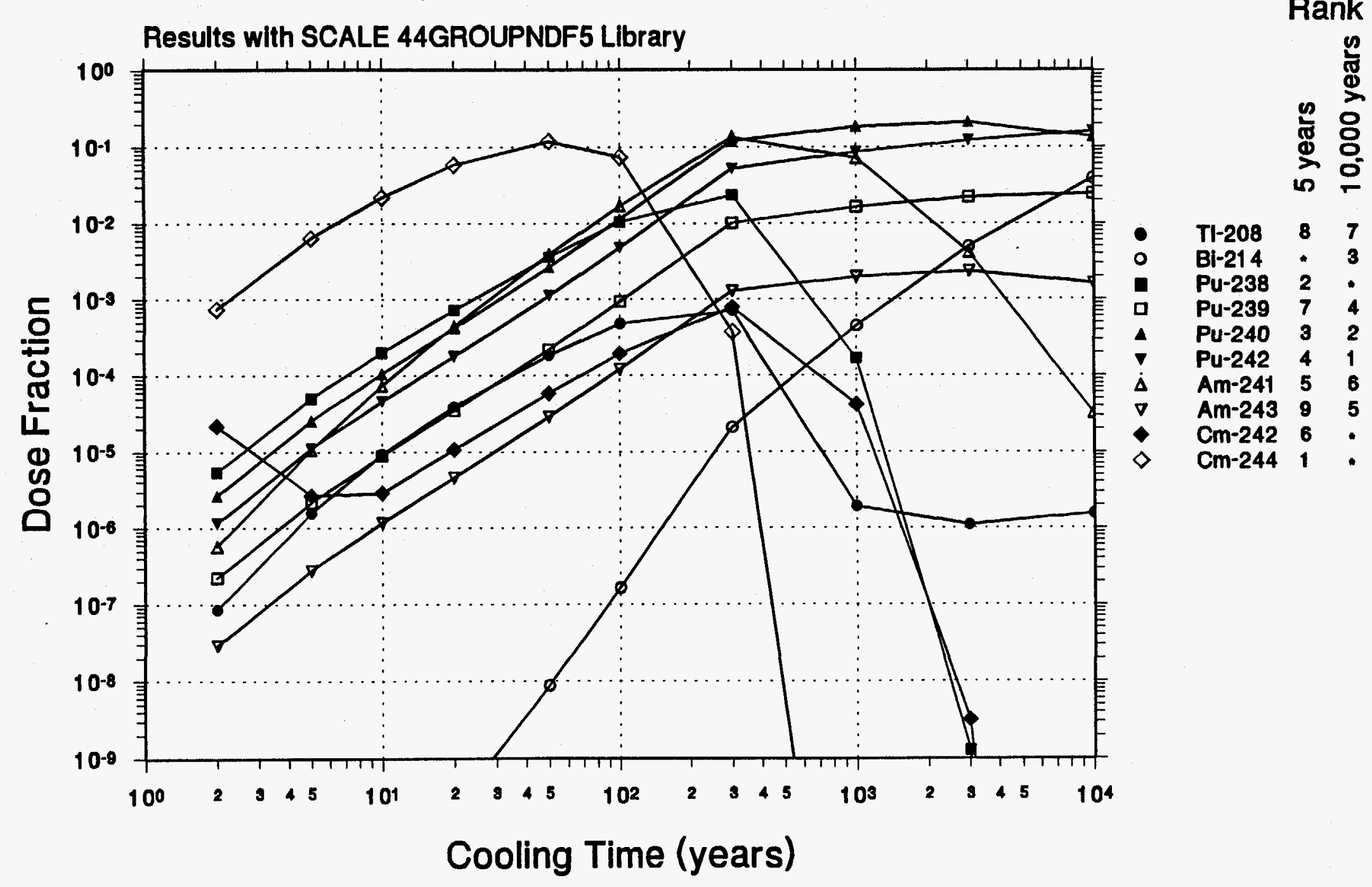




\section{Dose Rate vs Cooling Time \\ Lead Cask; 4.5 wt \% U-235, 50 GWd/t}

Results with SCALE 44GROUPNDF5

- Primary Gamma Dose

- Secondary Gamma Dose

- Neutron Dose

- Total Dose
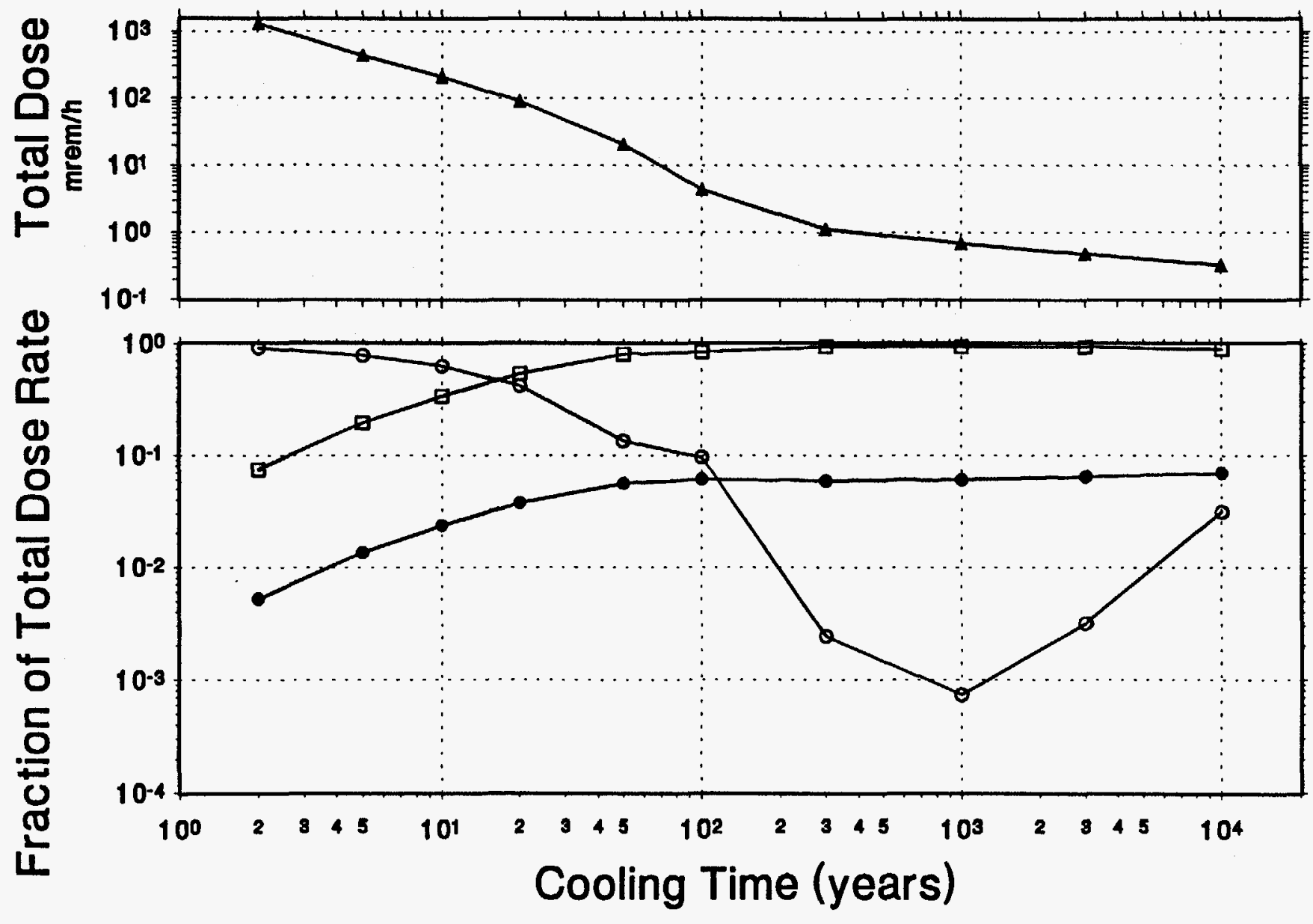


\section{Neutron Dose Fraction vs Cooling Time}

for Lead; $4.5 \mathrm{wt} \% \mathrm{U}-235,50 \mathrm{GWd} / \mathrm{t}$

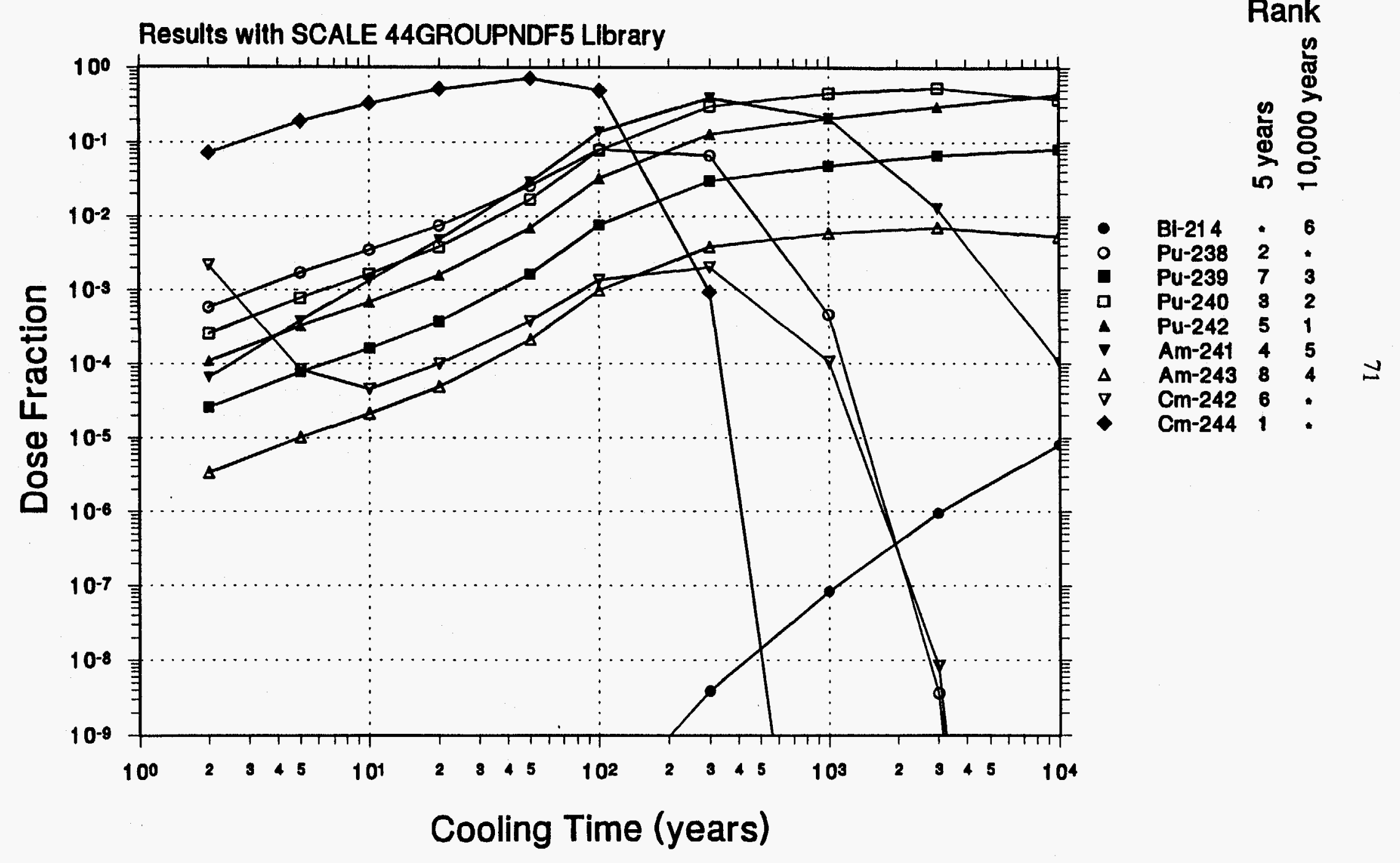




\section{Primary Gamma Dose Fraction vs Cooling Time}

for Lead; 4.5 wt \% U-235, $50 \mathrm{GWd} / \mathrm{t}$

\section{Actinides}

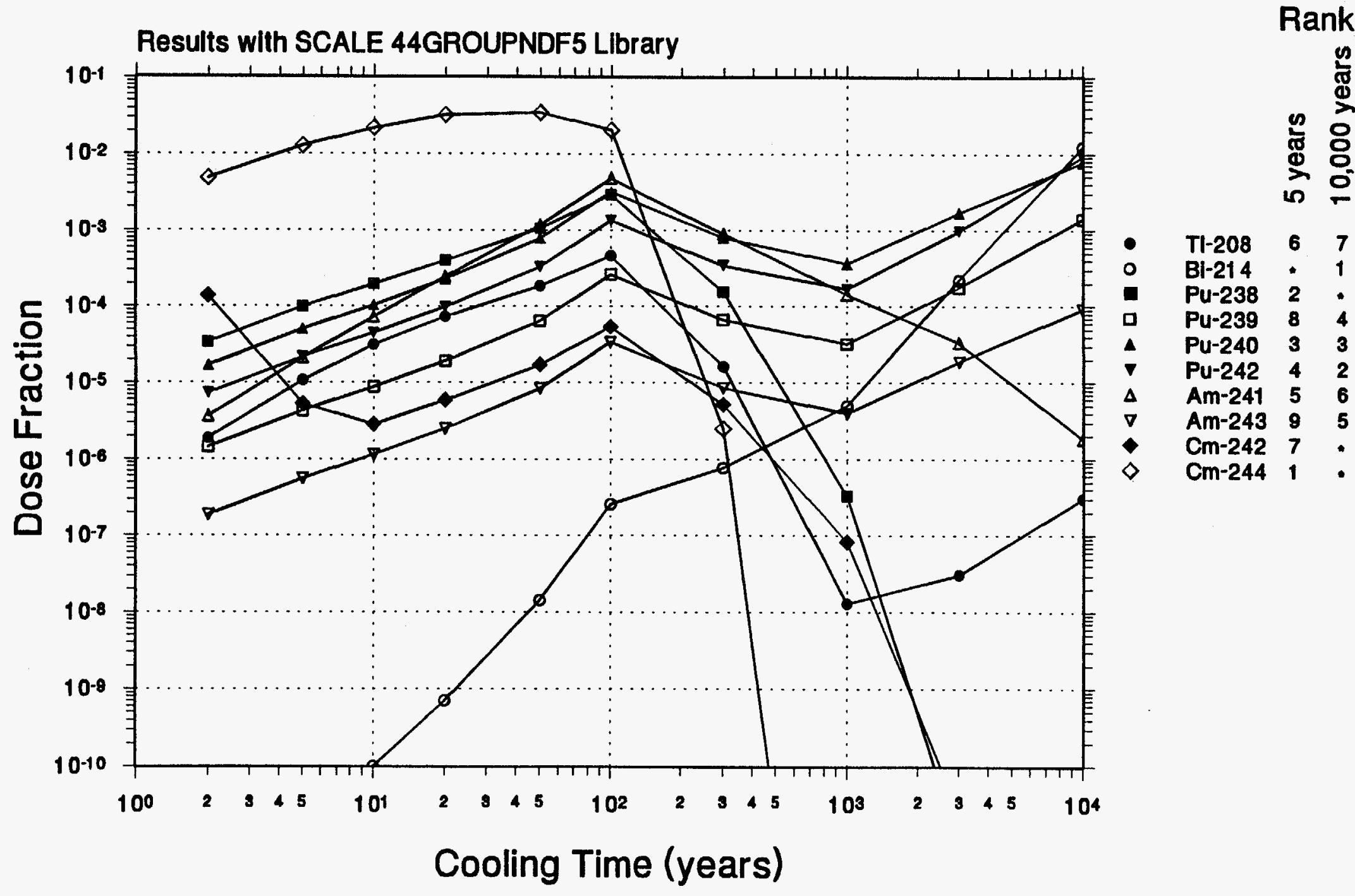


Primary Gamma Dose Fraction vs Cooling Time for Lead; $4.5 \mathrm{wt} \% \mathrm{U}-235,50 \mathrm{GWd} / \mathrm{t}$

Fission Products and Light Elements

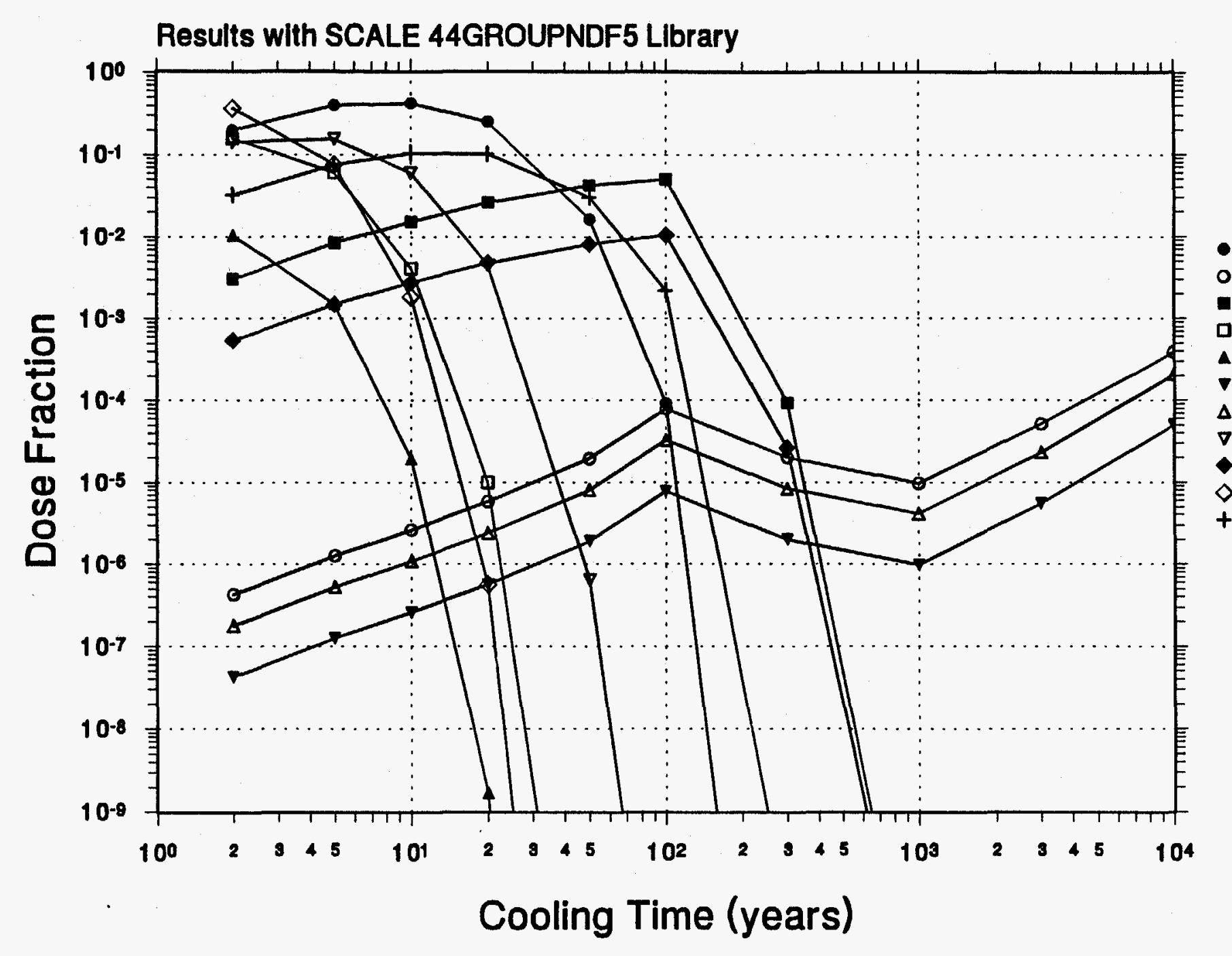

Rank

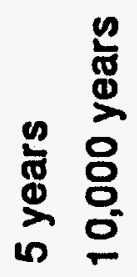

Co-60 1 .

$\mathrm{Nb}-94 \quad 9 \quad 1$

$Y-90$

Rh-1065:

Ag-110m 8 .

Sb-126 113

Sb-126m 10

Cs-134 2 .

Ba-137m 7 .

$\begin{array}{ll}\text { Pr-144 } 3 & 3 \\ \text { Eu-154 } & 4\end{array}$ 
Secondary Gamma Dose Fraction vs Cooling Time for Lead; $4.5 \mathrm{wt} \% \mathrm{U}-235,50 \mathrm{GWd} / \mathrm{t}$

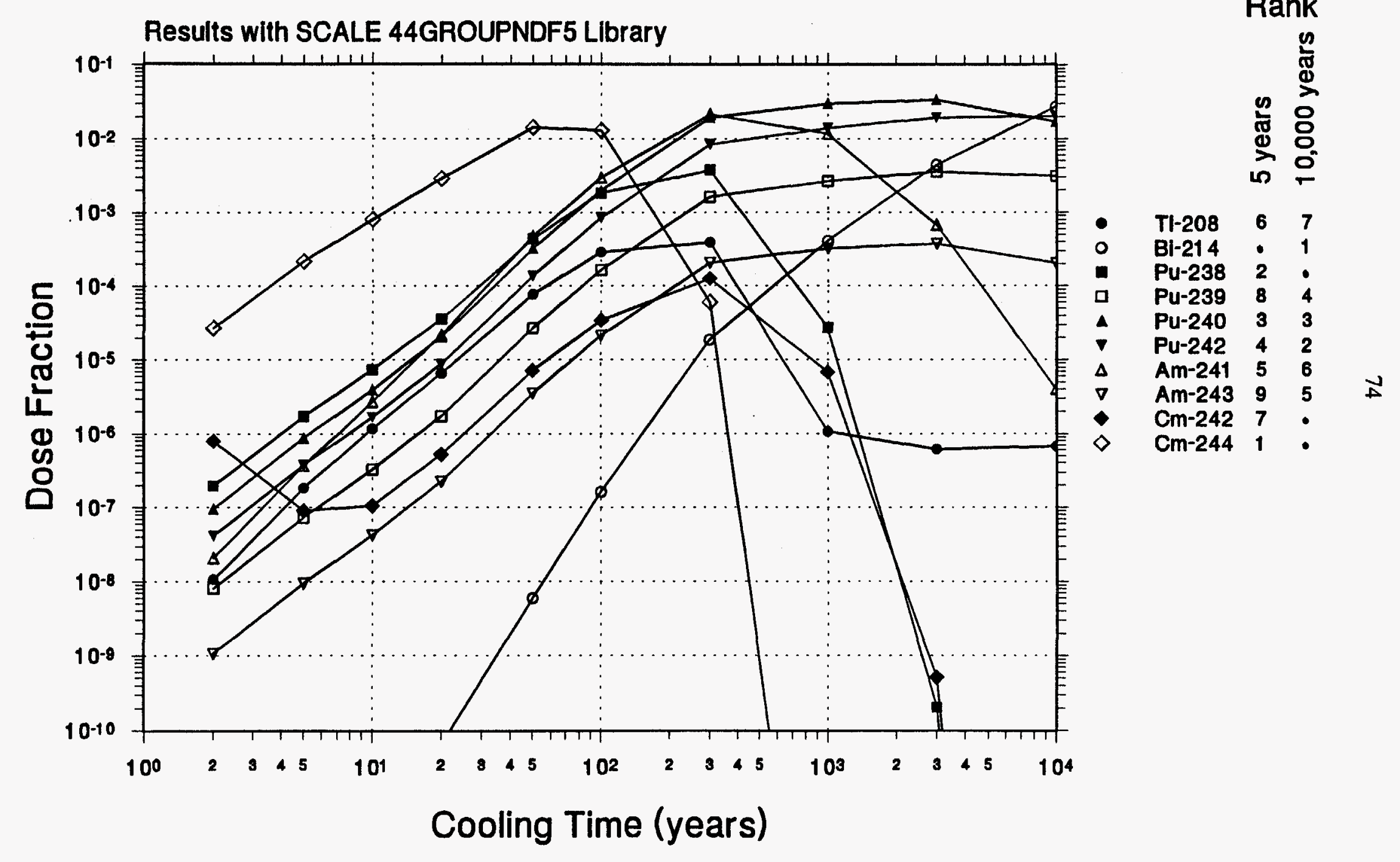




\section{Dose Rate vs Cooling Time}

VSC Cask; 4.5 wt \% U-235, 50 GWd/t

Results with SCALE 44GROUPNDF5

- Primary Gamma Dose

- Secondary Gamma Dose

口 Neutron Dose

$\Delta$ Total Dose
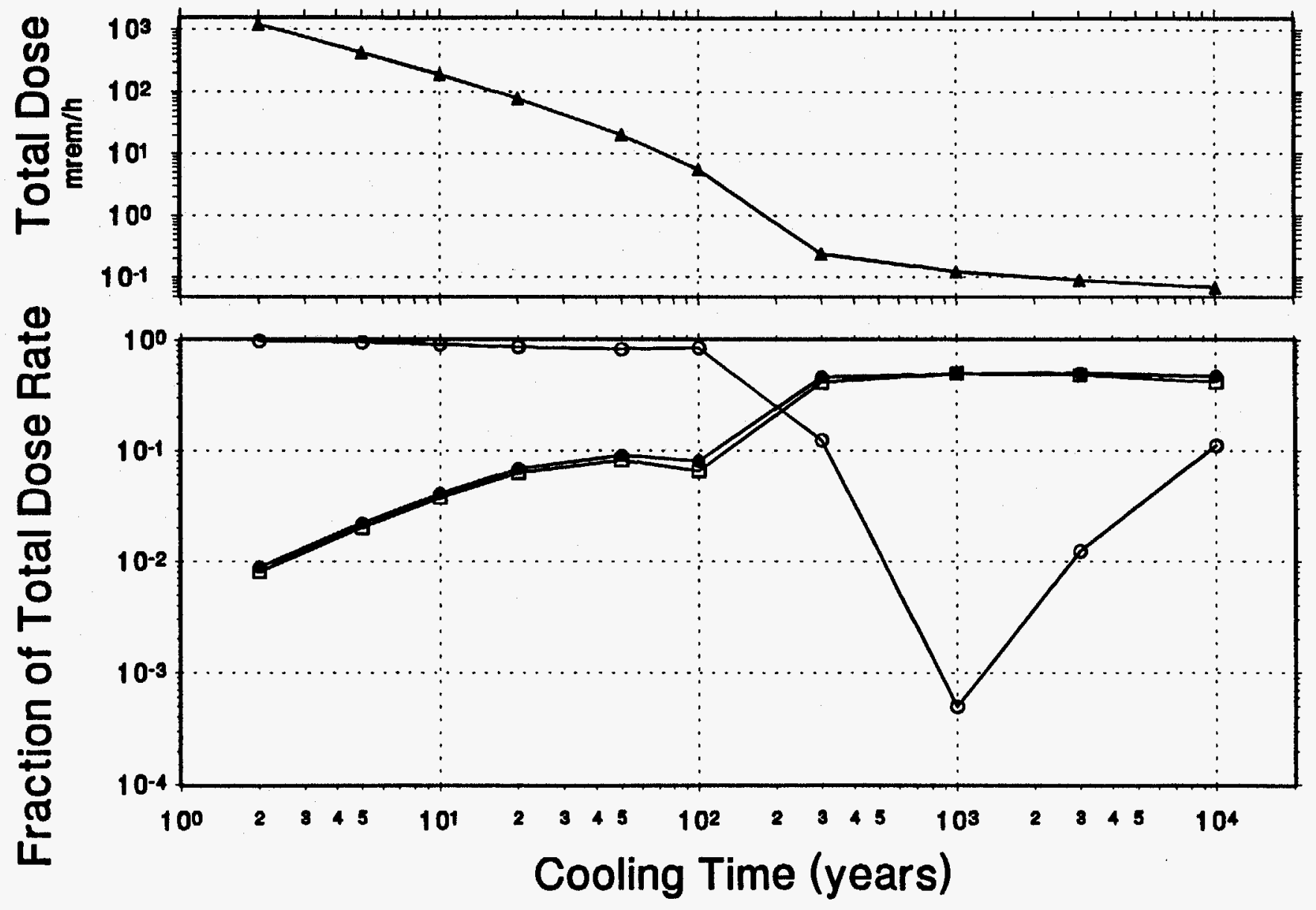


\section{Neutron Dose Fraction vs Cooling Time}

for VSC; 4.5 wt \% U-235, $50 \mathrm{GWd} / \mathrm{t}$

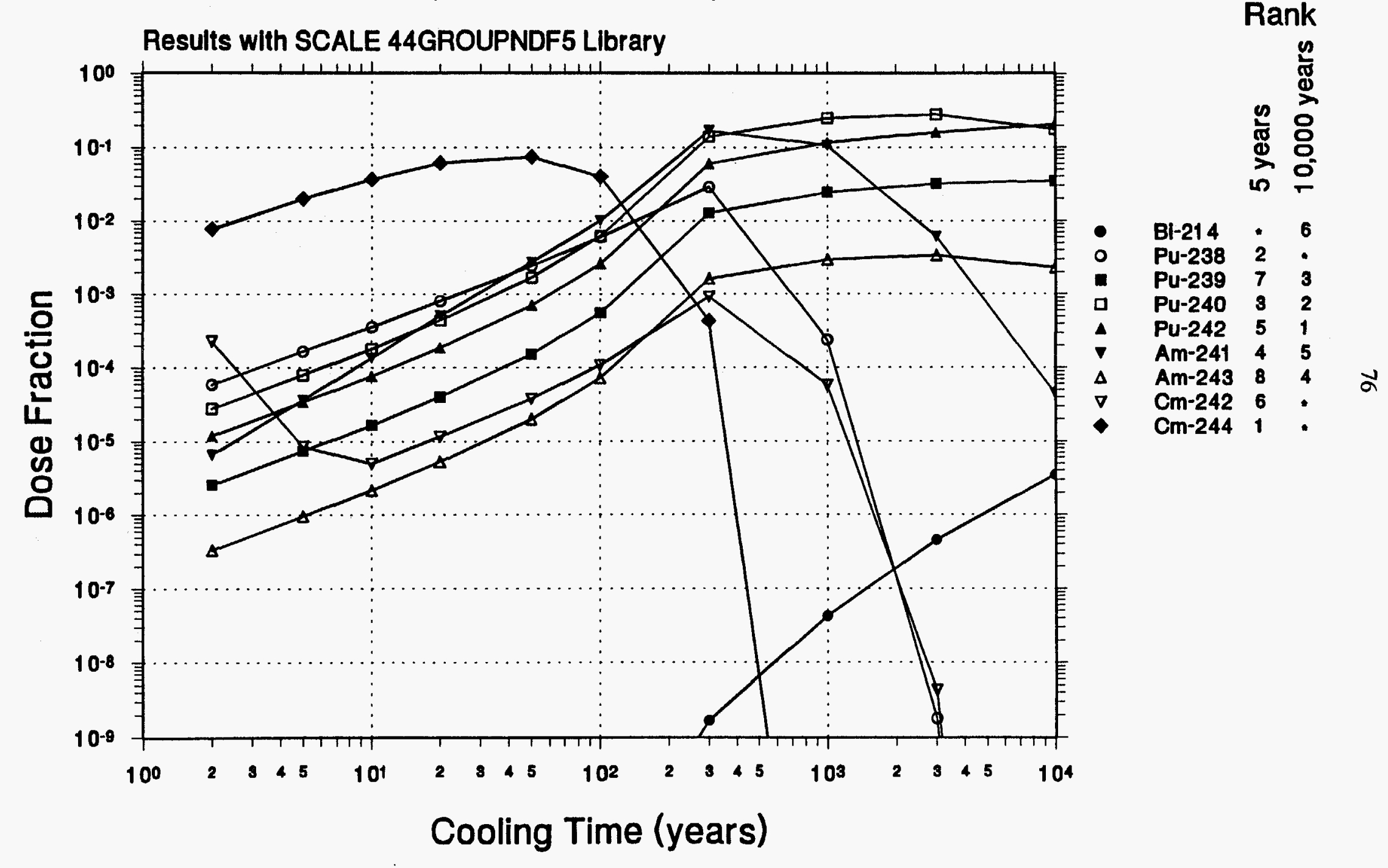




\section{Primary Gamma Dose Fraction vs Cooling Time}

for VSC; 4.5 wt \% U-235, $50 \mathrm{GWd} / \mathrm{t}$

\section{Actinides}

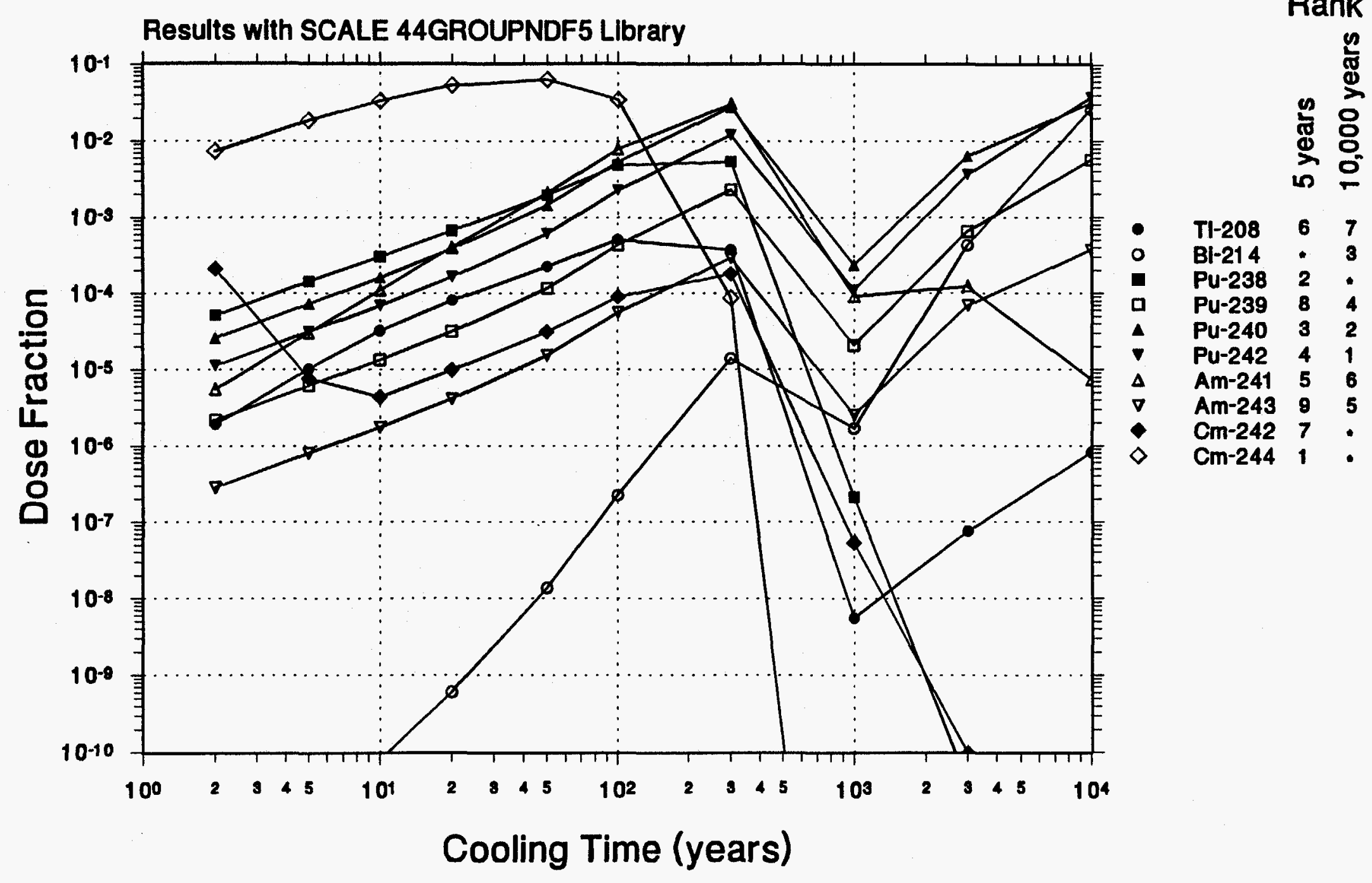




\section{Primary Gamma Dose Fraction vs Cooling Time}

for VSC; 4.5 wt \% U-235, $50 \mathrm{GWd} / \mathrm{t}$

Fission Products and Light Elements

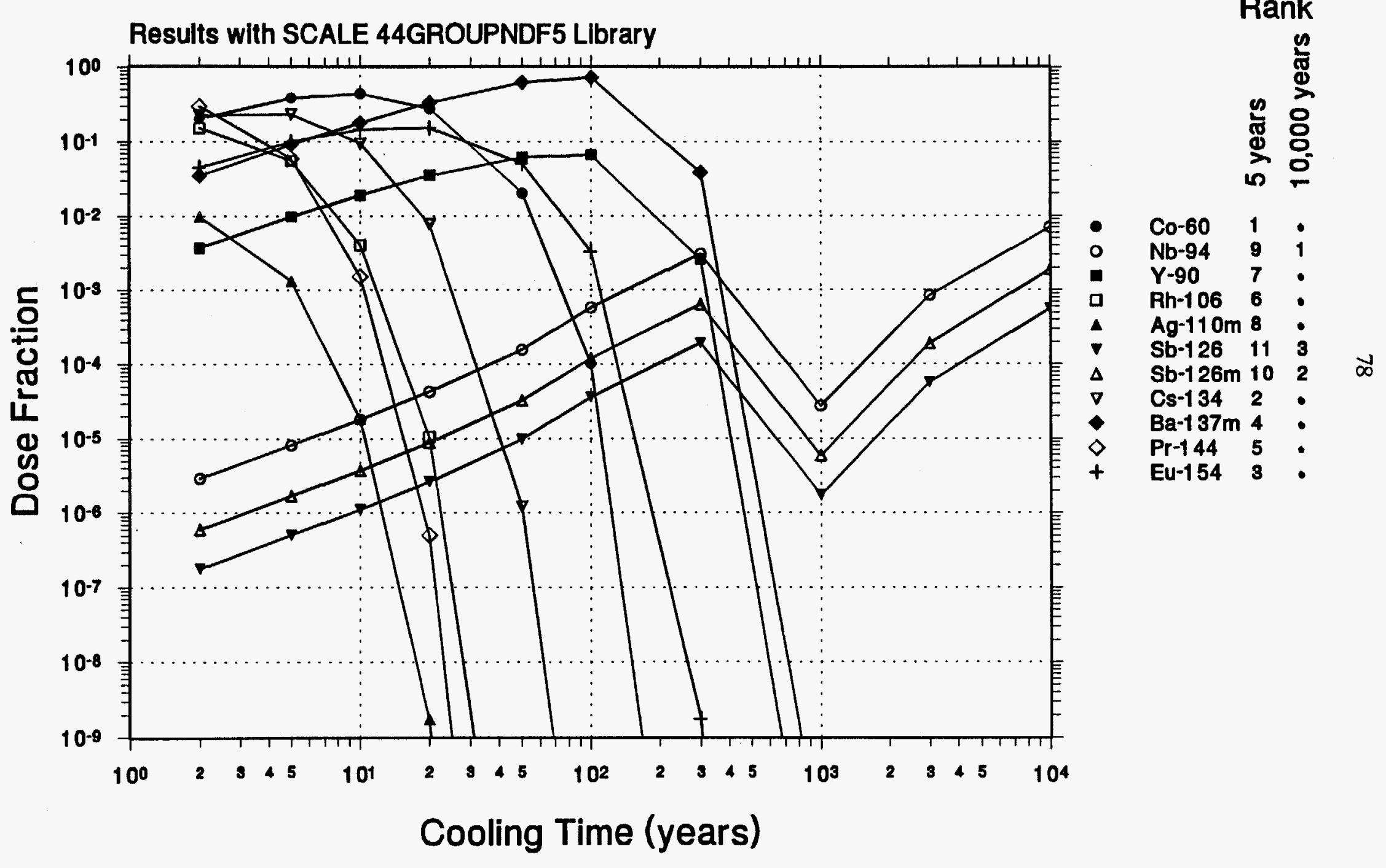




\section{Secondary Gamma Dose Fraction vs Cooling Time}

for VSC; $4.5 \mathrm{wt} \% \mathrm{U}-235,50 \mathrm{GWd} / \mathrm{t}$

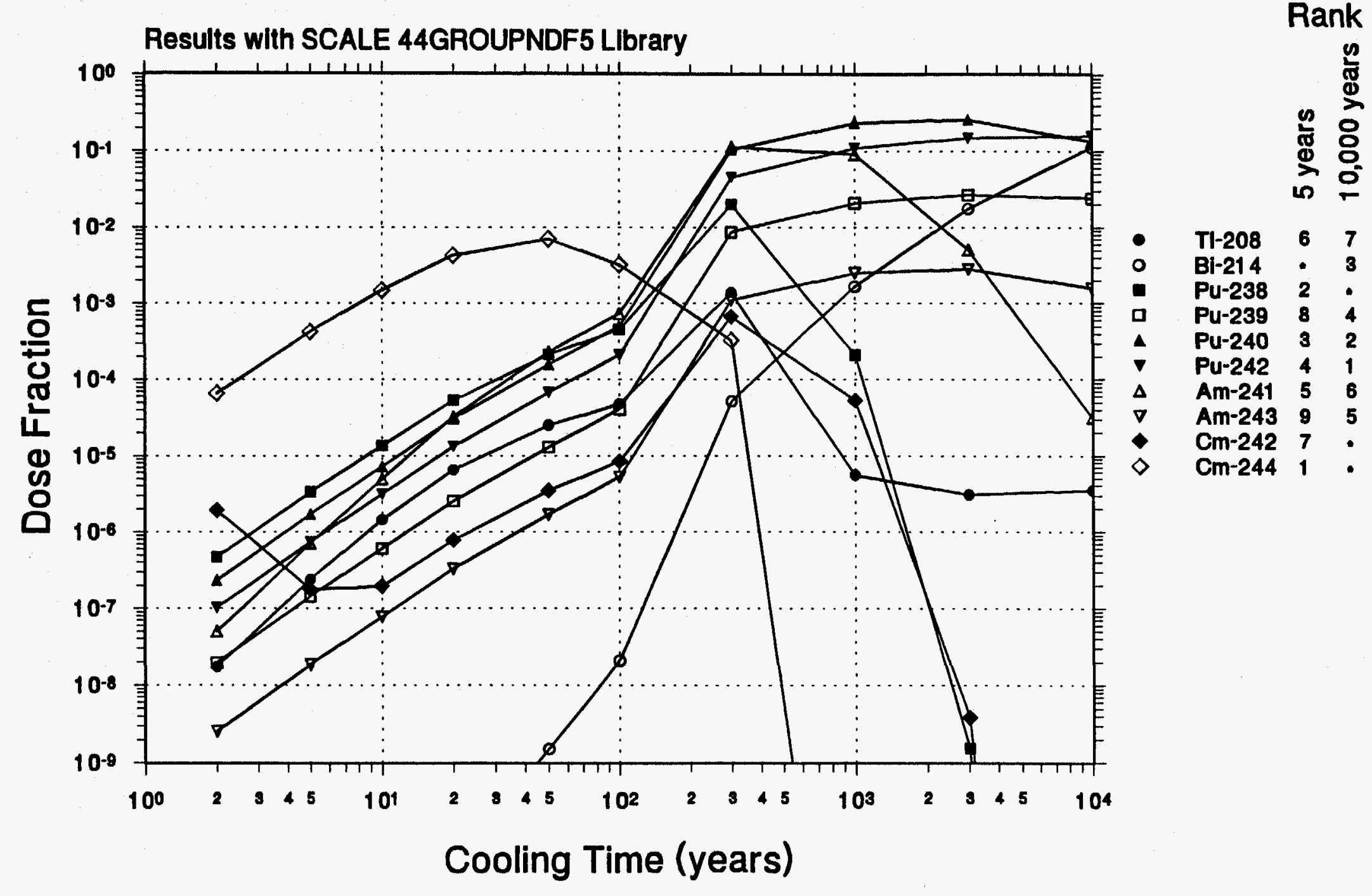





\section{APPENDIX C}

\section{CURIE LEVEL FRACTION PLOTS}

This section contains the complete listing of all plots generated for the curie ranking portion of this work. Plots are given for two burnup/enrichment combinations: $3.0 \mathrm{wt} \%, 20 \mathrm{GWd} / \mathrm{t}$, and $4.5 \mathrm{wt} \%, 50 \mathrm{GWd} / \mathrm{t}$. Three plots are given for each of these two cases corresponding to:

1. the total curies for ten decay periods from 2 to 10,000 years, followed by the fractional contributions from the actinides, light elements, and fission products;

2. the fraction of the total curie levels due to individual light elements and fission products; the legend gives the relative rankings for these isotopes at 5 and 10,000 years;

3. the fraction of the total curie levels due to individual actinides; the legend gives the relative rankings for these isotopes at 5 and 10,000 years. 


\section{Curies vs Cooling Time \\ $3.0 \mathrm{wt} \% \mathrm{U}-235,20 \mathrm{GWd} / \mathrm{t}$}

Results with SCALE 44GROUPNDF5

- Actinide Curle Fraction

- Light-Element Curle Fraction

- Fission-Product Curie Fraction

- Total Curies
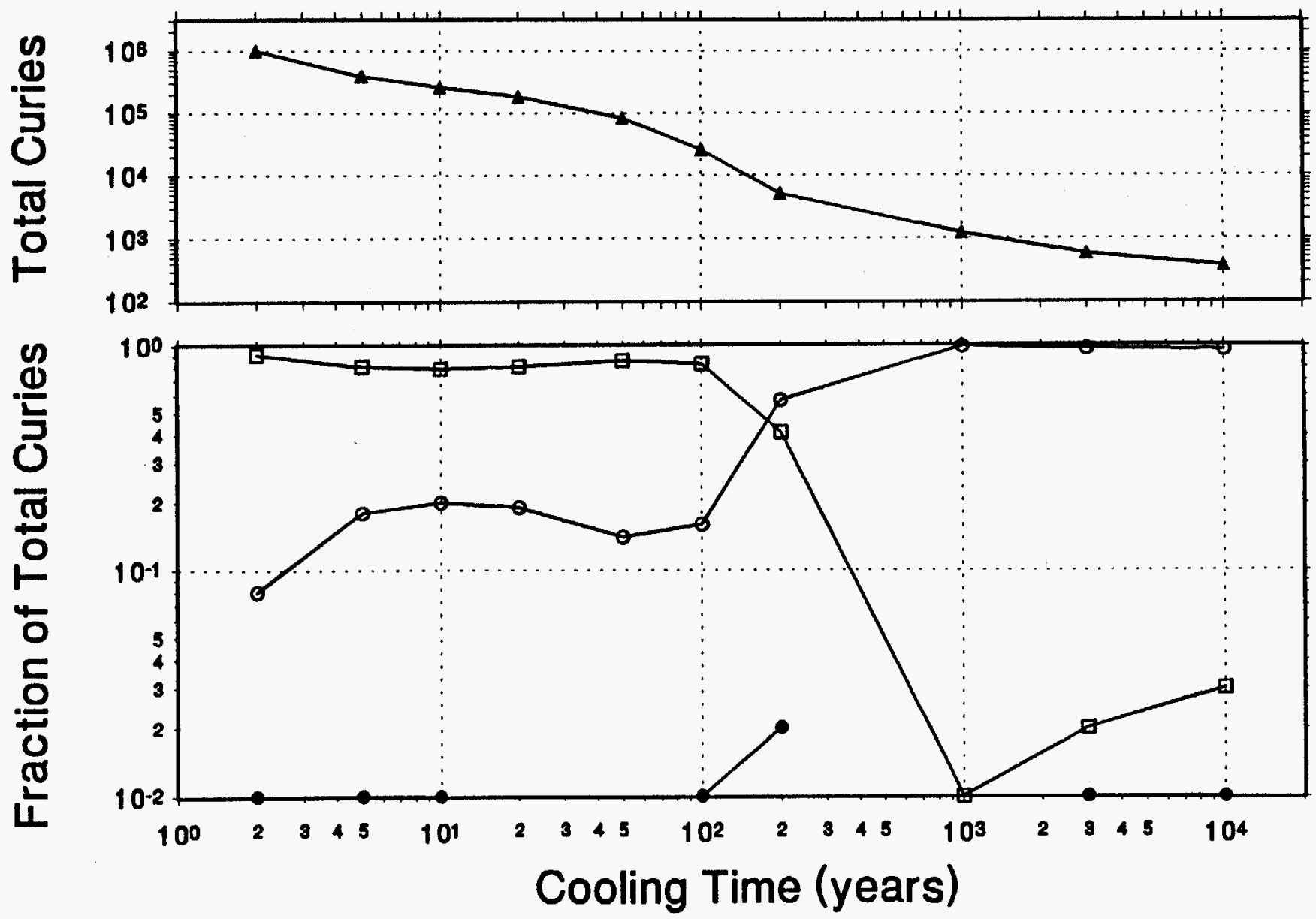
Fraction of Total Curie Levels for Actinides At Various Cooling Times; 3.0 wt $\%$ U-235, 20 GWd/t

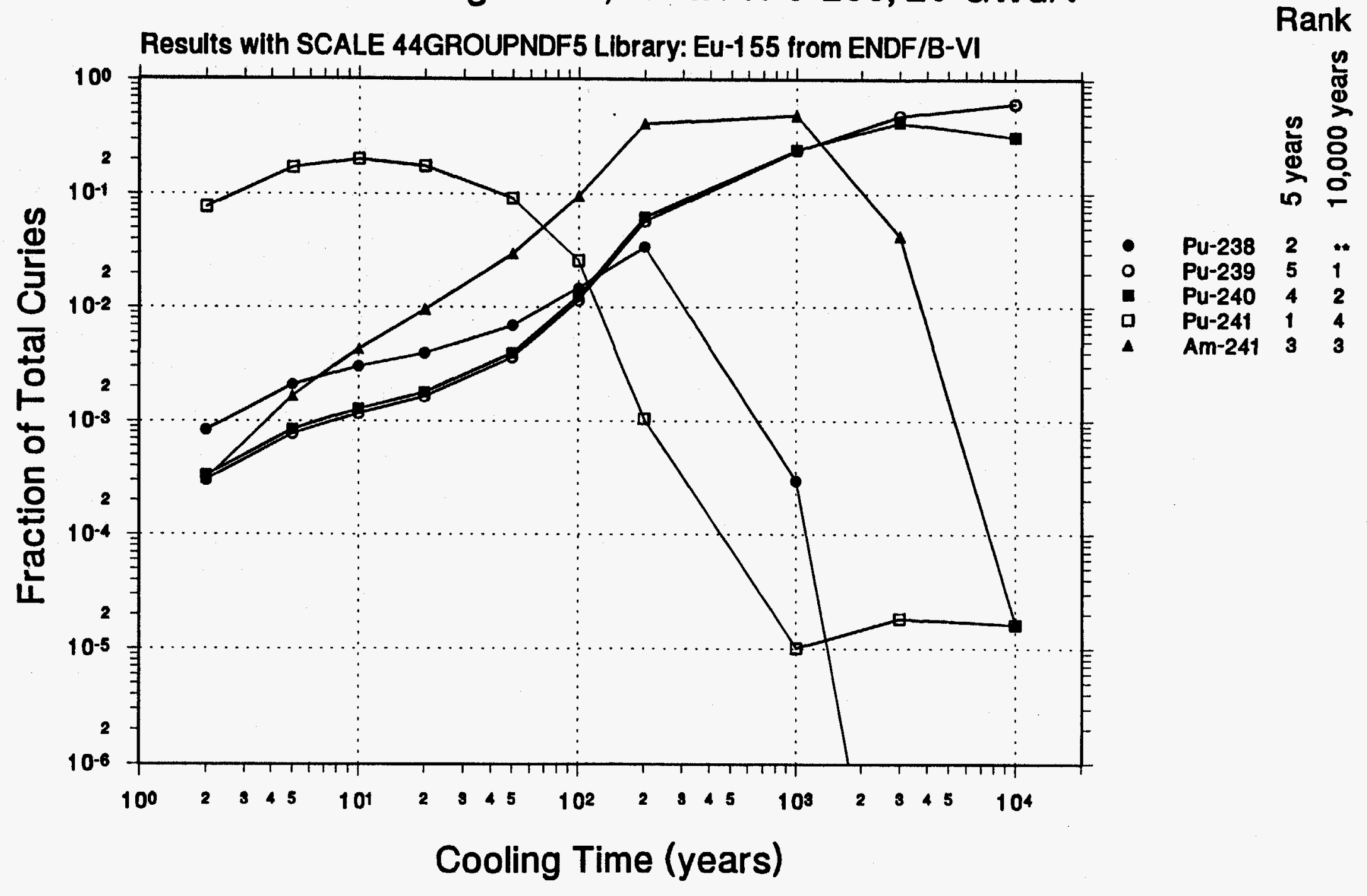


Fraction of Total Curie Levels for Light Elements and Fission Products

At Various Cooling Times; 3.0 wt \% U-235, $20 \mathrm{GWd} / \mathrm{t}$

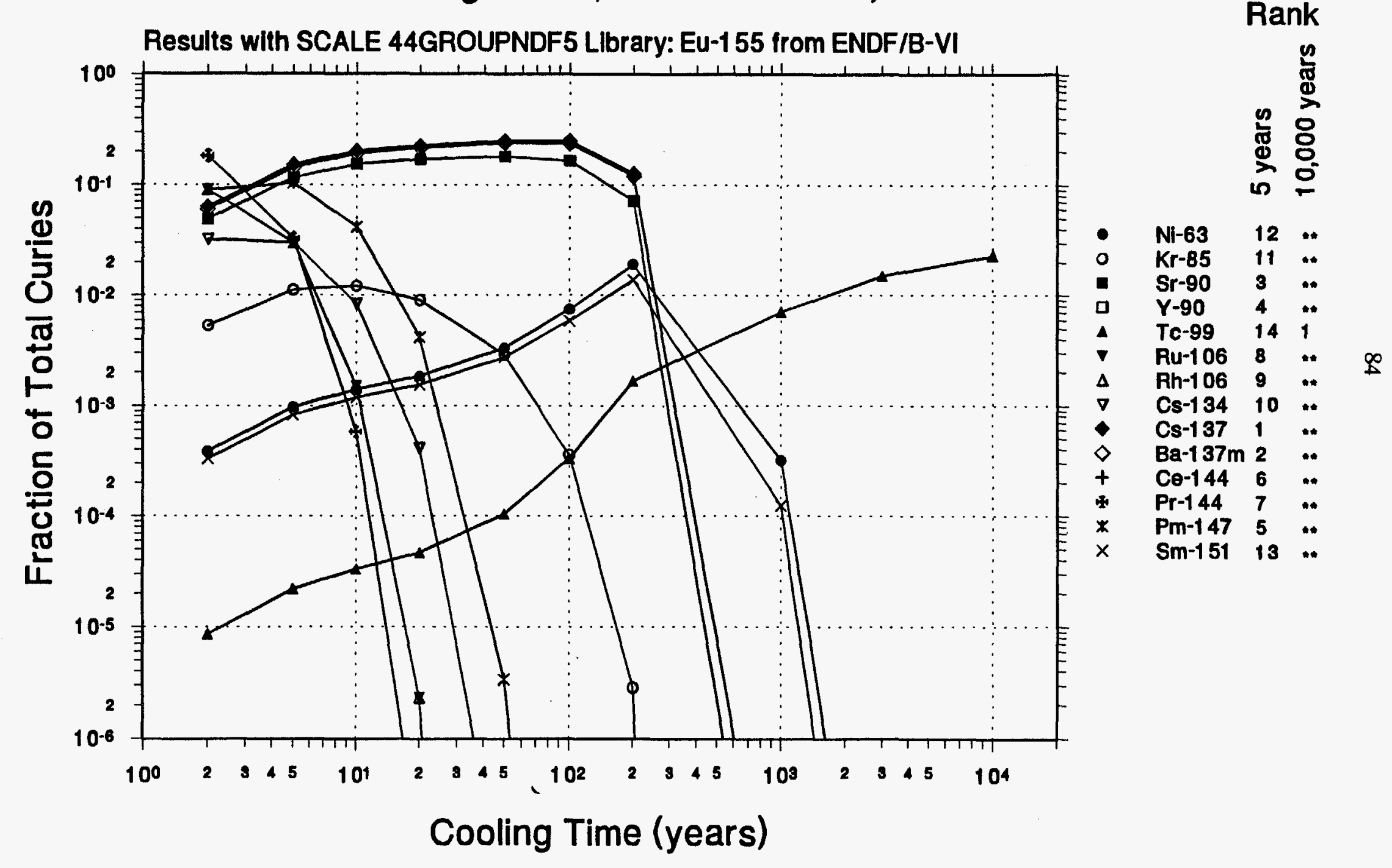




\section{Curies vs. Cooling Time}

$4.5 \mathrm{wt} \% \mathrm{U}-235,50 \mathrm{GWd} / \mathrm{t}$

Results with SCALE 44GROUPNDF5

- Actinide Curle Fraction

- Light-Element Curle Fraction

- Fission-Product Curie Fraction

- Total Curles
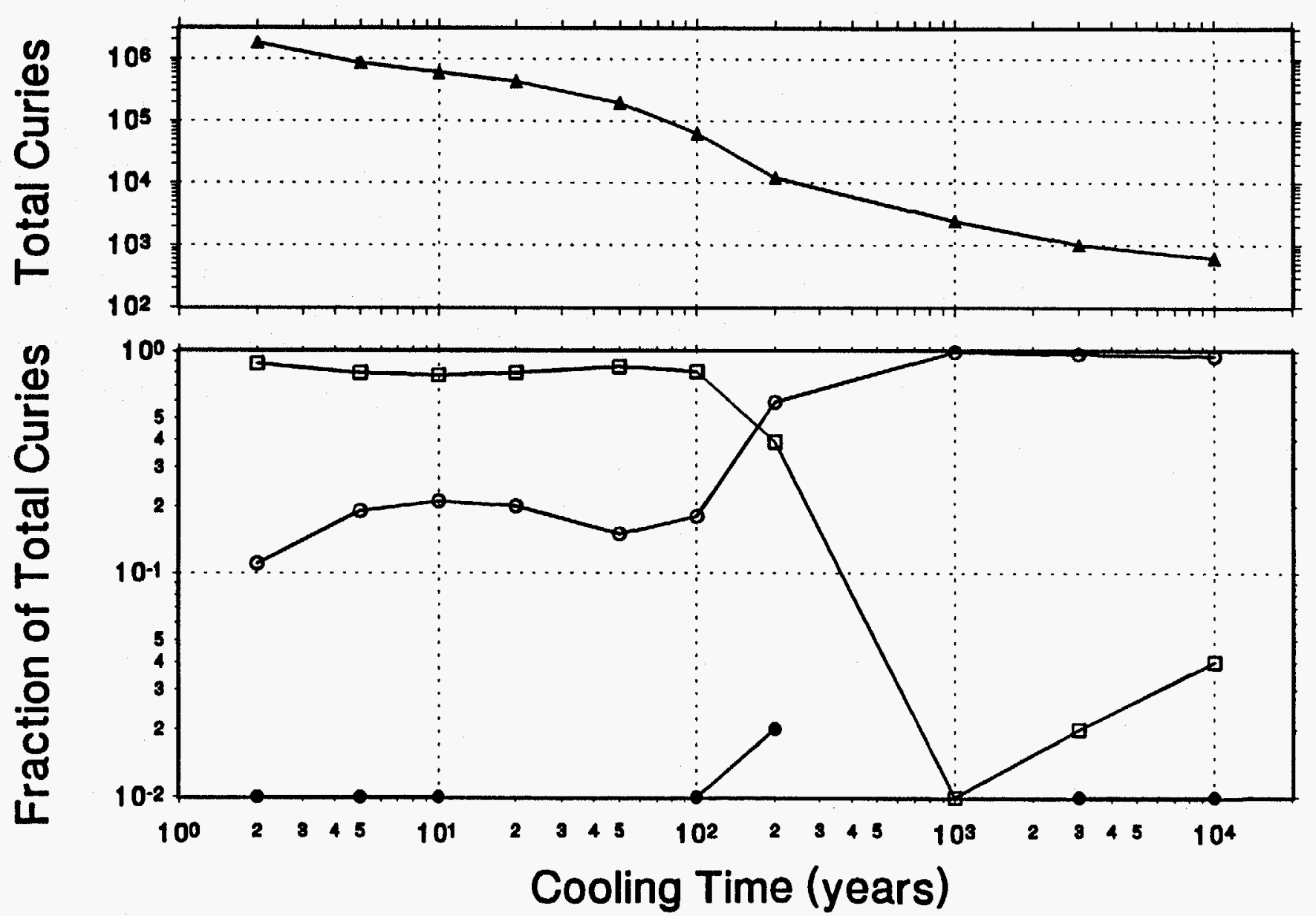
Fraction of Total Curie Levels for Actinides At Various Cooling Times; 4.5 wt \% U-235, 50 GWd/t

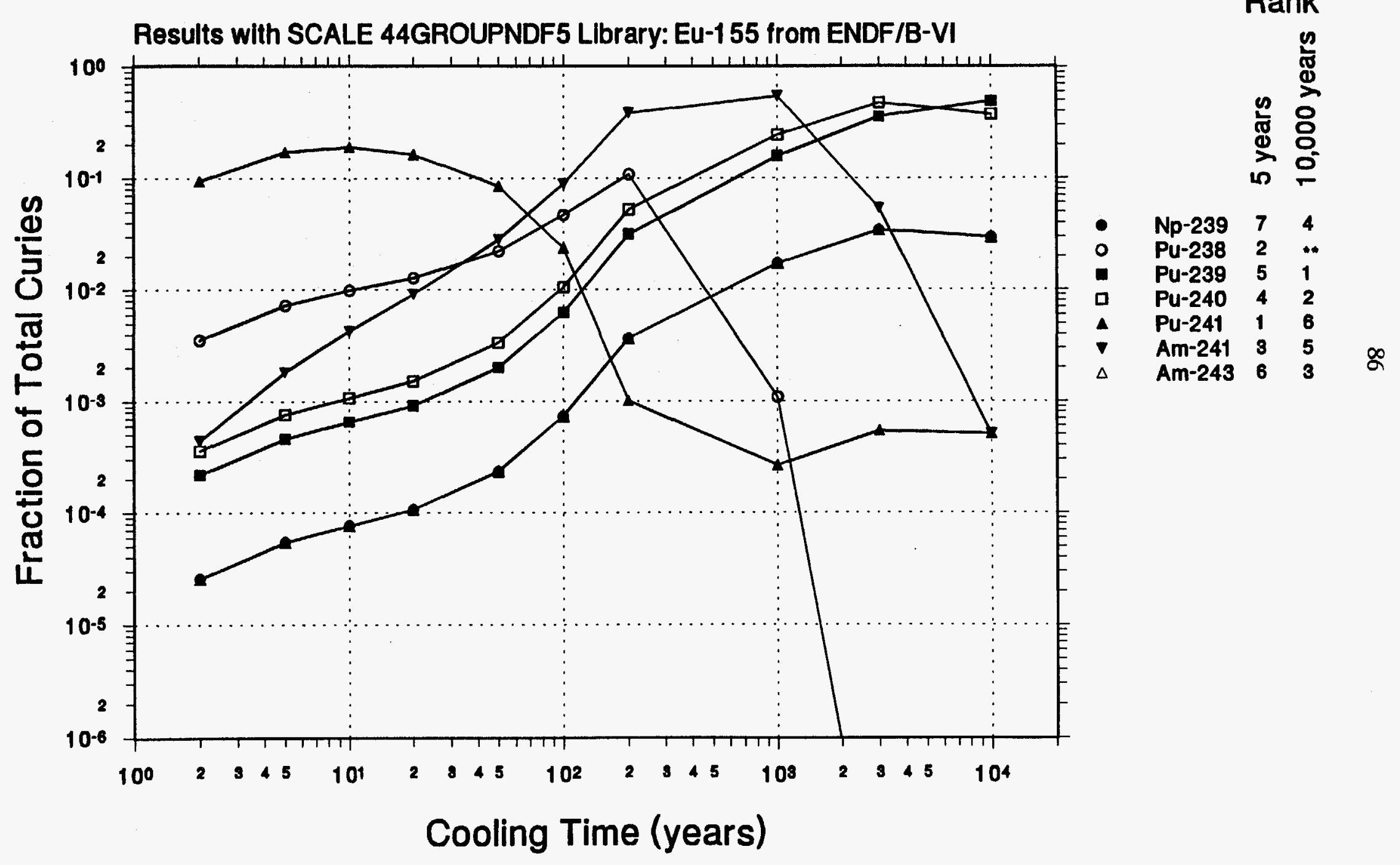




\section{Fraction of Total Curie Levels for Light Elements and Fission Products}

At Various Cooling Times; $4.5 \mathrm{wt} \% \mathrm{U}-235,50 \mathrm{GWd} / \mathrm{t}$

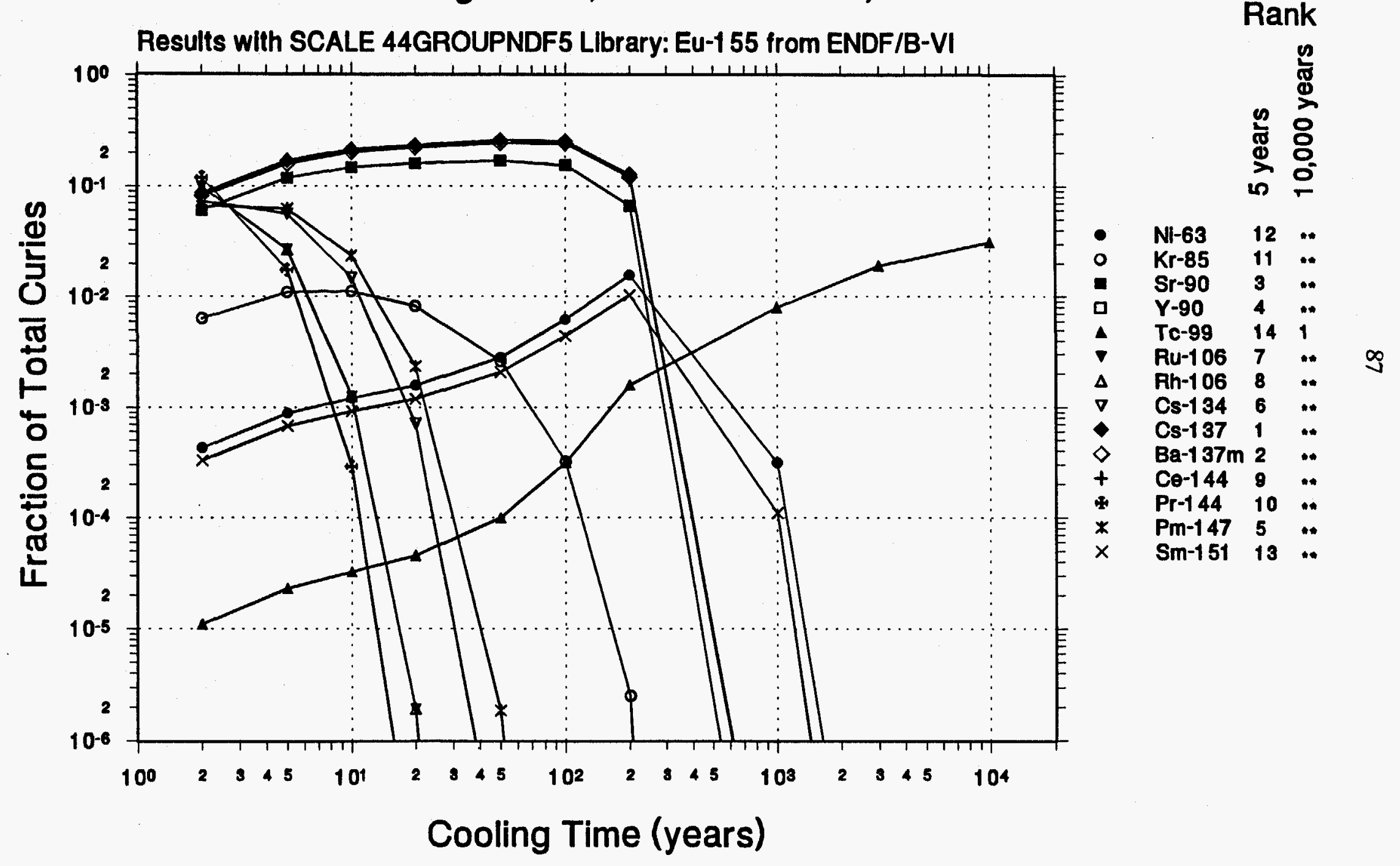





\section{APPENDIX D \\ DECAY HEAT FRACTION PLOTS}

This section contains the complete listing of all plots generated for the decay heat ranking portion of this work. Plots are given for two burnup/enrichment combinations: $3.0 \mathrm{wt} \%, 20 \mathrm{GWd} / \mathrm{t}$, and $4.5 \mathrm{wt} \%, 50 \mathrm{GWd} / \mathrm{t}$. Three plots are given for each of these two cases corresponding to:

1. the total decay heat in watts for ten decay periods from 2 to 10,000 years, followed by the fractional contributions from the actinides, light elements, and fission products;

2. the fraction of the total decay heat levels due to individual light elements and fission products; the legend gives the relative rankings for these isotopes at 5 and 10,000 years;

3. the fraction of the total decay heat levels due to individual actinides; the legend gives the relative rankings for these isotopes at 5 and 10,000 years. 
Watts vs Cooling Time

3.0 wt \% U-235, $20 \mathrm{GWd} / \mathrm{t}$

Results with SCALE 44GROUPNDF5

- Actinide Watt Fraction

- Light-Element Watt Fraction

a Fission-Product Watt Fraction

- Total Watis
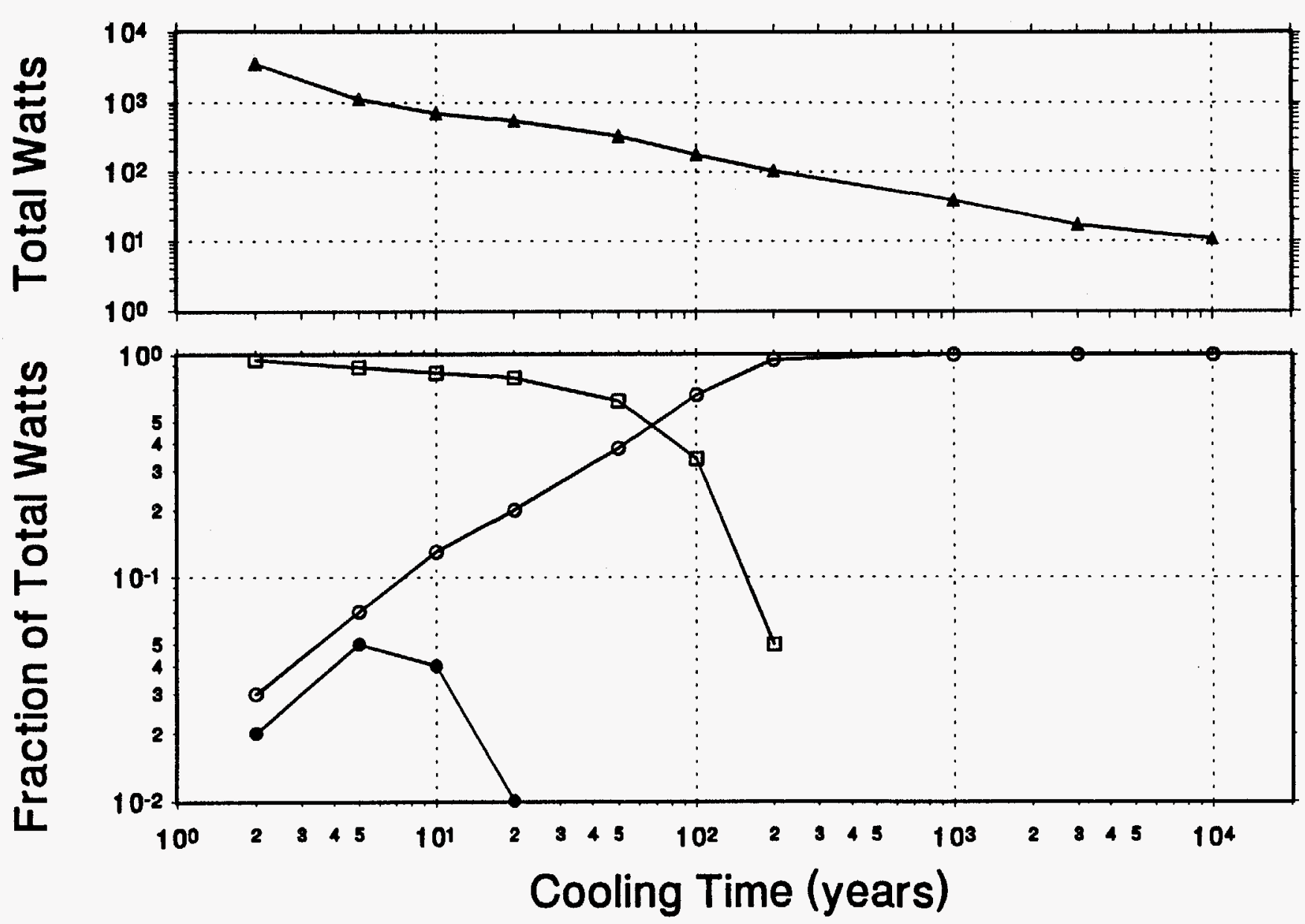


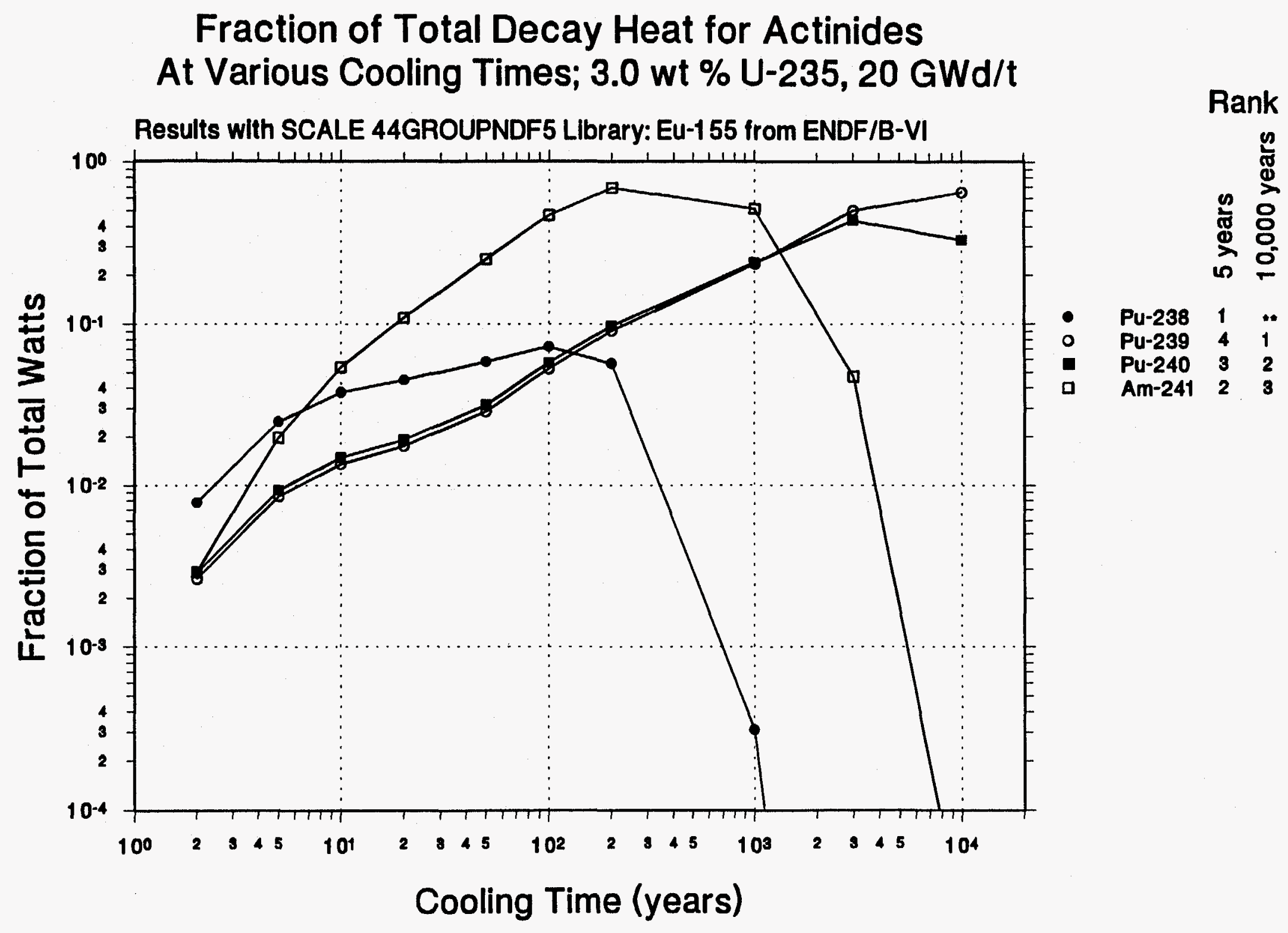




\section{Fraction of Total Decay Heat for Light Elements and Fission Products}

At Various Cooling Times; $3.0 \mathrm{wt} \% \mathrm{U}-235,20 \mathrm{GWd} / \mathrm{t}$

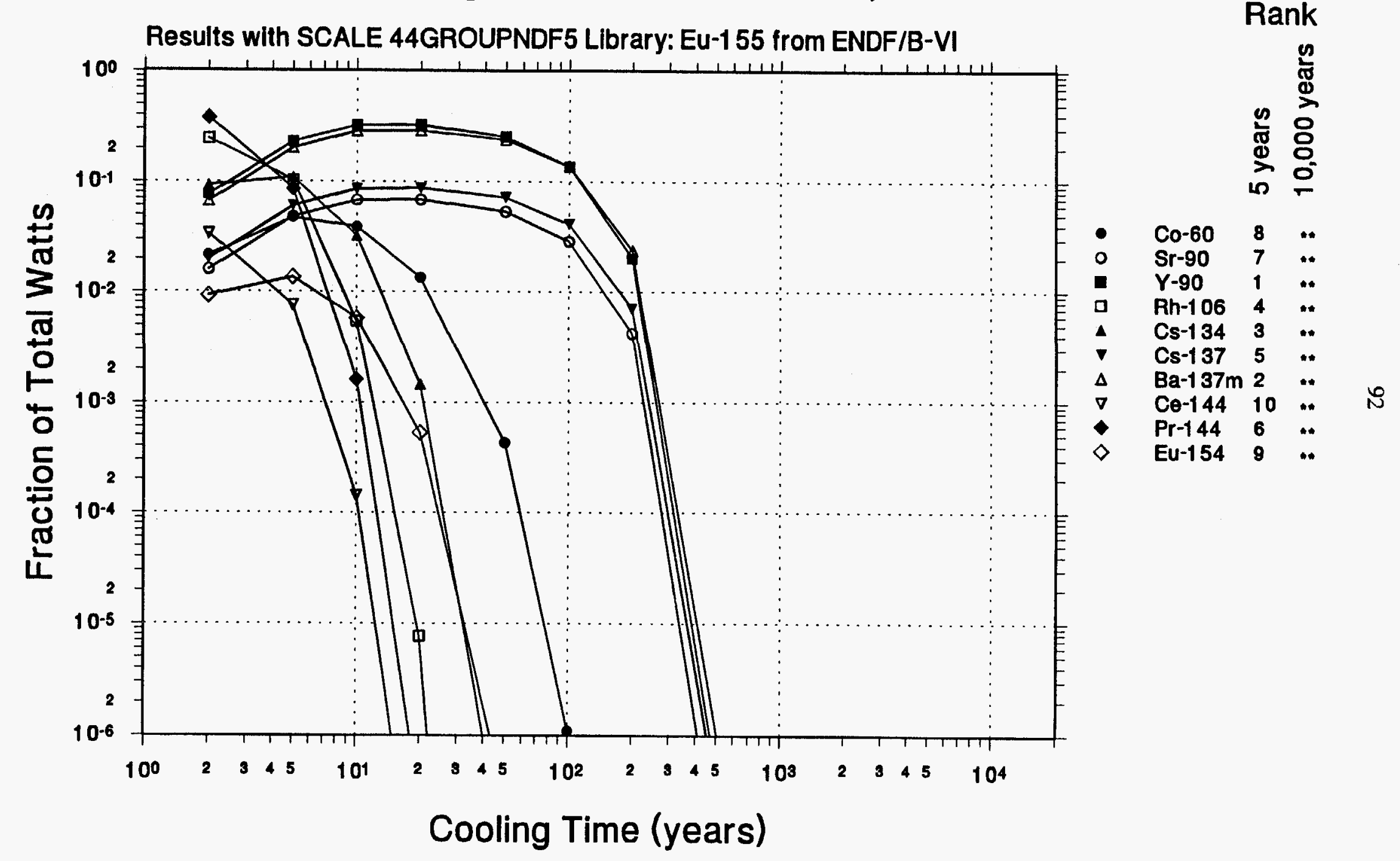




\section{Watts vs Cooling Time}

$4.5 \mathrm{wt} \% \mathrm{U}-235,50 \mathrm{GWd} / \mathrm{t}$

Results with SCALE 44GROUPNDF5

- Actinido Watt Fraction

- Light-Element Watt Fraction

a Fission-Product Watt Fraction

- Total Watts
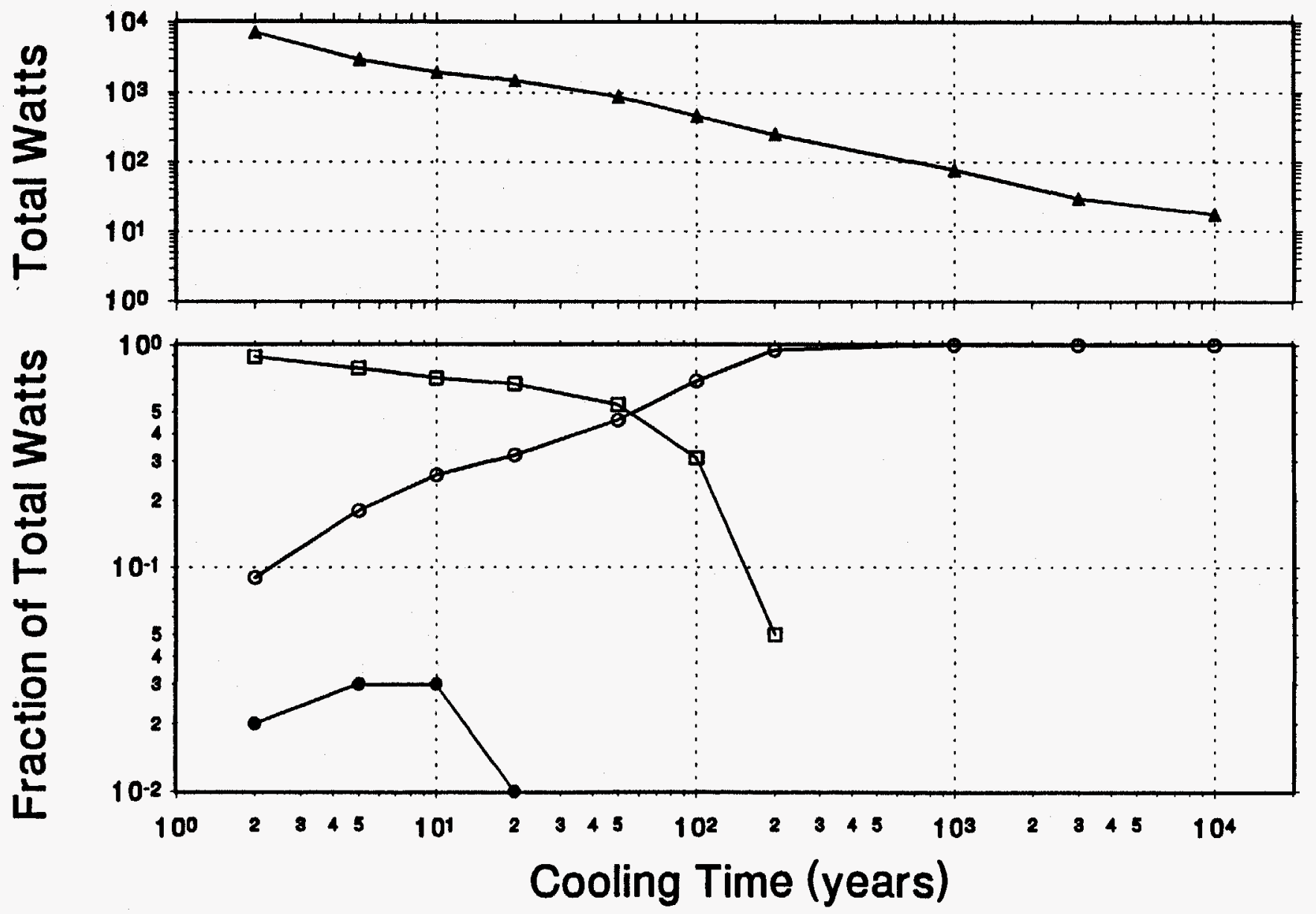
Fraction of Total Decay Heat for Actinides

At Various Cooling Times; 4.5 wt $\%$ U-235, $50 \mathrm{GWd} / \mathrm{t}$

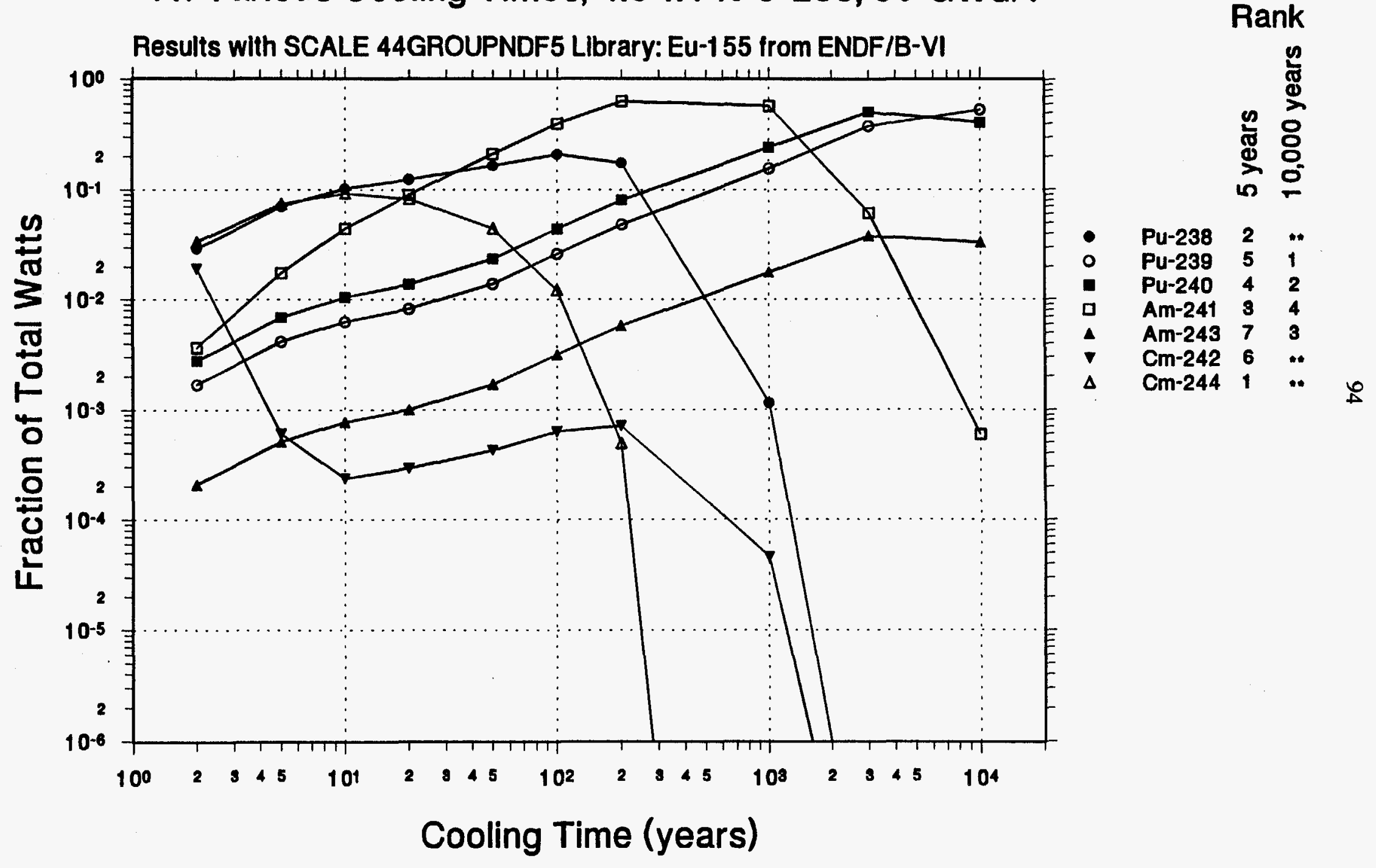


Fraction of Total Decay Heat for Light Elements and Fission Products At Various Cooling Times; $4.5 \mathrm{wt} \% \mathrm{U}-235,50 \mathrm{GWd} / \mathrm{t}$

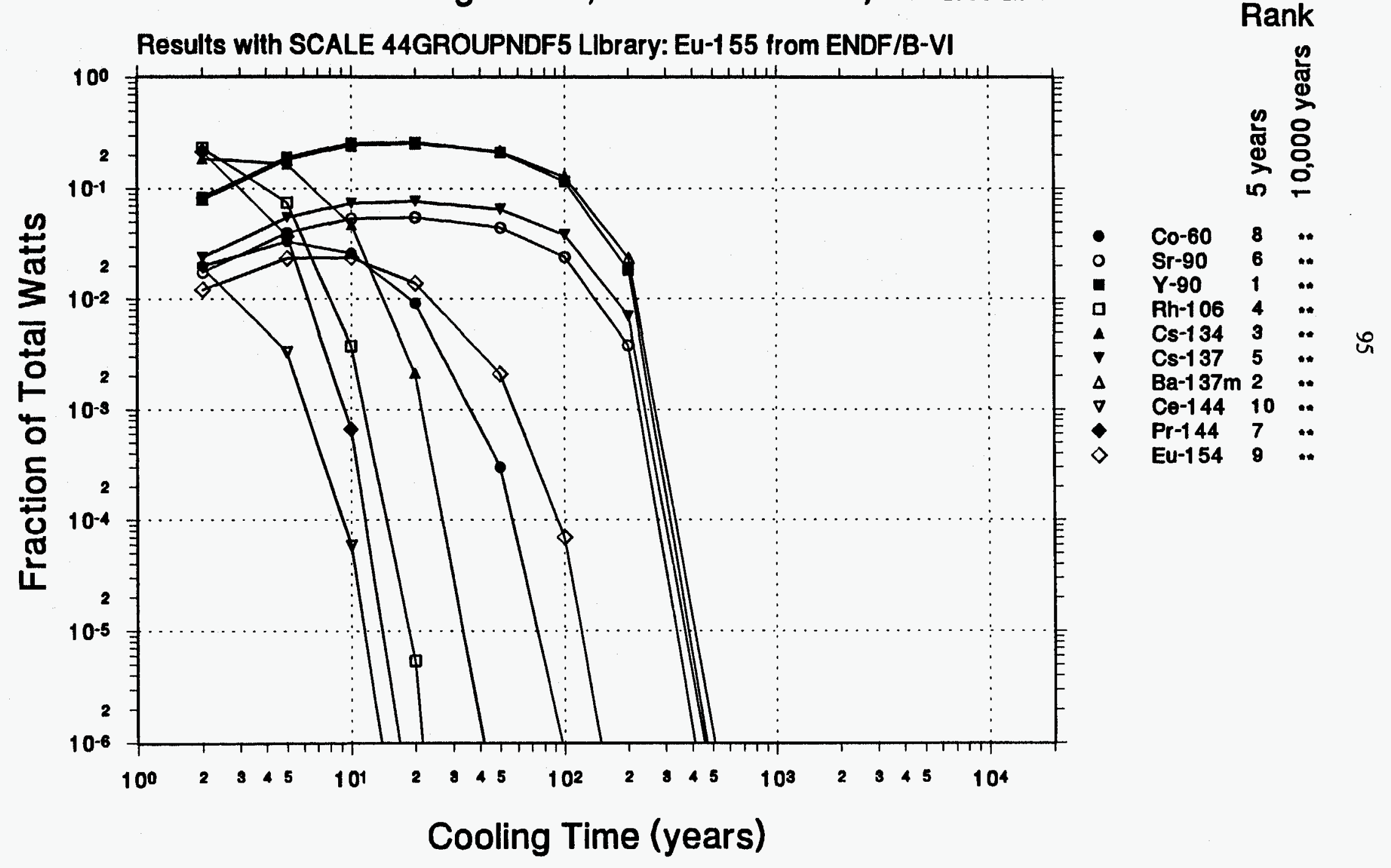


- 


\section{APPENDIX E \\ RADIOLOGICAL TOXICITY FRACTION PLOTS}

This section contains the complete set of plots generated for the radiological toxicity ranking portion of this work. Plots are given for two burnup/enrichment combinations: $3.0 \mathrm{wt} \%, 20 \mathrm{GWd} / \mathrm{t}$, and $4.5 \mathrm{wt} \%, 50 \mathrm{GWd} / \mathrm{t}$. All plots include decay times from 2 through 100,000 years. Seven plots are given for each of these two cases, corresponding to:

1. the fraction of potential committed effective dose equivalent from ingestion of individual actinides;

2. the fraction of potential committed effective dose equivalent from ingestion of individual fission products;

3. the fraction of potential committed effective dose equivalent from inhalation of individual actinides;

4. the fraction of potential committed effective dose equivalent from inhalation of individual fission products and ${ }^{60} \mathrm{Co}$;

5. the fractional contributions from the light-element, actinide, and fission-product groups to the potential committed effective dose equivalent from ingestion;

6. the fractional contributions from the light-element, actinide, and fission-product groups to the potential committed effective dose equivalent from inhalation; and

7. the fraction of activity neglected in computing the committed effective dose equivalent. 
Fraction of Potential Committed Effective Dose Equivalent for Actinides from Ingestion at Various Cooling Times; $3.0 \mathrm{wt} \% \mathrm{U}-235,20 \mathrm{GWd} / \mathrm{t}$

Results with SCALE 44GROUPNDF5 Library; Eu-1 55 from ENDF/B-VI

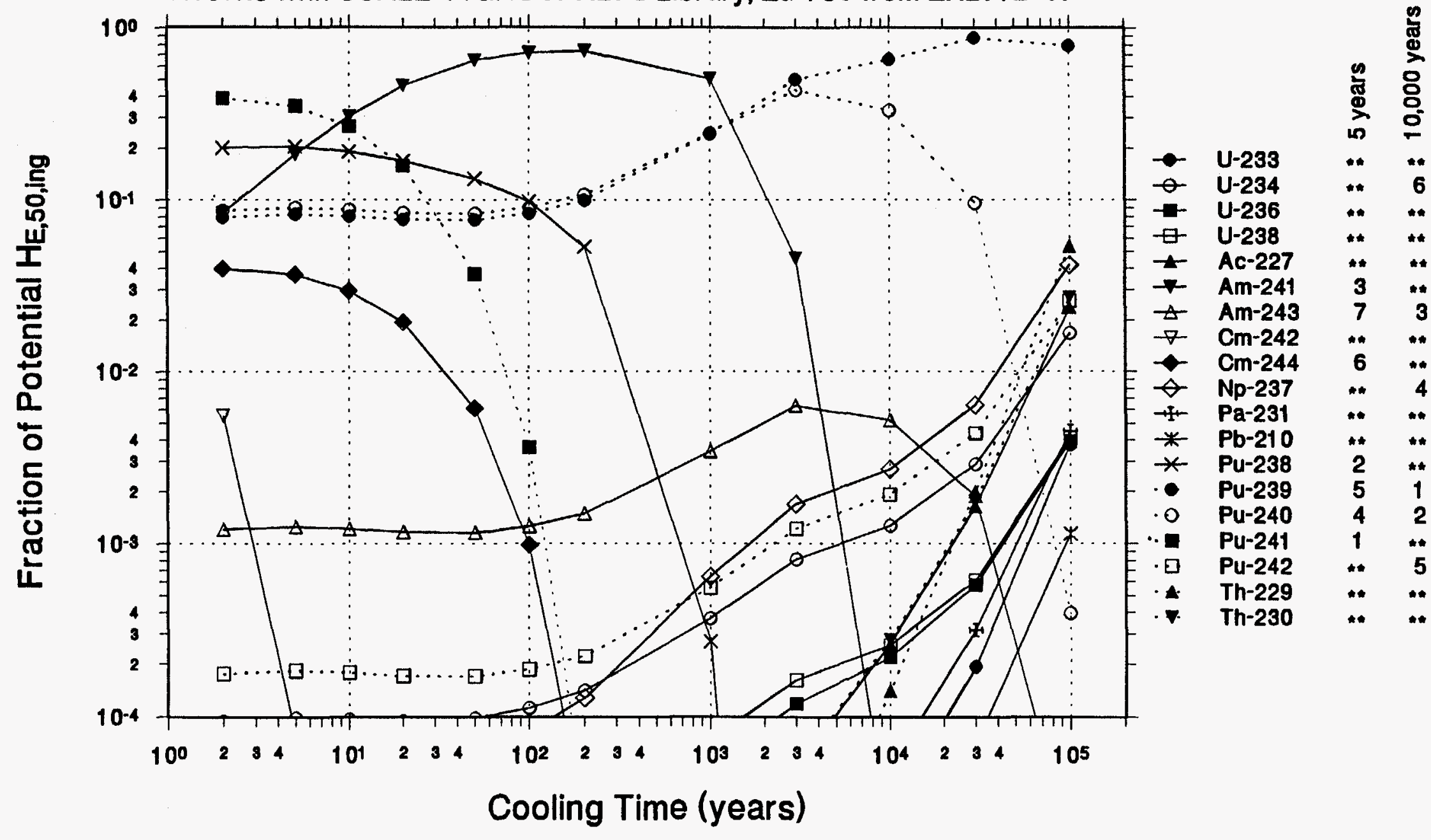


Fraction of Potential Committed Effective Dose Equivalent for Fission Products from Ingestion at Various Cooling Times; $3.0 \mathrm{wt} \% \mathrm{U}-235,20 \mathrm{GWd} / \mathrm{t}$

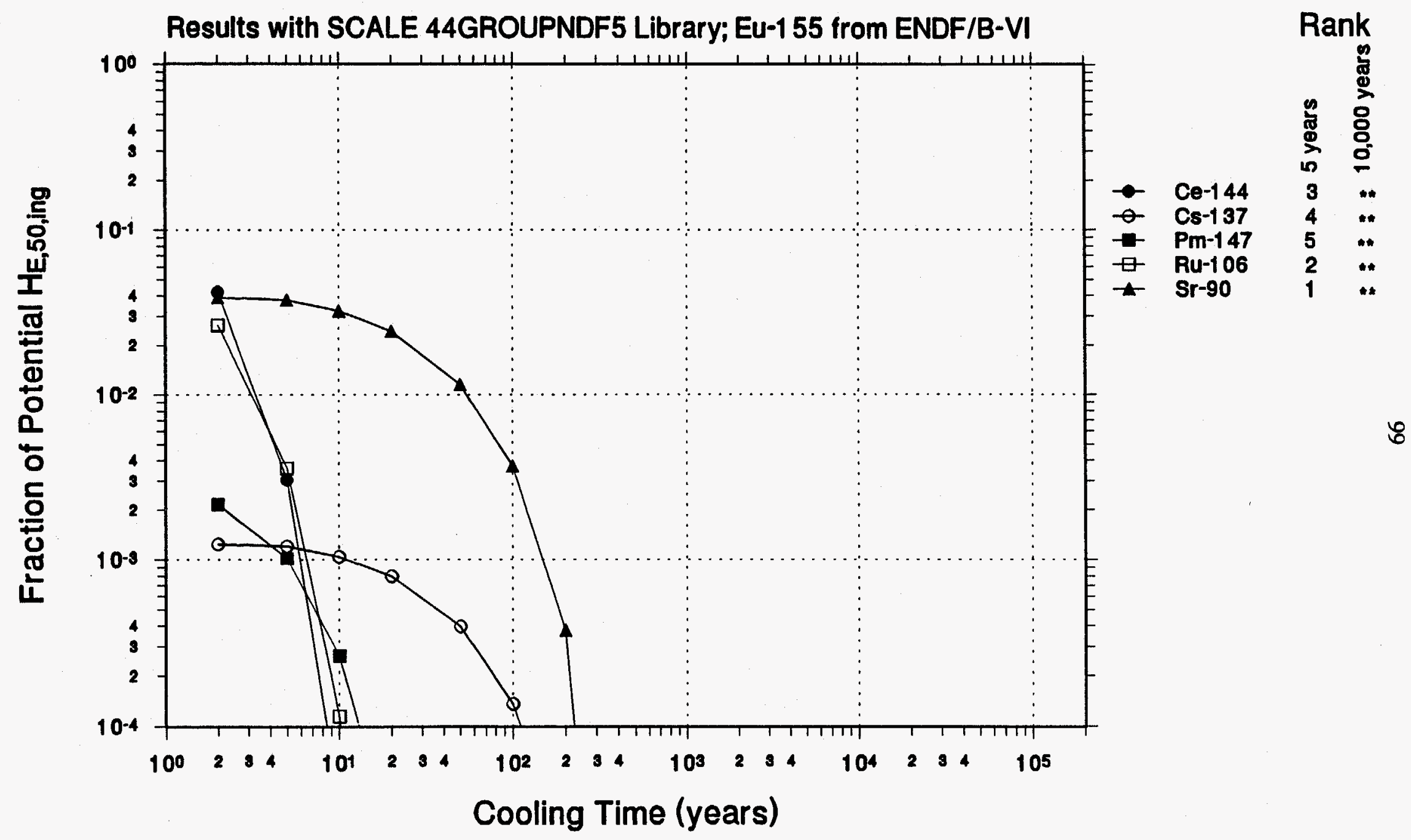


Fraction of Potential Committed Effective Dose Equivalent for Actinides from Inhalation at Various Cooling Times; $3.0 \mathrm{wt} \% \mathrm{U}-235,20 \mathrm{GWd} / \mathrm{t}$

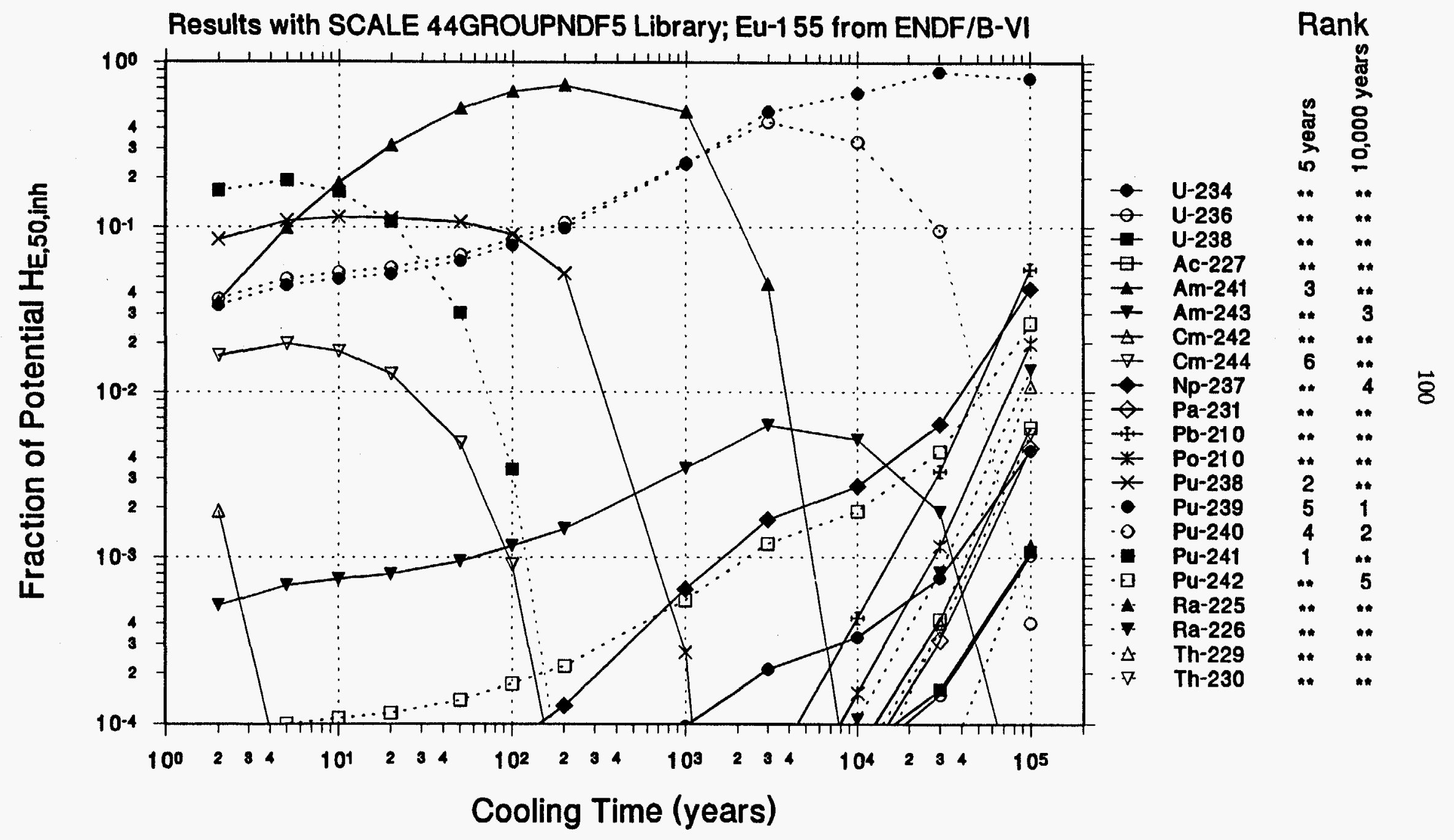


Fraction of Potential Committed Effective Dose Equivalent for Fission Products and Co-60 from Inhalation; $3.0 \mathrm{wt} \% \mathrm{U}-235,20 \mathrm{GWd} / \mathrm{t}$

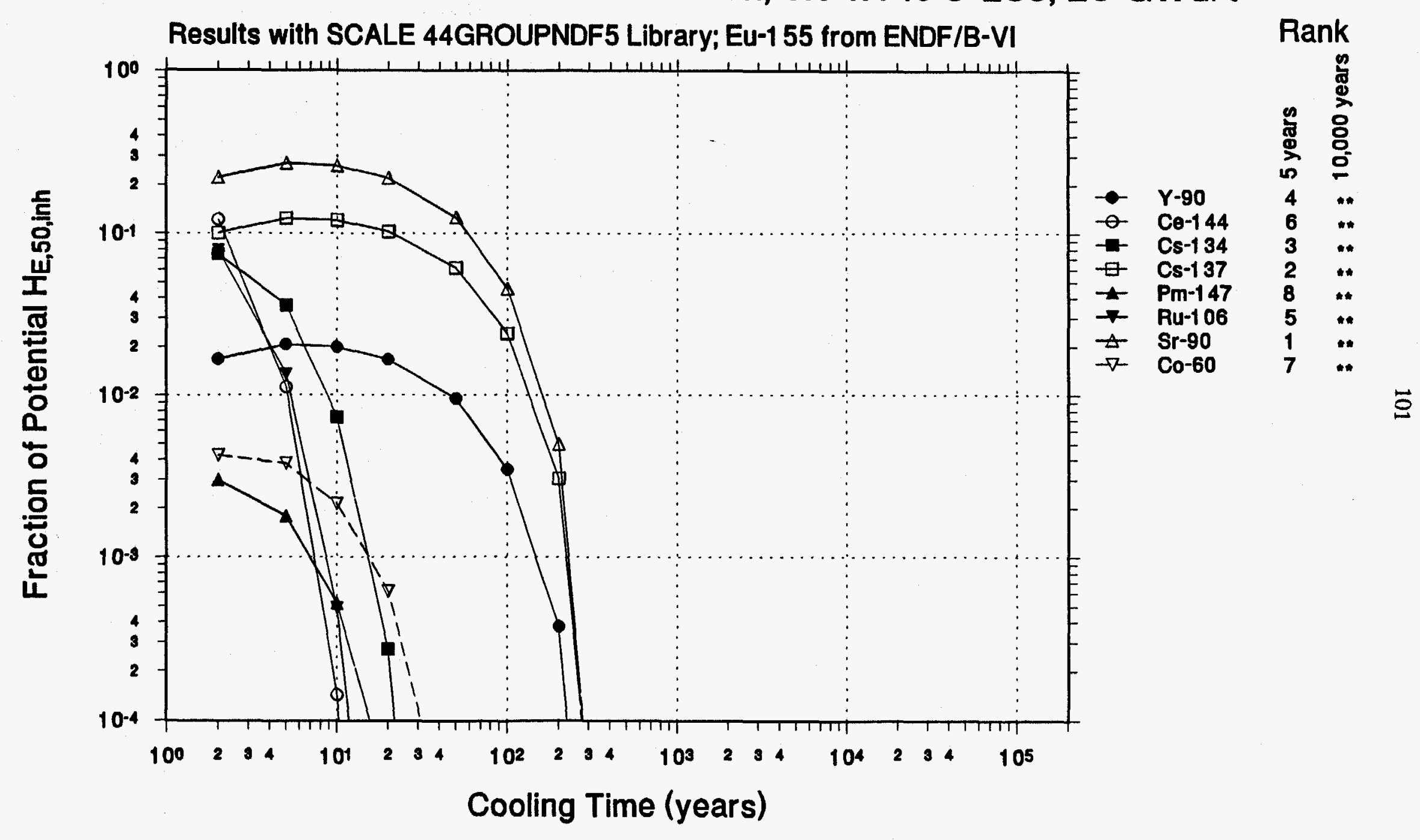


Fraction of Potential Committed Effective Dose Equivalent from Ingestion at Various Cooling Times; $3.0 \mathrm{wt} \% \mathrm{U}-235,20 \mathrm{GWd} / \mathrm{t}$

Results with SCALE 44GROUPNDF5 Library; Eu-1 55 from ENDF/B-VI

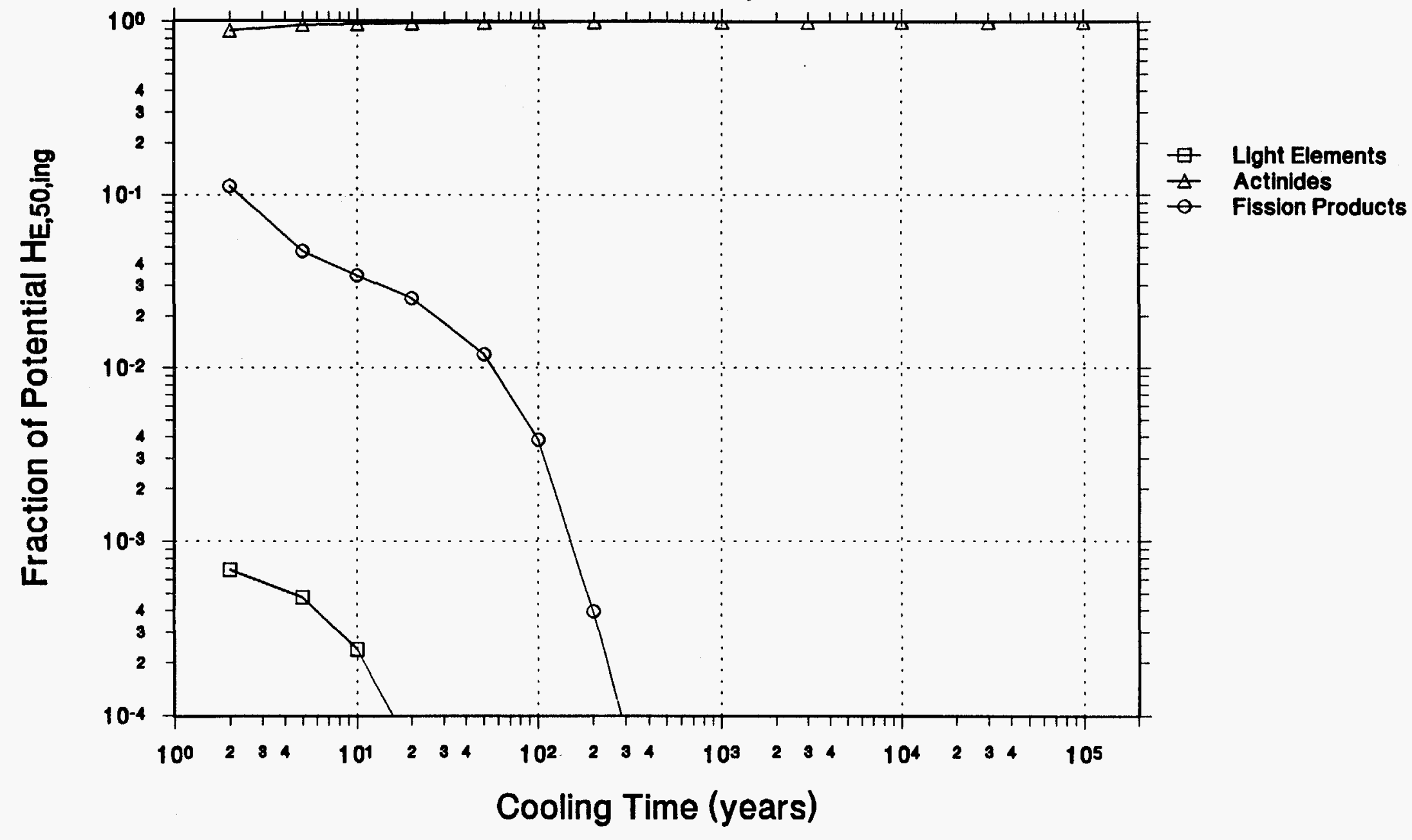


Fraction of Potential Committed Effective Dose Equivalent from Inhalation at Various Cooling Times; 3.0 wt \% U-235, $20 \mathrm{GWd} / \mathrm{t}$

Results with SCALE 44GROUPNDF5 Library; Eu-1 55 from ENDF/B-VI

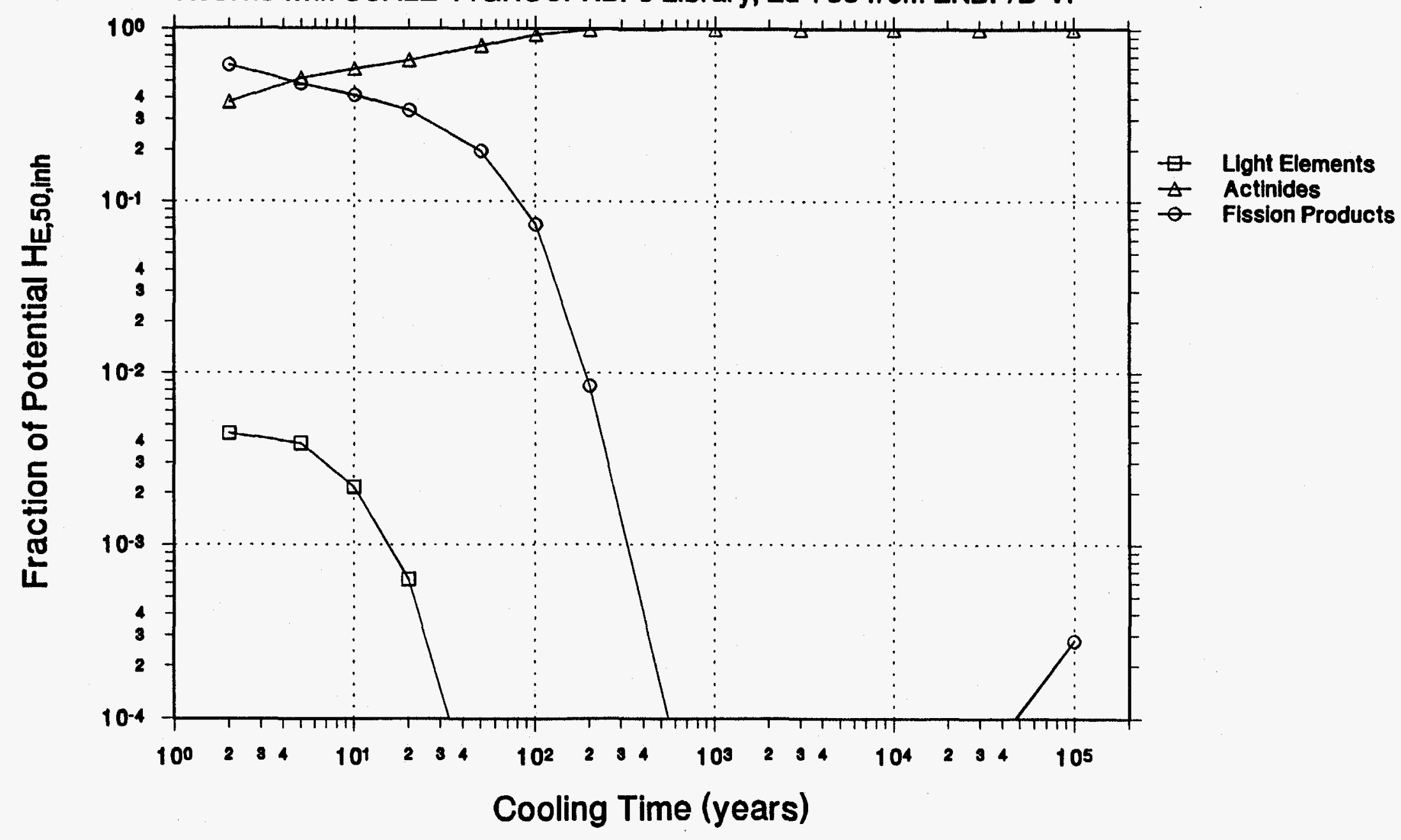


Fraction of Activity Neglected in Computing Committed Effective Dose Equivalent at Various Cooling Times; 3.0 wt \% U-235, $20 \mathrm{GWd} / \mathrm{t}$

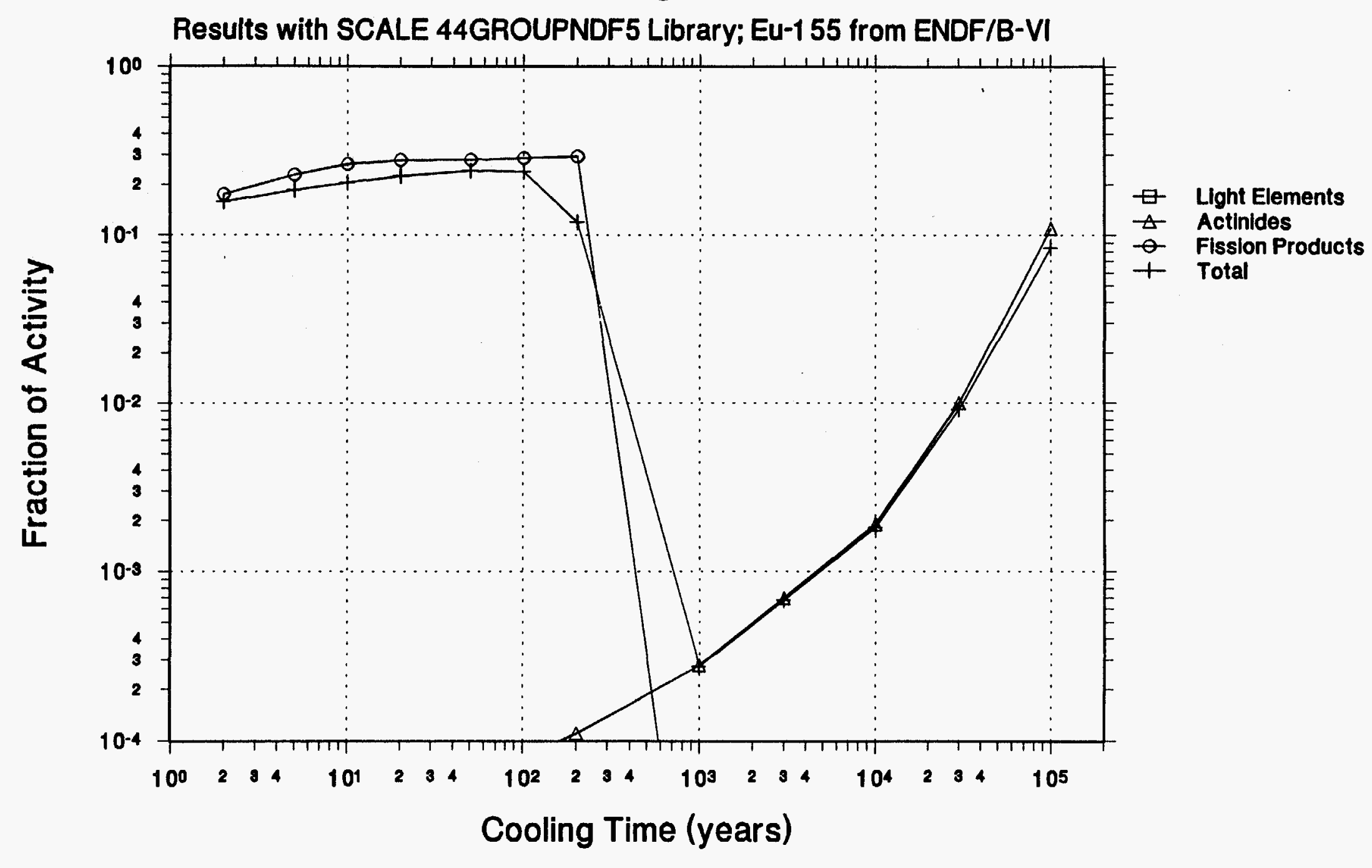


Fraction of Potential Committed Effective Dose Equivalent for Actinides from Ingestion at Various Cooling Times; $4.5 \mathrm{wt} \% \mathrm{U}-235,50 \mathrm{GWd} / \mathrm{t}$

Results with SCALE 44GROUPNDF5 Library; Eu-155 from ENDF/B-VI

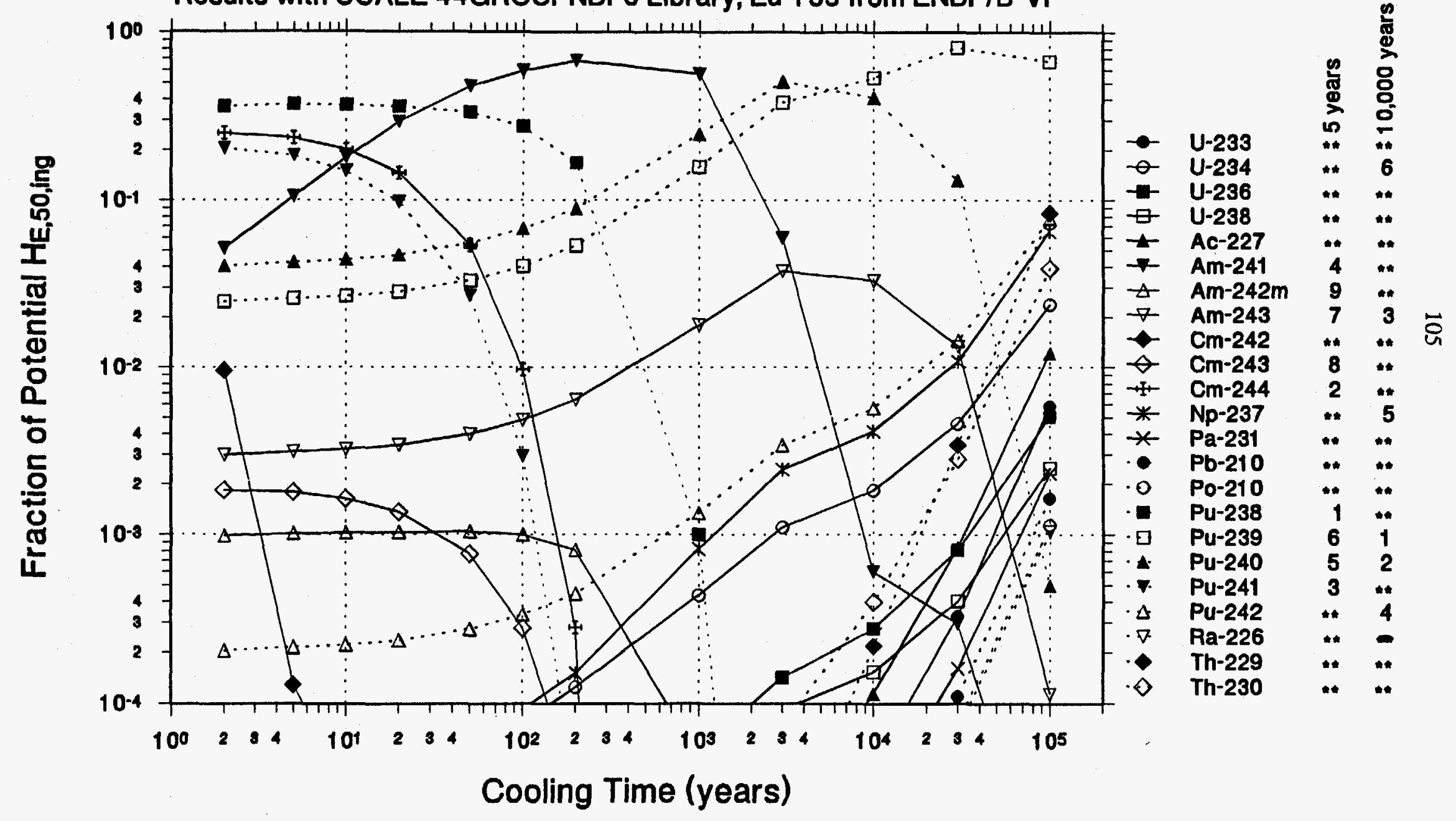


Fraction of Potential Committed Effective Dose Equivalent for Fission Products from Ingestion at Various Cooling Times; 4.5 wt \% U-235, 50 GWd/t

Results with SCALE 44GROUPNDF5 Library; Eu-1 55 from ENDF/B-VI

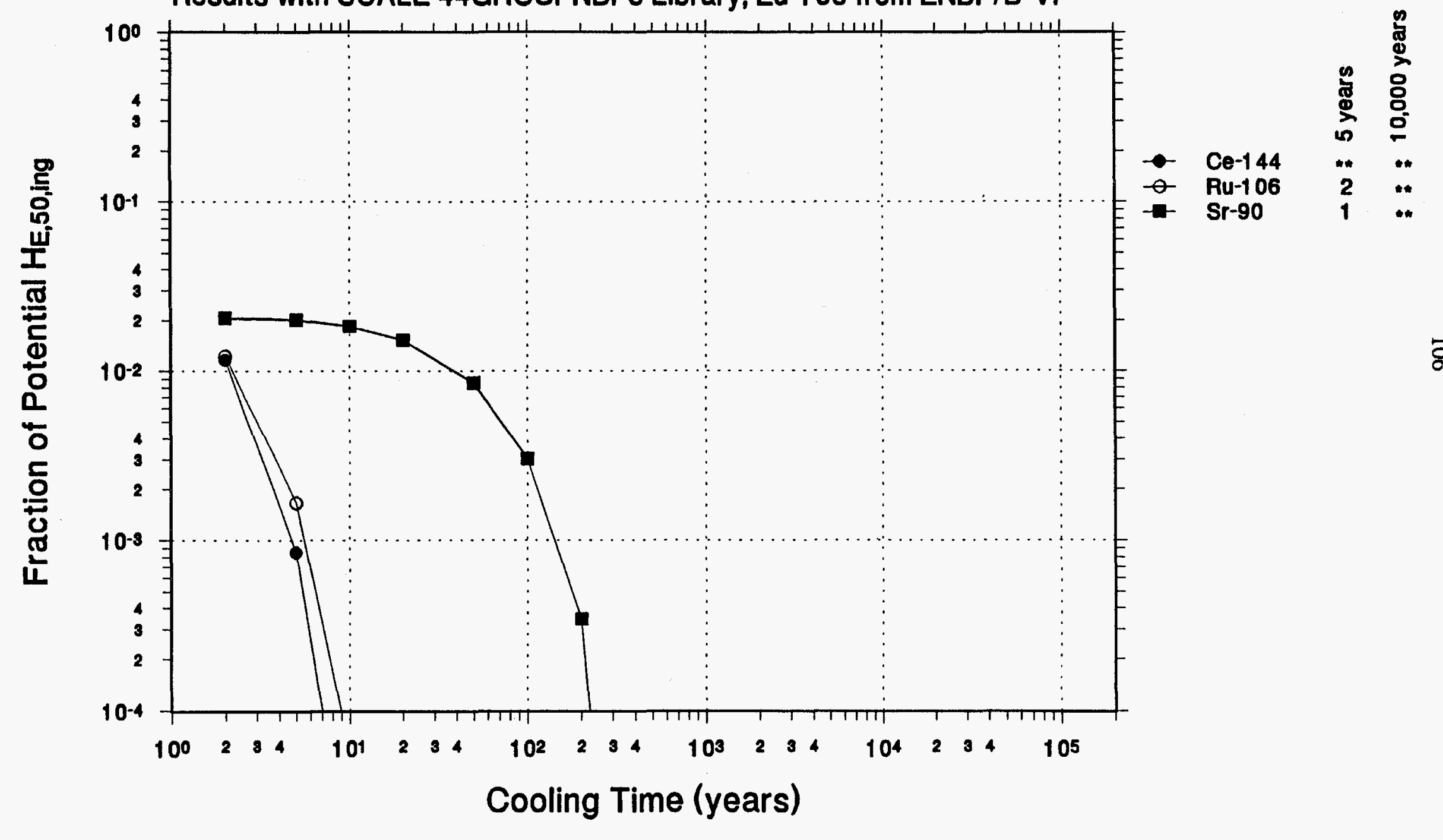


Fraction of Potential Committed Effective Dose Equivalent for Actinides from Inhalation at Various Cooling Times; $4.5 \mathrm{wt} \% \mathrm{U}-235,50 \mathrm{GWd} / \mathrm{t}$

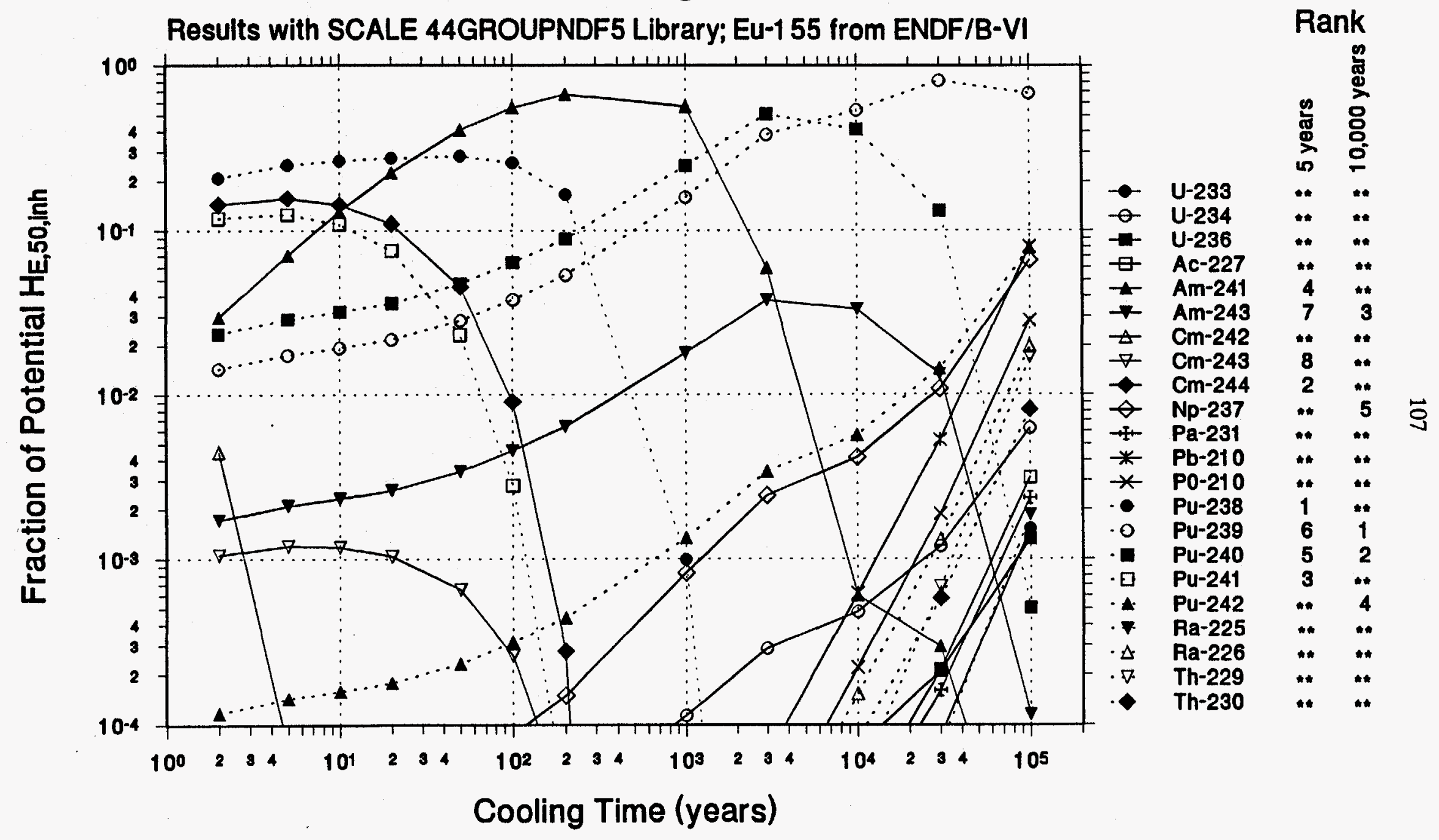


Fraction of Potential Committed Effective Dose Equivalent for Fission Products and Co-60 from Inhalation; $4.5 \mathrm{wt} \% \mathrm{U}-235,50 \mathrm{GWd} / \mathrm{t}$

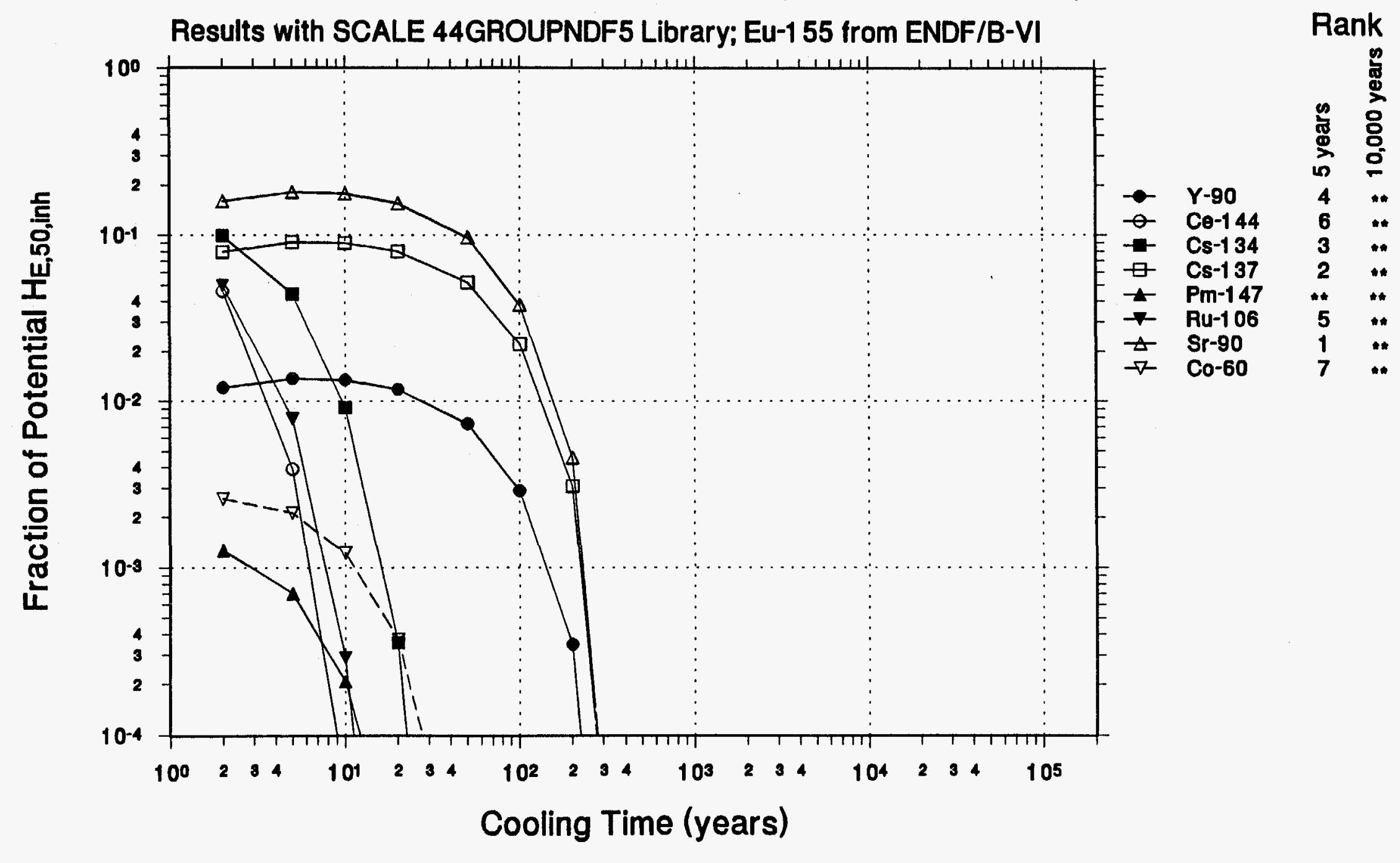


Fraction of Potential Committed Effective Dose Equivalent from Ingestion at Various Cooling Times; $4.5 \mathrm{wt} \% \mathrm{U}-235,50 \mathrm{GWd} / \mathrm{t}$

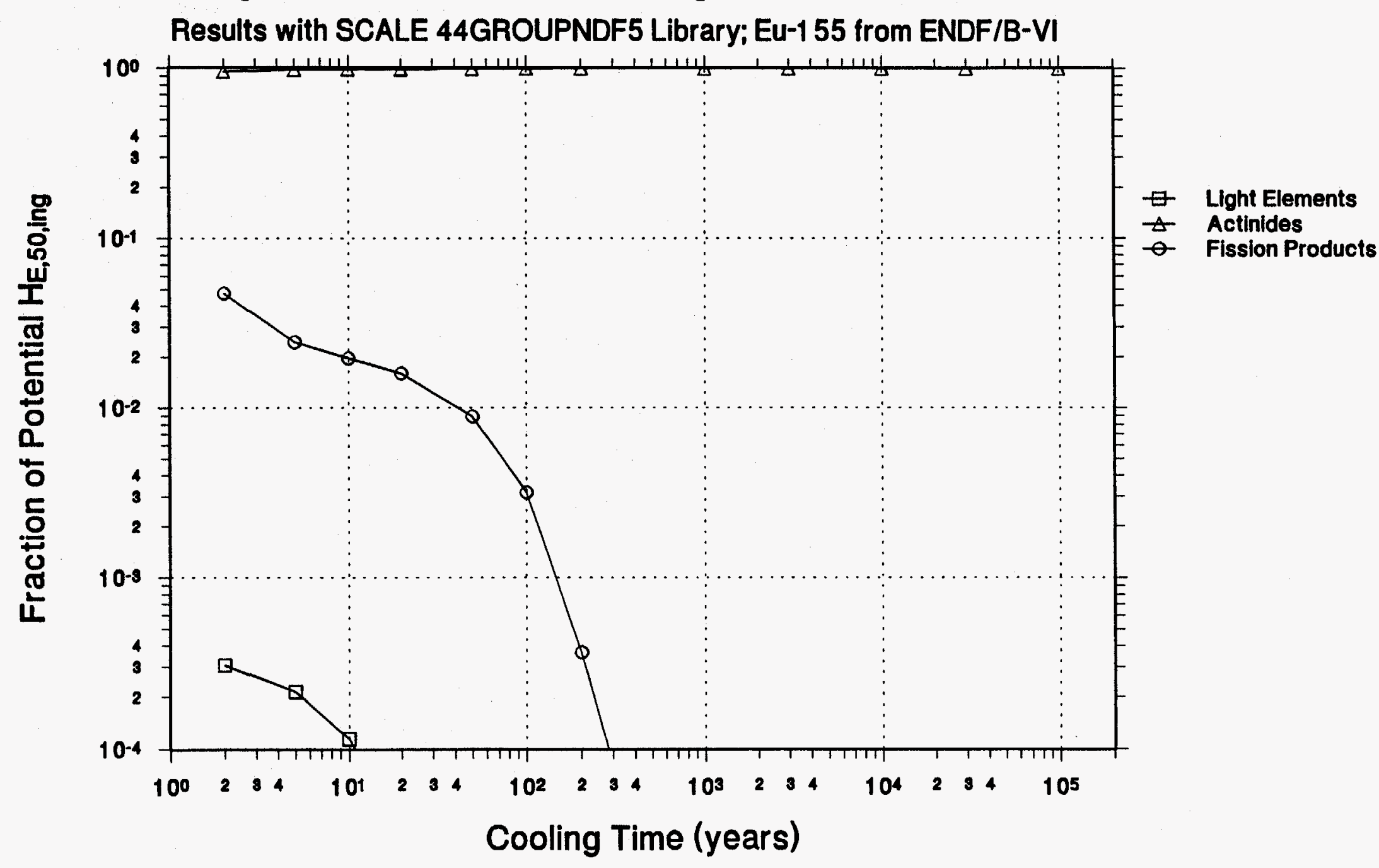


Fraction of Potential Committed Effective Dose Equivalent from Inhalation at Various Cooling Times; 4.5 wt \% U-235, $50 \mathrm{GWd} / \mathrm{t}$

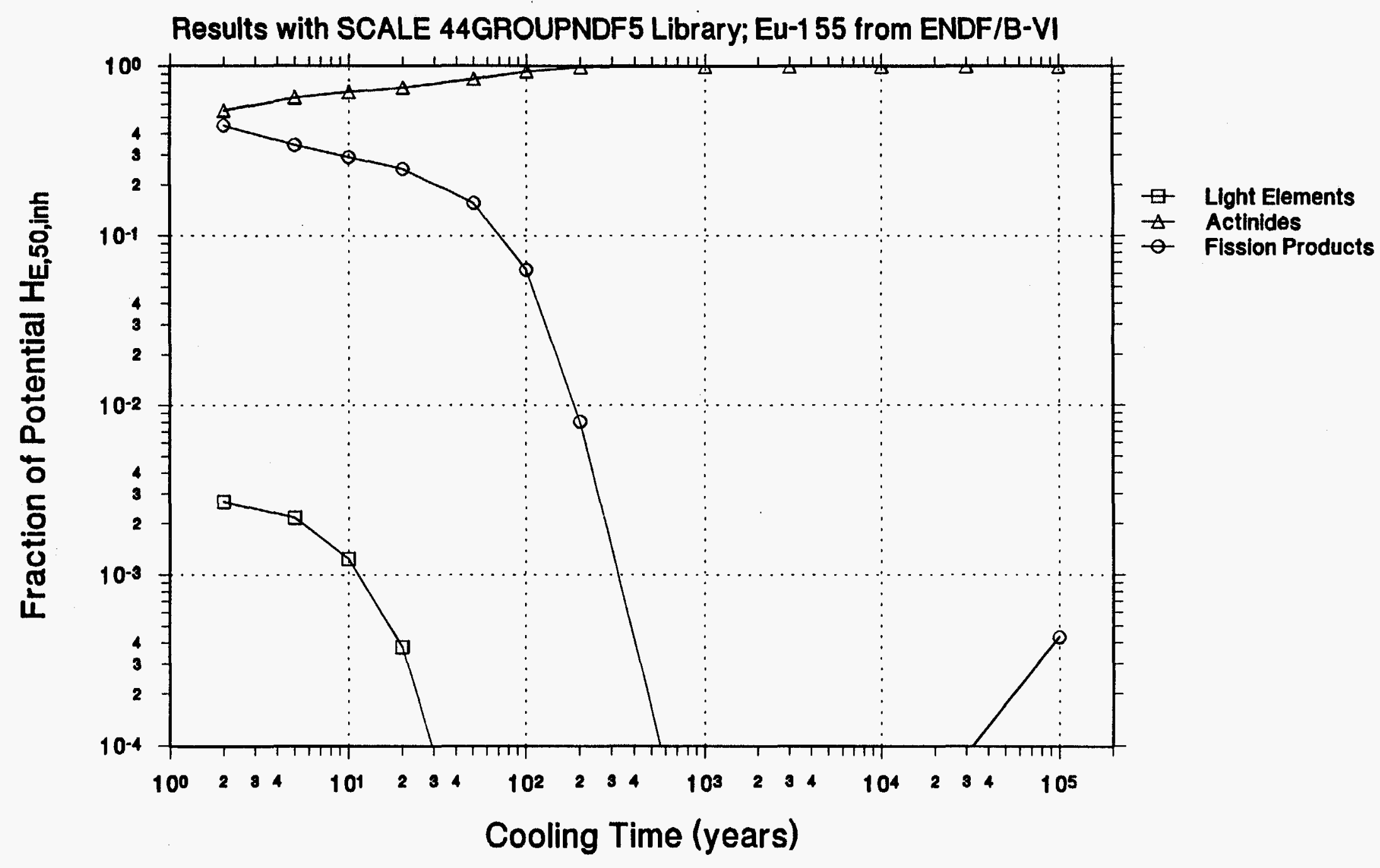


Fraction of Activity Neglected in Computing Committed Effective Dose Equivalent at Various Cooling Times; 4.5 wt \% U-235, $50 \mathrm{GWd} / \mathrm{t}$

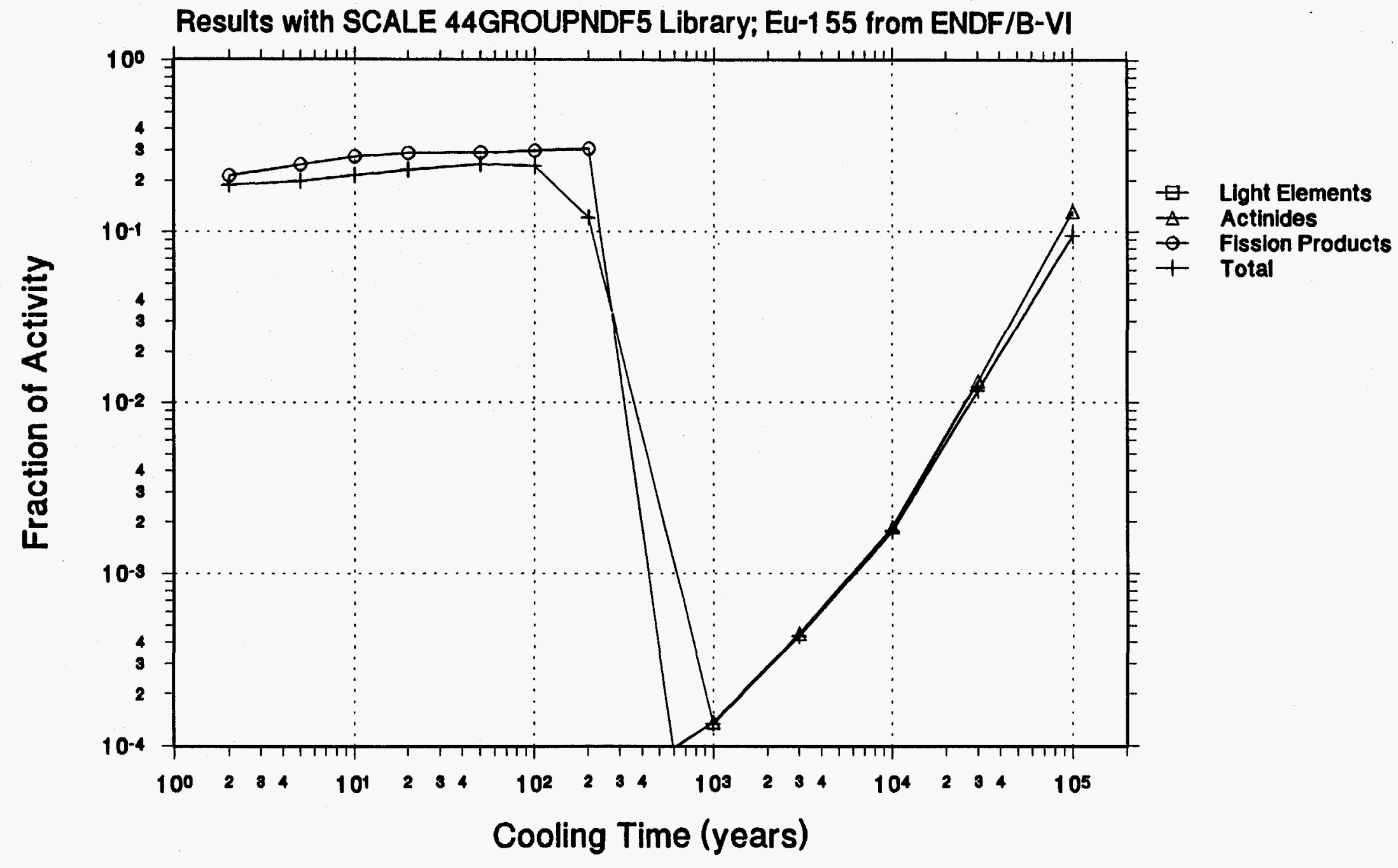





\section{INTERNAL DISTRIBUTION}

$\begin{aligned} 1 . & \text { C. W. Alexander } \\ 2 . & \text { J. M. Begovich } \\ 3 . & \text { S. M. Bowman } \\ 4-8 . & \text { B. L. Broadhead } \\ 9 . & \text { J. A. Bucholz } \\ 10 . & \text { B. S. Cowell } \\ 11 . & \text { A. G. Croff } \\ 12-16 . & \text { M. D. DeHart } \\ 17 . & \text { K. R. Elam } \\ 18 . & \text { M. B. Emmett } \\ 19 . & \text { W. E. Ford III } \\ 20 . & \text { C. W. Forsberg } \\ 21 . & \text { N. M. Greene } \\ 22 . & \text { M. J. Haire } \\ 23 . & \text { O. W. Hermann } \\ 24 . & \text { C. M. Hopper } \\ 25 . & \text { D. T. Ingersoll } \\ 26 . & \text { H. T. Kerr } \\ 27 . & \text { M. A. Kuliasha } \\ 28 . & \text { L. C. Leal } \\ \text { 29-33. } & \text { S. B. Ludwig } \\ 34 . & \text { G. E. Michaels } \\ 35 . & \text { B. D. Murphy } \\ 36 . & \text { L. F. Norris } \\ 37 . & \text { J. V. Pace III } \\ & \end{aligned}$

1. C. W. Alexander

2. J. M. Begovich

3. S. M. Bowman

4-8. B. L. Broadhead

9. J. A. Bucholz

10. B. S. Cowell

17. K. R. Elam

18. M. B. Emmett

W. E. Ford III

21. N. M. Greene

22. M. J. Haire

23. O. W. Hermann

24. C. M. Hopper

25. D. T. Ingersol

27. M. A. Kuliasha

28. L. C. Leal

34. G. E. Michaels

36. L. F. Norris

37. J. V. Pace III
38. R. B. Pope
39-43. C. V. Parks
44. L. M. Petrie
45. R. T. Primm III
46. R. R. Rawl
47. W. J. Reich
48. J.-P. Renier
49. J. W. Roddy
50. R. W. Roussin
51-55. J. C. Ryman
56. C. H. Shappert
57. L. B. Shappert
58-62. J. S. Tang
63. T. D. Welch
64. R. M. Westfall
65. B. A. Worley
66. R. Q. Wright
67. Central Research Library
68. ORNL Y-12 Research Library
Document Reference Section
69-70. Laboratory Records Department
71. Laboratory Records, ORNL (RC)
72. ORNL Patent Office

\section{EXTERNAL DISTRIBUTION}

73. R. D. Ankney, East Energy Center, MS 4-13, Westinghouse Electric, P. O. Box 355, Pittsburgh, PA 15230

74. Harry Alter, NE 530, Safety and Physics Division, Office of Reactor Research \& Technology, Office of Nuclear Energy, U.S. Department of Energy, Washington, DC 20545

75. M. G. Bailey, Office of Nuclear Material Safety \& Safeguards, U.S. Nuclear Regulatory Commission, MS TWFN 8F5, Washington, DC 20555

76. C. A. Beard, Los Alamos National Laboratory, Group T-2, MS B243, Los Alamos, NM 87545

77. M. C. Brady, Sandia National Laboratories, 101 Convention Center Drive, Suite 880, Las Vegas, NV 89109

78. J. Carlson, Office of Civilian Radioactive Waste Management, DOE/RW-37, U.S. Department of Energy, Washington, DC 20545

79. R. Carlson, Lawrence Livermore National Laboratory, P.O. Box 808, Livermore, CA 94550 
80. R. N. Collier, Department of Energy, Oak Ridge Operations (DOE-ORO), P.O. Box 2008, Oak Ridge, TN 37831

81. T. W. Doering, TESS, B\&W Fuel Co., MS 423, Suite 527, P.O. Box 98608, 101 Convention Center Drive, Las Vegas, NV 89109

82. S. Gomberg, Office of Civilian Radioactive Waste Management, DOE/RW-37, U.S. Department of Energy, Washington, DC 20545

83. P. Gottlieb, TESS, 101 Convention Center Drive, Las Vegas, NV 89109

84. W. H. Lake, Office of Civilian Radioactive Waste Management, U.S. Department of Energy, RW-33, Washington, DC 20585

85. R. Lambert, Electric Power Research Institute, 3412 Hillview Ave., P.O. Box 10412, Palo Alto, CA 94303

86. Y. Y. Liu, Argonne National Laboratory, 308, 9700 South Cass Avenue, Argonne, II 60439-4825

87. H. K. Manaktala, Southwest Research Institute, P.O. Drawer 28510, San Antonio, TX 78228

88. R. S. Moore, Automated Sciences Group, Inc., 800 Oak Ridge Turnpike, Suite A300, Oak Ridge, TN 37830

89. B. M. Morris, U.S. Nuclear Regulatory Commission, Office of Nuclear Regulatory Research, MS TWFN-9F29, Washington, DC 20555

90. C. W. Nilsen, Office of Nuclear Material Safety and Safeguards, U.S. Nuclear Regulatory Commission, MS TWFN-9F29, Washington, DC 20555

91. D. A. Nitti, B\&W Fuel Co., Civilian Radioactive Waste Management System, 2650 Park Tower Dr., Suite 800, Vienna, VA 22180

92. Larry D. Noble, GE Nuclear Energy, Nuclear Operations, 175 Curtner Avenue, San Jose, CA 95125

93. D. J. Nolan, 2650 Park Tower Drive, Suite 800 , Vienna, VA 22180

94. Office of the Deputy Assistant Manager for Energy, Research, and Development, U.S. Department of Energy, Oak Ridge Operations (DOE-ORO), P.O. Box 2008, Oak Ridge, TN 37831

95. Office of Scientific and Technical Information, P.O. Box 62, Oak Ridge, TN 37831

96. N. L. Osgood, Office of Nuclear Material Safety \& Safeguards, U.S. Nuclear Regulatory Commission, MS TWFN 8F5, Washington, DC 20555

97. F. Prohammer, Argonne National Laboratory, 9700 S. Cass Ave., Bldg. 308, Argonne, IL 60439-4825

98. M. Rahimi, 2650 Park Tower Drive, Suite 800, Vienna, VA 22180

99. B. Reid, Pacific Northwest Laboratory, Battelle Blvd., P.O. Box 999, Richland, WA 99352

100. J. P. Roberts, Office of Civilian Radioactive Waste Management, U.S. Department of Energy, Washington, DC 20585

101. R. E. Schenter, HO-36, Hanford Engineering Development Laboratory, P. O. Box 1970, Richland, WA 99352

102. F. Schmittroth, HO-36, Westinghouse Hanford Company, P. O. Box 1970, Richland, WA 99352

103. V. E. Schrock, Department of Nuclear Engineering, 4167 Etcheverry Hall, University of California, Berkeley, CA 94720

104. M. Senderling, Office of Civilian Radioactive Waste Management, DOE/RW-37, U.S. Department of Energy, Washington, DC 20545 
105. Kal Shure, Westinghouse Bettis, P.O. Box 79, West Mifflin, PA 15122

106. B. I. Spinrad, 18803 37th Avenue North, Seattle, WA 98155

107-131. W. R. Standley, TESS, 2650 Park Tower Drive, Suite 800, Vienna, VA 2218012

132. R. Stout, Lawrence Livermore National Laboratory, P.O. Box 808, Livermore, CA 94550

133. J. B. Stringer, Duke Engineering \& Services, 230 S. Tryon St., P.O. Box 1004, Charlotte, NC 28201-1004

134. F. C. Sturz, Office of Nuclear Material Safety \& Safeguards, U.S. Nuclear Regulatory Commission, MS TWFN 8F5, Washington, DC 20555

135. B. Teer, TESS, 2650 Park Tower Drive, Suite 800, Vienna, VA 2218012

136. D. A. Thomas, B\&W Fuel Co., 101 Convention Center Drive, Suite 527, MS 423, Las Vegas, NV 89109

137. J. R. Thornton, TESS, 2650 Park Tower Drive, Suite 800, Vienna, VA 2218012

138. A. Tobias, National Power Nuclear, Berkeley Nuclear Laboratories, Berkeley, Gloucestershire GL13 9PB, United Kingdom

139. C. A. Trottier, Office of Nuclear Material Safety and Safeguards, U.S. Nuclear Regulatory Commission, MS TWFN-9F29, Washington, DC 20555

140. D. Wang, Chinese Nuclear Data Center, Institute of Atomic Energy, P.O. Box 275(41), Beijing, P.R. China

141. M. E. Wangler, U.S. Department of Energy, Transportation \& Packaging Safety Div., MS EH-33.2, Washington, DC 20585

142. B. H. White, Office of Nuclear Material Safety \& Safeguards, U.S. Nuclear Regulatory Commission, MS TWFN 8F5, Washington, DC 20555

143. H. W. Wiese, Kernforschungszentrum Karlsruhe, Institut fur Neutronenphysik, Postfach 3640, 75 Karlsruhe, Germany

144. M. L. Williams, LSU Nuclear Science Center, Baton Rouge, LA 70803

145. R. F. Williams, Electric Power Research Institute, 3412 Hillview Ave., P.O. Box 10412, Palo Alto, CA 94303

146. W. B. Wilson, Los Alamos National Laboratory, B243, Los Alamos, New Mexico 87545

147. C. J. Withee, Office of Nuclear Material Safety \& Safeguards, U.S. Nuclear Regulatory Commission, MS TWFN 8F5, Washington, DC 20555 